\title{
MORE THAN MEETS THE EYE: \\ EXPLICATING THE ESSENCE OF GERONTOLOGY NURSING
}

by

\section{ANNE THERESE SCHUMACHER}

A thesis submitted to the Victoria University of Wellington in fulfilment of the requirements for the degree of

Master of Arts in Nursing

Victoria University of Wellington

2001 


\section{MORE THAN MEETS THE EYE: \\ EXPLICATING THE ESSENCE OF GERONTOLOGY NURSING}

by

\section{ANNE THERESE SCHUMACHER}

A thesis submitted to the Victoria University of Wellington in fulfilment of the requirements for the degree of

Master of Arts in Nursing

Victoria University of Wellington

2001 


\section{ABSTRACT}

The purpose of this hermeneutic phenomenological study was to explore the essence of gerontology nursing. This project sought to look beyond the practical tasks and skills of gerontology nursing to reveal what is more than meets the eye and thereby explicate the essence of gerontological nursing practice.

Gerontology nursing is troubled by its unpopular status and negative image that in turn has serious implications for the recruitment and retention of nurses who are both willing and able to work in this field of nursing. The purpose for doing this study was to unveil a deeper meaning and understanding of gerontology nursing, thus contributing to its value and worth as a speciality area of nursing.

Conversations with four gerontology nurses were taped, transcribed and then analysed using van Manen’s (1990) approach to researching lived experience. From the analysis, four cardinal elements emerged: true acceptance, personal knowing, being present, and being alive. Those four cardinal elements were reworked and further analysed to reveal three central aspects or essences of gerontology nursing. These essences were the centrality of temporality, the interconnectedness of human relationships, and the significance of the lived body. Temporality is demonstrated by nursing application of objective, or clock time, as well as subjectively in regards to the lived time of the clients. Interconnectedness is the lived human relationship between nurse and client and is represented by commitment, presencing/giving of self, connecting, and knowing the client holistically. The third essence is corporeality, which is portrayed by the 
gerontology nurses' distinguishing characteristics and their perception of the lived body of the nursed. The final analysis unveiled caring for the body, the act of seeing, and the joy of care as emergent essences of gerontology nursing. Language of nursing in relationship to 'basic nursing care' is critiqued for its potential to devalue gerontology nursing and, by association, old people.

The significance of these findings is that there is more than meets the eye in gerontology nursing, however, it is not widely known. To balance the abundance of literature about the science of gerontology nursing practice more research needs to be focused on the art. Establishing and disseminating a clearer, complete picture of gerontology nursing would go toward not only changing its negative image, but may also address recruitment and retention issues. Furthermore, this study has highlighted the need to recruit nurses who possess the necessary personal attributes to ensure they 'fit' into gerontology nursing.

Key words: gerontology nursing, essence, temporality, relationality, body, phenomenology, van Manen 


\section{ACKNOWLEDGMENTS}

I would like to acknowledge and thank the following people who have assisted me in the preparation of this thesis. First, I am indebted to the four gerontology nurses who participated in this study. For their willingness and enthusiasm to talk freely about their lives and work, I am deeply grateful.

To my supervisor, Christine Wilson, I am truly thankful. Her understanding and support to me personally enabled me to balance my obligations and responsibilities as a mother and as a student. For her knowledge, insights, and timely feedback, I am indebted. I am also thankful to Chris for her ability to get 'into step' beside me, for taking in her stride my long periods of inactivity and then the sudden bursts of productivity. I would like to acknowledge the assistance of Cheryle Moss for her expert supervision and guidance. Special thanks also to my nursing colleagues at the Graduate School of Nursing and Midwifery for listening to my presentations, offering feedback and providing stimulus for my project.

I wish to acknowledge the financial support of the NZNO, and the Faculty of Humanities and Social Science.

Finally, I would like to thank my family and friends for their ongoing support and encouragement, especially Vincent and Mary. I am particularly grateful to Clare Maihi for her computing prowess and invaluable assistance in editing and formatting this work. I owe a debt of gratitude and sincere thanks to Alison Ross and Lyncia Podmore for minding my daughters Elizabeth and Hannah, enabling me to work on my thesis knowing that they were in safe loving hands. 


\section{TABLE OF CONTENTS}

TITLE PAGE

ABSTRACT

ACKNOWLEDGMENTS

TABLE OF CONTENTS

1. INTRODUCTION - SETTING THE SCENE 1

Introduction 1

The Substantive Question 1

Methodology 3

Gerontology Nursing $\quad 4$

$\begin{array}{ll}\text { Demographics } & 6\end{array}$

$\begin{array}{ll}\text { Workforce Statistics } & 7\end{array}$

Overview of Literature $\quad 8$

$\begin{array}{ll}\text { Ageism and Nurses Attitudes to Aged Care } & 10\end{array}$

Unpopularity of Gerontology Nursing/Negative Image 12

Role of Gerontology Nursing as a Specialist Nursing Domain 13

$\begin{array}{ll}\text { Outline of Thesis } & 15\end{array}$

$\begin{array}{ll}\text { Terminology } & 18\end{array}$

$\begin{array}{lr}\text { Conclusion } & 19\end{array}$

2. DETERMINING THE METHODOLOGY 21

$\begin{array}{ll}\text { Introduction } & 21\end{array}$

Getting Started $\quad 22$

From Essence to Art and Back Again 23

Design Issues $\quad 24$

Criteria for Selecting Participants - Experts? 26

$\begin{array}{ll}\text { Phenomenology } & 27\end{array}$

$\begin{array}{ll}\text { Conclusion } & 28\end{array}$ 
3. AN EXPLORATION OF ESSENCE 30

Introduction 30

Etymology of Essence $\quad 30$

$\begin{array}{ll}\text { Essence and Phenomenology } & 31\end{array}$

Nursing and Essence $\quad 33$

Essence and Gerontology Nursing 35

Discussion 36

$\begin{array}{ll}\text { Conclusion } & 39\end{array}$

4. THEORY OF PHENOMENOLOGY AND THE RELATIONSHIP 40 TO NURSING

$\begin{array}{ll}\text { Introduction } & 40\end{array}$

$\begin{array}{ll}\text { The Constructivist Paradigm } & 40\end{array}$

Philosophy of Phenomenology $\quad 42$

History of Phenomenology 44

Husserl 45

$\begin{array}{ll}\text { Heidegger } & 47\end{array}$

$\begin{array}{ll}\text { French Phase } & 48\end{array}$

$\begin{array}{ll}\text { Hermeneutics } & 50\end{array}$

Gadamer $\quad 52$

Van Manen $\quad 54$

$\begin{array}{ll}\text { Phenomenology and Nursing } & 58\end{array}$

$\begin{array}{ll}\text { Conclusion } & 61\end{array}$

5. GETTING STARTED - RESEARCH DESIGN 63

Introduction $\quad 63$

Intersubjectivity $\quad 63$

Selection of Participants $\quad 64$

Criteria for Inclusion $\quad 64$

Establishing Trustworthiness $\quad 66$

$\begin{array}{ll}\text { Consultation with Mäori } & 67\end{array}$

$\begin{array}{ll}\text { Ethical Concerns } & 68\end{array}$ 
$\begin{array}{ll}\text { Beneficence } & 68\end{array}$

Respect for Human Dignity $\quad 69$

$\begin{array}{ll}\text { Justice } & 69\end{array}$

$\begin{array}{ll}\text { Gathering Material - The Conversational Interview } & 70\end{array}$

$\begin{array}{ll}\text { Establishing Rapport } & 71\end{array}$

Remaining Orientated to the Topic 73

$\begin{array}{ll}\text { Style of Questioning } & 74\end{array}$

$\begin{array}{ll}\text { Listening } & 75\end{array}$

$\begin{array}{ll}\text { Discussion } & 76\end{array}$

$\begin{array}{ll}\text { Conclusion } & 78\end{array}$

6. INTRODUCING THE PARTICIPANTS AND REVEALING 80 MYSELF

$\begin{array}{ll}\text { Introduction } & 80\end{array}$

$\begin{array}{ll}\text { Jean } & 80\end{array}$

Madison $\quad 82$

Tärati $\quad 84$

Dorothy 85

My Lived Experience as a Gerontology Nurse $\quad 87$

$\begin{array}{lr}\text { Conclusion } & 90\end{array}$

7. PICKING UP THE GEMSTONES 93

Introduction 93

Thematic Analysis $\quad 94$

$\begin{array}{ll}\text { Other Sources of Lived Experience } & 97\end{array}$

Initial Thoughts - Cardinal Elements of Gerontology Nursing 98

$\begin{array}{ll}\text { True Acceptance } & 98\end{array}$

$\begin{array}{ll}\text { Personal Knowing } & 100\end{array}$

$\begin{array}{ll}\text { Being Present } & 101\end{array}$

$\begin{array}{ll}\text { Being Alive } & 102\end{array}$

$\begin{array}{lr}\text { Conclusion } & 102\end{array}$ 
$\begin{array}{ll}\text { Introduction } & 104\end{array}$

$\begin{array}{ll}\text { Temporality } & 105\end{array}$

$\begin{array}{ll}\text { Nursing and Objective Time } & 106\end{array}$

$\begin{array}{lr}\text { Temporality and Gerontology Nursing } & 110\end{array}$

$\begin{array}{ll}\text { Lived Time of Clients } & 110\end{array}$

Appreciation of Past and Impact on Present 111

$\begin{array}{ll}\text { Conclusion } & 113\end{array}$

9. INTERCONNECTEDNESS: LIVED HUMAN RELATIONSHIPS 116

$\begin{array}{ll}\text { Introduction } & 116\end{array}$

$\begin{array}{ll}\text { Commitment } & 118\end{array}$

$\begin{array}{ll}\text { Presencing/Giving of Self } & 123\end{array}$

$\begin{array}{ll}\text { Connecting } & 126\end{array}$

$\begin{array}{ll}\text { Knowing the Client Holistically } & 129\end{array}$

$\begin{array}{ll}\text { Conclusion } & 132\end{array}$

10. CORPOREALITY OF THE NURSE AND THE NURSED 134

$\begin{array}{ll}\text { Introduction } & 134\end{array}$

$\begin{array}{ll}\text { Distinguishing Characteristics } & 134\end{array}$

$\begin{array}{ll}\text { Lived Body of the Nursed } & 140\end{array}$

$\begin{array}{lr}\text { Conclusion } & 144\end{array}$

11. MORE THAN MEETS THE EYE: EMERGENT ESSENCES 148

$\begin{array}{ll}\text { Introduction } & 148\end{array}$

$\begin{array}{ll}\text { The View from Within } & 149\end{array}$

$\begin{array}{ll}\text { Emergent Essences } & 151\end{array}$

Caring for the Body 152

Basic Care - Primary Care 153

$\begin{array}{ll}\text { The Act of Seeing } & 155\end{array}$

$\begin{array}{ll}\text { The Joy of Care } & 156\end{array}$

$\begin{array}{ll}\text { The View from the Outside } & 158\end{array}$

$\begin{array}{ll}\text { Insights from the Study } & 161\end{array}$ 


\section{APPENDICES}

Appendix A - Consent to Participate in Research

Appendix B - Information Sheet

171

Appendix C - Transcriber Confidentiality Agreement

173

REFERENCES

174 


\section{INTRODUCTION - SETTING THE SCENE}

\section{INTRODUCTION}

This research project explores the essence of gerontology nursing. In this chapter, I introduce the study, and describe the background for the research, by overviewing the project and outlining the structure of the thesis. First, I introduce the substantive question, the purpose of my study, and offer justification for doing the research. Secondly, in setting the scene, I briefly describe what gerontology nursing is, presenting workforce statistics and demographic trends relevant to the topic. Thirdly, this chapter includes the literature review, offered now at the beginning of the thesis, because it serves as additional background information in setting the scene of my inquiry. Finally, I outline the structure and content of my thesis by briefly summarising each chapter and then conclude this chapter by explaining why I have chosen to use certain terminology throughout the thesis.

\section{The Substantive Question}

The real essence of nursing, as of any fine art, lies not in the mechanical details of execution, nor yet in the dexterity of the performer, but in the creative imagination, the sensitive spirit, and the intelligent understanding lying back of these techniques and skills. Without these, nursing may become a highly skilled trade, but it cannot be a profession or a fine art. (Stewart, 1929, p 1)

Stewart's (1929) words as quoted above formed the basis of my research inquiry.

The aim of this study was to explore the essence, or essential nature of gerontology nursing. Those of us who practise gerontology nursing know that it is not the tasks alone that sustain us or give us the greatest satisfaction. My project sought to look beyond the practical tasks and skills of gerontology nursing in order to explicate the 
quintessential nature of gerontological care. By having conversations with four gerontology nurses, I intended to uncover what is embedded in practice that enables the nurse to perform the daily tasks of gerontology nursing. The purpose was to try and surface those things that underlie the practice and the nursing interventions. What are the integrity, values, beliefs, and ideals that constitute gerontology nursing in all its complexity? I wanted to explicate the "intelligent understanding", the knowing, and the experiencing, that hold the practice and interventions together. Alison Kitson (1999a) in a two-part article entitled The Essence of Nursing stated:

The complexity of nursing is not necessarily about the challenge of discrete tasks, rather it is the requirement of nurses to be able to undertake a whole range of practical duties in such a way that protects the humanity and the individuality of the person for whom they are caring. (Kitson, 1999a, p 44 emphasis added)

My question was, how do gerontology nurses care in such a way as described by Kitson.

My aim in doing this research was to shed some light on the work of gerontology nurses. As the literature review reveals, gerontology nursing is troubled by its unpopular status and negative image. As a Nurse Manager, I experienced first hand the implications of gerontology being the 'poor cousin' in nursing. Serious problems with recruitment and retention of satisfactory nursing staff were ongoing which impacted directly with the quality of care being offered to our clients. Another issue was the common perception that caring for old people was simple, so nurses wanting to return to the workforce after considerable time away believed they could find their nursing feet again by caring for old people, and then leave for greener pastures once they were up and running. I had a fat file of curriculum vitae 
in my bottom drawer of such nurses. It was obvious to me, that to many people gerontology nursing is just a stepping stone, something to move on from and not taken at all seriously as a career option. Gerontology nursing was considered by these nurses as something that anybody could do, and as being an easy and convenient way to re-enter the workforce. This widespread view is reinforced by the aged care industry itself, an example being one care provider who I notice when advertising for registered nurses, often state the only requirement for the position is a nurse who possesses a sense of humour! This lack of recognition of the professional skills and knowledge that gerontology nurses have prompted me to want to know more about those nurses who do have, not only the professionalism, but also the passion and commitment for gerontology nursing. And what is it about them and the job that clicks together and works so effectively? So, by conducting this study I hoped for a deeper understanding and meaning of gerontology nursing thus contributing to its value and worth as a specialty area of nursing.

\section{Methodology}

I have used van Manen's (1990) approach to hermeneutic phenomenology as a guide for my research method. Phenomenology attempts to uncover and understand the nature of being through the lived experience of the study participants. The title of my research More than meets the eye: Explicating the essence of gerontology nursing is a reference to the phenomenological act of seeing meaning. Husserl, the father of phenomenology, referred to the attempt of describing a thing under investigation as the act of "pure seeing” (Husserl, 1999). Phenomenology is also regarded as the study of essences, of revealing the whatness of something as 
opposed to their thatness (van Manen, 1990). Van Manen's (1990) method of researching lived experience focuses on giving voice to the texts themselves, therefore, it was appropriate to use for this study because it is through the words of the participants that we get to see what is more than meets the eye in gerontology nursing. The methodology for the research is discussed in detail in chapter four. Next, I set the scene for the research by describing what gerontology nursing is and then looking at relevant demographic trends and statistics.

\section{GERONTOLOGY NURSING}

Gerontology nursing is the area of nursing concerned with the care of old people. Before progressing further, it is important to clarify the difference between the terms geriatric and gerontology. According to the Mosby’s Medical, Nursing, and Allied Health Dictionary (1990), geriatric is derived from the Greek stem geras meaning old age and iatros meaning physician. Thus, geriatrics is the branch of medicine dealing with the diagnosis and treatment of diseases affecting the aged. Gerontology is derived from geras and logos meaning a science, or a subject of study. So, gerontology is the study of all aspects of the ageing process. The significance of this is that geriatrics is focused on the medical aspect of old age, whereas gerontology is a holistic approach to old age. Koch and Webb (1996) differentiate between geriatric and gerontology as the former addresses the problems relating to malfunctioning in old people whereas the later identifies the characteristics of normal ageing. Gerontology has been described as "the study of the complex multidimensional process of ageing which occurs over time (Ryder, 1994, p 432). 
A gerontology nurse is concerned with the physical, mental, spiritual, social, and emotional wellbeing of an old person. A gerontology nurse may consider the whole person in determining appropriate care interventions whereas for example, a surgical nurse, will focus on the one part of the old person, say the fractured neck of femur, that has caused the health care contact. This does not mean that surgical nurses can not be holistic in their care, what I am saying though, is that it is the nature of the healthcare setting that determines the type of care. In this example, priority is given to physical needs and holistic needs may be less pressing.

The titles gerontology and geriatric are often used interchangeably with many nurses working in geriatric settings referring to themselves as gerontology nurses. It appears that if a nurse sees her role as being holistic and approaches her work in that manner, then regardless of the setting, the title gerontology nurse is appropriate. I believe another reason that nurses prefer to call themselves gerontology nurses is that the term geriatric has many negative connotations associated with it. It is reminiscent of the task orientated, malodorous, and neglectful work of the geriatric nurse of the past (Nolan, 1994). In an attempt to shake off that image, the term gerontology is used as an indication that the nursing of old people is changing for the better.

The actual work of the gerontology nurse is very broad and is dependent on the setting. For example, the duties of a community gerontology nurse will differ significantly from those of a gerontology nurse working in an assessment, treatment and rehabilitation unit, which again will be different to the work of a nurse in a continuing care setting. The one factor that unifies nurses working in such diverse 
settings is the fact that we all work with old people and have a unique body of knowledge and skills to competently nurse this sector of society. For example, we know about skin integrity and wound cares, meeting the psychosocial needs of old people, and how to holistically care for the dying. As a broad description though, the discussion document for nurse prescribing issued by the Ministry of Health offers the following definition of the scope of practice for gerontology nursing.

These nurses utilise nursing knowledge, judgement, and assessment to plan and provide competent care, advice, advocacy, and treatment and ongoing monitoring for older people. This is provided in the areas of health promotion, health maintenance, restoration of health, continuation or encouragement of independence, rehabilitation, minimisation of disability, and death with dignity. (Ministry of Health, 1998, p 16)

This is an apt definition of the work of gerontology nurses, it is particularly fitting because of the emphasis on holistic care and it also recognises the broad scope that we practise within.

Having described what gerontology nursing is, next I look at some background information for this project in the way of demographics, workforce statistics, and an overview of the literature.

\section{DEMOGRAPHICS}

It is now a well-known fact that the population is not only ageing but also living longer. Statistics New Zealand (2000) predicts the population will take on an older profile and that by the year 2051, the number of New Zealanders aged 65 and older will be 1.18 million. That is $26 \%$ of the population, or 1 in 4 , will be aged 65 or older. Within that age group, those aged 85 and older will increase sixfold, making 
up $25 \%$ of the over 65 age group. Compare that with the $10 \%$ it was in 1999 . The number of centenarians will also increase from 300 in 1999 to a projected 12,000 in 2051 (Statistics New Zealand, 2000).

The implications of the population trends are debatable. It is anticipated that as life expectancy improves so too will the health of old people with many living healthy independent lives. On the other hand, it is argued that with the dramatic increase in numbers of old people there will be a corresponding increase in the numbers of people with chronic disease and disabilities (National Advisory Committee on Health and Disability, 2000; Statistics New Zealand, 2000).

\section{WORKFORCE STATISTICS}

However the demographic trends are interpreted, the need is obvious for nurses with the skills and expertise to nurse this growing sector of the community. It would appear there will be a need for a diverse range of services including specialist gerontology health promotion as well as gerontology nurses with the knowledge and experience to nurse the complex health care and support needs of an increasing number of old people. However a major issue facing the nursing profession, and indeed society at large, is the long-standing shortage of nurses dedicated to providing excellent care to old people (Robertson and Cummings, 1996; Nolan, 1994; Treharne, 1990; Snape, 1986; Schumacher, 1999).

An interesting statistic is the number of nurses identified as working in aged care. According to the New Zealand Workforce Statistics 1999, nurses working in continuing care (elderly) number 3,884 or $12.1 \%$ of the total registered nurse workforce. This is second only to surgical as being the largest type of practice 
nurses are engaged in. Those nurses who work in assessment and rehabilitation, it is not specified as aged care, number 1009 or $3.1 \%$. It has to be pointed out though that these figures are taken from the Nursing Council of New Zealand's annual practising certificate questionnaire. The questionnaire has a $98.6 \%$ response rate and importantly includes nurses working on a part-time or casual basis. I would suggest, therefore, that the high numbers of nurses working in aged care probably indicate the high number of part-time or casual nurses working in gerontology. I believe this may explain some of the issues facing gerontology nursing particularly the chronic nursing shortage, the high staff turnover, and the struggle to establish professional credibility. Part time staff per se are not the problem, but the implications of not having a higher proportion of full time registered nurses are many and varied. There are issues with continuity of care, training, and communication, also, full time staff are more likely to see, and get a deeper understanding of, the whole picture in terms of client care. Therefore, having a large body of part-time nurses making up the total of gerontology nurse practitioners can be seen as problematic in the development of gerontology as a viable and valuable career option. The above population and workforce statistics indicate the very real need for gerontology nursing research as a means of validating and informing practice.

\section{OVERVIEW OF LITERATURE}

In carrying out a review of the literature, it was striking to note the relative scarcity of literature, particularly research on gerontology nursing. Within that paucity, searching of nursing and medical databases (CINAHL and Medline) revealed an 
abundance of literature about the 'how to' care of old people. The use of complementary therapies such as massage, music, and validation used in gerontology nursing are discussed and evaluated (Hartshorn, Delage, Field, and Olds, 2002; Dunning and James, 2001). There is also much written about treatment options and practical issues concerned with meeting the daily needs of old people in institutional care, for example wound management (Bennett, 2001; Spoelhof, 2001; Scott, Leaper, Clark, and Kelly, 2001) and promoting sleep (Ersser et al, 1999). Vast quantities have been written about dementia, particularly Alzheimer's disease and the nursing management of people with dementia (Snyder et al, 2001; Rowe and Alfred, 1999).

Literature originating from Britain prompted by the introduction of Project 2000 stressed the importance of so called 'basic cares' as being a fundamental element of nursing, however, the connection is not made specifically to gerontology nursing (Castledine, 1997; Elzubeir and Sherman, 1995; Firn, 1995; Stevenson, 1996). I question using the term 'basic care' to describe the physical cares that the nurse carries out with the patient, and would argue that 'primary care' is a more appropriate term. This is discussed more fully in chapter eleven.

There is a dearth of literature on the experiences of gerontology nurses or the nature or essence, of gerontology nursing. A recent Australian study by Retsas and Wilson (1997) used personal construct theory to elicit characteristics of gerontological nurses. Analysis revealed the personal construct 'caring, compassionate, empathetic' was the most highly rated characteristic both of gerontology nurses 
generally and of 'effective’ gerontology nurses. Retsas and Wilson (1997, p 274) concluded that:

Gerontological nurses fail to see the importance of a disciplined body of knowledge as the basis of their practice... without an emphasis on improving knowledge and skills as legitimate bases for effective gerontological nursing, and without curricula which are designed to alter negative stereotypes, this area of nursing practice will struggle to establish a professional status in its own right."

They suggest gerontology nurses need to develop a clear image of themselves and their area of practice in order to effect positive change.

Some common themes could be identified from the literature that are relevant to my research and are described in more detail below: ageism and nurses' attitudes to aged care; unpopularity and negative image of gerontology nursing; and the role of gerontology nursing.

\section{Ageism and Nurses Attitudes to Aged Care}

There is a large body of literature reporting on the difficulties associated with attracting nurses to gerontology nursing. It is generally concluded that a contributing factor to this chronic problem is the ageist attitudes of society at large as well as within the nursing profession itself, particularly in the educational arena (Carr and Kazanowski, 1994; Chinn, 1991; Herrick, Pearcey and Ross 1997; Huber, Reno, and McKenney, 1992; Lookinland and Anson, 1995; McMinn, 1996; Pursey and Luker, 1995; Seymour, 1994; Slevin, 1991; Stevens and Crouch, 1992; Treharne, 1990). 
The term ageism was first coined by Butler in 1969 to describe the discrimination against people on the basis of age (Lookinland and Anson, 1995). Ageism is characterised by negative stereotypes, and identifies old age with disability, frailty and uselessness (Butler, 1975). Herrick, Pearcey and Ross (1997, p 24) in a paper on the effects of stigma and ageism on the mentally ill elderly, write that ageism is demonstrated by health workers "by the lack of: respect, sensitivity, empathy, and caring; and by exclusion”.

Slevin (1991) presented evidence to support the existence of ageism among young adults and that, unexpectedly, entry into nursing did not lead to attitudes that are more positive but actually had the opposite effect. Lookinland and Anson (1995) conducted a study to describe and compare the attitudes of registered nurses and high school students interested in pursing health related careers. Their findings revealed both groups to have ageist attitudes, with the students expressing significantly more unfavourable attitudes toward old people than the trained nurses.

Courteney, Tong, and Walsh (2000) conducted a literature review on knowledge and attitudes of acute care nurses to older patients. They reported, not surprisingly, that nurses who prefer to care for older patients tend to work in community or elderly care areas as opposed to acute care settings. The implications of this being “nurses with less positive and more negative attitudes towards older people and a lack of interest in this group of patients are caring for older patients in the acutecare setting and such a situation may jeopardise the health care of older patients” (Courteney, Tong, and Walsh, 2000, p 67). 
The findings of a study by Pursey and Luker (1995) challenged the common assumption that nurses' attitudes were the sole reason for a lack of interest in a career in gerontology nursing. They concluded that the high dependency levels of older patients and the structure of hospital nursing care of old people was a more likely cause of fewer nurses making aged care a positive career choice.

An existential phenomenological study by Koch and Webb (1996) found that the inhumane caring practices reported by previous studies in the United Kingdom remained unchanged. They interviewed 14 patients in a care of elderly people ward and asked the interviewees to tell their own experiences of what it was like to be in hospital. Two themes, routine geriatric style and segregation were revealed as negative experiences for the patients. Koch and Webb (1996) examined the history of aged care and the biomedical construction of ageing as explanations for the care deprivation and depersonalisation the patients experienced. The researchers concluded ageism and ageist stereotypes need to be challenged from a social and political angle, and that the routine geriatric style of care and segregation be reviewed through the introduction of a nurse education programme in social gerontology (Koch and Webb, 1996).

\section{Unpopularity of Gerontology Nursing/Negative Image}

The unpopularity of gerontology nursing has been ascribed to its historical beginnings in Britain where it was stigmatised and denigrated (Koch and Webb, 1996; Norton, 1990). According to Cheah and Moon (1993), the history of gerontology nursing is “characterised by professional neglect and prejudice” and as a consequence this area of nursing has not attracted the most able nurses. 
Robertson and Cummings (1996, p 25) claim gerontology nursing is "plagued by its negative image from both within and outside the nursing profession”.

Researchers such as Snape (1986), Treharne (1990), and Robertson and Cummings (1996) have addressed the unpopularity of gerontology nursing amongst nurses. Robertson and Cummings (1996) conducted a qualitative study to identify factors that would contribute to registered nurse recruitment and retention in nursing homes. The recruitment needs they identified include the following: having enough qualified and dedicated staff, supportive and competent administration; competitive salaries and benefits; functional, attractive facilities; improved professional and public image; and progressive nurse practice models.

Carr and Kazanowski (1994) studied factors affecting job satisfaction of long term care nurses in the United States. Their findings suggest that working conditions must be improved in order to improve job satisfaction. Other factors they identified included better educational opportunities to not only expand gerontological nursing knowledge, but also to build self esteem amongst personnel.

\section{Role of Gerontology Nursing as a Specialist Nursing Domain}

In recent literature, the role of gerontology nursing has been addressed particularly in relation to gerontology as a specialism (Nolan, 1994, 1997; Oberski, Carter, Gray, and Ross 1999; Cheah and Moon, 1993). Nolan (1997) reiterating on a paper he wrote in 1994, contends the two greatest challenges facing gerontology nursing are to clarify their sphere of activity and to establish a research base for gerontology nursing practice. Cheah and Moon (1993) explored whether nursing work with old people constitutes a nursing speciality. They present arguments for and against and 
concluded there are clear characteristics that enable it to be identified as a speciality, particularly in terms of nursing skills and knowledge. Cheah and Moon (1993) warn though, about the dangers of further marginalisation of old people and the perpetuation of negative stereotypes as being potential problems if indeed nursing care of old people is recognised as a speciality. Oberski, Carter, Gray, and Ross (1999) explored further the specialism/generalism theme in the context of the changing role of gerontology nursing. Their study focused on the move of care into the community and the subsequent changing educational needs of nurses to cope with this changing role. Oberski, Carter, Gray, and Ross (1999) found that whilst it is perceived to be a highly specialised area, nurses found it difficult to describe the exact unique nature of their work. They argued that community gerontology nurses need to have a depth and breadth of knowledge and skills which is different to the nature of hospital based gerontology nursing which tends to mirror the medical model of geriatric care. One of the conclusions from their study is that nurses need to gain a deeper insight and understanding of their knowledge, skills and abilities as well as the purpose they are to fulfil in their role as community gerontology nurses.

Nay, Garratt, and Koch (1999) highlight challenges facing Australian gerontology nurses. They discuss the role of gerontology nurses in relation to the trend for qualified nurses being replaced by unqualified staff in aged care facilities. This is resulting in a major challenge for gerontology nurses to maintain quality care and to change the image and status of the speciality, with education being the key to achieving this aim. Furthermore, Nay, Garratt, and Koch (1999, p 17) assert:

The time is ripe for lateral-thinking employers and others interested in the development of gerontologic nursing expertise 
to propose solutions that will engage RNs in a positive attitude toward work in the field and develop a level of competence that meets specialist practice.

This concludes my review of the literature that is the background to my topic and sets the scene for the study. I have discussed nurses’ attitudes, the unpopular image of gerontology nursing, and lastly the role of gerontology nursing as a specialist nursing domain. I now turn to the specifics of my thesis by briefly summarising each chapter.

\section{OUTLINE OF THESIS}

Having introduced the research and set the scene for the inquiry in this chapter, chapter two describes the circular route I took to arrive at, and settle on, an appropriate design and methodology. Design issues, including my own position as researcher in the project, are addressed as well as the selection of participants.

Chapter three delves into the etymology of essence as being a key term used throughout the thesis. The relationship of essence to phenomenology is made explicit as well as the association essence has with nursing knowledge. The similarities and differences between nurses' interest in essence and phenomenology’s portrayal of essence are explored.

The purpose of chapter four is to specify the theoretical underpinnings of my project. I explain my understanding of the constructivist paradigm as being the philosophy that has informed my research. The history of phenomenology is outlined, and hermeneutics is described focusing on the key philosophers who are attributed to its development. The philosophical underpinnings of van Manen's 
(1990) hermeneutic phenomenology are briefly set out before then reviewing the commonalities between nursing and phenomenology in regard to nursing research.

Chapter five details the practical application of getting my project started. I cover selection of participants, criteria for inclusion, trustworthiness, consultation with Mäori, and ethical considerations. The second part of the chapter explains how I used conversational interviews, as informed by Minichiello (1990), as a means of gathering material for the study.

The four participants, Jean, Madison, Tärati, and Dorothy are introduced in chapter six. Their distinct contribution to this research is acknowledged by focusing on each participant individually. My own lived experience of being a gerontology nurse is included, thereby making explicit my position in the research as an active participant. This chapter marks a transitional point in the thesis, as from this point on, I move from being in the academic world to the human, personal part of the study.

Chapter seven, Searching for Gemstones, describes how I conducted the thematic analysis using van Manen’s (1990) process of dwelling in the data and phenomenological reflection. The central theme to emerge from the analysis of the conversations was the interpersonal relationship as being the heart of gerontology nursing. My initial thoughts were presented to a group of gerontology nursing colleagues whom I saw as another source of data. Resulting from our discussion, I was able to formulate some early thoughts as to what the essence of gerontology nursing might be. The cardinal elements of true acceptance, personal knowing, 
being present and being alive are introduced as foundational concepts from which the further analysis arises.

Chapter eight reveals the first of the three emergent essences of gerontology nursing. The existential concept of temporality was a central theme, like a thread running through the fabric of the conversations. The nurse-client relationship is seated within the concept of temporality, and this is discussed further in relation to the work of the nurse in both a subjective and objective sense, and in the process uncovers what is more than meets the eye in gerontology nursing practice.

The second essence of gerontology nursing is the interconnectedness between nurse and client and this is the focus of chapter nine. In order to facilitate the description of this I have broken it down into four parts or themes. The four themes of commitment, presencing/giving of self, connecting, and knowing the client holistically are described and illustrated with excerpts from the conversations. It was a difficult task unpicking the structure of the nurse-client relationship as each of the four themes is interrelated and informed by each other, they do not standalone. But by focusing on the parts, we can then make more visible the whole.

Then in chapter ten the third essence is described, which is the centrality of the lived body to gerontology nursing. This chapter explores the participants' worldview of old people by describing their common attitudes and beliefs and how that is embodied in their practise. Then, I focus on the nurses' perception of the lived body of their clients as another way of seeing what is more than meets the eye in gerontology nursing. 
In chapter eleven, I bring all the previous analysis together, to reveal the emergent essences as a whole, and make explicit what is more than meets the eye in gerontology nursing. For the nurses who participated in this study, the act of seeing, caring for the body, and the joy of care is the essence of gerontology nursing that underpins their actual nursing practise. In this chapter, I also discuss some practical issues about the research process, including the limitations and implications of the study.

Finally, in chapter twelve, the whole project is summarised and brought to a close.

That concludes the outline and structure of the thesis, what follows next is some brief notes about the terminology used throughout the work.

\section{TERMinOLOGY}

I have three points to make about the terminology used throughout the thesis. First, is the use of the pronoun 'she' to connote nurse, this is purely to facilitate the flow

of language. Second, I have used the terms 'patient' and 'client' interchangeably. The third point is a little more complex and is concerned with what term to use when making reference to the clients of gerontology nurses. A variety of terms are in current use including older adults, elders, older people, the older person, the elderly, and the aged. I use the term old people, or if appropriate old woman, or old man. My reason for this is that a few years ago, I heard an old woman being interviewed on the radio. Unfortunately, I don't recall the details of who she was, or even what she was talking about. I think she was either a poet or a writer. What I do recall, however, is her very strong views on being old. She clearly stated that to be old was an achievement. Afterall, she had devoted her entire life to it! 
Therefore, she argued, why do "politically correct" people diminish that achievement by referring to her as being older. Older than whom? Will she ever actually get to be old or will she always be relegated to being older? This old woman went on to argue what is so wrong with being old, and claimed she was old and proud to be old. Since that day, I now refer to old people as just that, old people.

\section{CONCLUSION}

This chapter has introduced the substantive question of my research project. I have explored the background to the study by describing what gerontology nursing is, and by looking at two factors affecting gerontology nursing - workforce statistics, and the ageing population. The literature review contributed to setting the scene of my inquiry and elaborated on the themes of nurses' attitudes towards caring for old people, the unpopularity and negative image of gerontology nursing and the role of gerontology nursing as a specialist nursing domain.

As the literature review highlighted, gerontology nursing is associated with negativity and is not a popular career choice for nurses. Given the ageing population, this has serious implications, not only for nursing but society in general. There is a very real need to know more about gerontology nursing, and to make known its finer points with the ultimate aim of attracting more nurses to the field. Thus, my study is concerned with exposing, as Stewart (1929, p 1) wrote, "the creative imagination, the sensitive spirit, and the intelligent understanding” that underpins gerontology nursing practice. 
The next chapter discusses the process I went through to determine a suitable methodology highlighting some of the issues I had to grapple with along the way, and describing how I decided, on what was eventually to be, a final course of action to carry out my research. 


\section{DETERMINING THE METHODOLOGY}

\section{INTRODUCTION}

Undertaking a research project has been likened to going on a journey. The path ahead may be unknown and in places steep and tortuous. There are challenges to be overcome and then the enjoyment and satisfaction of arriving at the destination having successfully completed the journey. In the case of this journey though, there is an added element of the unknown as there is no set itinerary to follow, it is more akin to going on a mystery tour where you don't quite know where you'll end up. Hermeneutic phenomenology, by its very nature, defies the adherence to a set of predetermined techniques or procedures that rule the method of inquiry (van Manen, 1990). The researcher has to remain free to explore whatever paths and avenues that may open up along the way, and that is how phenomenological inquiry becomes so rich because it is responsive to the process itself.

This chapter describes the processes and movement I went through from my original ideas through to narrowing the field of inquiry, and eventually arriving at a research design and methodology. It is interesting to note that in the main I have travelled a full circle and have returned to my original ideas of topic, design, and methodology. The important difference is that I along the way I have picked up a depth of meaning and understanding for my subject that was lacking at the beginning of my research journey. What follows is a personal account of how my project got off the ground, and then an outline of how I settled on the topic and finalised the design issues of how to actually do the project, and where to position myself as researcher within the research. The last issue I had to contend with was 
gaining an understanding of phenomenology, both as a research method and as a philosophy.

\section{GETTING STARTED}

My research project first started to take shape during informal discussions with a small group of fellow students who, like me, felt a little daunted with the task ahead. We presented to each other our ideas, our visions, our fears and our doubts. As we listened to and supported each other, our concepts started to take shape and for me a sense of permanence was created about my project.

The next step was the opportunity to discuss my project in depth in our group with university research lecturers. By this stage I was reading widely and had more understanding of my topic of inquiry and proposed methodology. As my knowledge and understanding increased so too did my bewilderment. I was in danger of being swamped by the complexities of phenomenology and was having difficulty seeing my way through to the pragmatic outcomes I was looking for. What was I going to do and how? At the conclusion of the session I had made some decisions about the design and methodology of my research project and had clarified my direction, the details are discussed later in this chapter.

The year culminated in the preparation and submission of my research proposal along with an academic paper on the proposed methodology. All that was left now was to put the plan into action. However, as I continued to think and mull over my proposal I felt uneasy about certain aspects of the methodology but was at a loss to articulate with what exactly I was uncomfortable. 
I had a meeting with my research professor with the aim of talking through and clarifying my proposal. I made significant progress after that discussion. In effect, I was returning to my original design and methodology with the important difference that now I had a depth of knowledge and understanding that was absent when I first decided on my original course of action. By the continuous process of narrowing the field and refining my ideas, I had come full circle and in doing so, I had gained an appreciation and comprehension of my methodology that would otherwise have been lacking in this research project. My thoughts and insights about how the methodology actually worked for me are discussed in chapter eleven.

\section{From Essence to Art AND Back Again}

My topic has been clear from the beginning. I wanted to explore gerontology nursing and reveal the essence of gerontology practice. Essence being the essential element that underlies the practice. The thing that makes it unique, the extraordinary that sustains the ordinary everyday practice. Essence is something that makes a thing what it is (van Manen, 1990). So, my question was to be "What is the essence of gerontology nursing practice?”

During the course of the year, I became interested in exploring the art of nursing and aesthetic ways of knowing. I was particularly influenced by the writings of Chinn and Watson (1994), Watson (1985), Kitson (1999a; 1999b). As a result, I broadened the focus of my research to go beyond the essence of gerontology practice to explore the wider concept of the art of gerontology nursing. There is an abundance of nursing literature about the art of nursing and as I read, it became clear to me that gerontology nursing is grounded in the art of caring. This is 
contrary to popular assumption that gerontology is task oriented and routine based. I was stimulated to pursue this further.

I had two pathways open to me. One was to explore the performance of the art, and the other was to explore the nature of the art of gerontology nursing. The nature of the art being the integrity, values, beliefs, ideals, all those major things that constitute gerontology nursing in all its complexities. Upon further reflection I decided the latter option was where my real interest lay and a more appropriate term to use for what I was intending to study was essence. Furthermore, essence has resonance with phenomenology. Phenomenology asks the question "What is the very essence or nature of a phenomenon?” (van Manen, 1990). Van Manen (1990, p 177) defines essence as "that what makes a thing what it is (and without which it would not be what it is)". So with that definition in mind, exploring the essence of gerontology nursing seemed to be more applicable for my project than the art and I returned to my original topic of explicating the essence of gerontology nursing.

\section{DESIGN ISSUES}

Keeping within the tenets of human science inquiry, the initial research design that I created enabled me to accommodate the complex and diverse nature of human beings. My method of inquiry was to be narrative as explicated by Sandelowski (1991) as well as being participative as described by Reason (1994). My intention was to have conversations with gerontology nurses in order for them to tell their stories. An emphasis was placed on the narrative, storytelling aspect as described by Moss (1991). As a co-participant in the study, my own story was to be included. From each of the individual stories I was to create a final statement distilled from 
the original conversation for each nurse, complete with biographical data and photograph. The purpose of this was to preserve the uniqueness of each story. The next phase was to collaboratively interpret all the statements and extract keywords and phrases from each participant. This was to be a dynamic group process with the researcher acting as facilitator.

On reflection, I had a number of problems with this design. I was uncomfortable with the expected commitment required from the participants particularly in regards to time and energy for the project. The process would have been a cooperative interpretative journey, resulting in a construction of a commonality within the uniqueness. I was unsure that this was the outcome I wanted.

I decided on a different course of action, to treat the texts individually as opposed to co-operatively. To work with each text myself using my interpretative skills in order to explicate the essence of each nurse's practice thus getting a deeper sense of the essence of gerontology nursing.

A further issue I had to grapple with was that of my position as researcher in the project. I made the decision to construct a position for myself within the thesis. To record what my thinking was, my pre-reflections, preconceived ideas and weave my own position around that of the participants. I was returning to my original idea of conducting an inquiry using a hermeneutic phenomenological approach as explicated by van Manen (1990). I wished to keep the method simple and allow for the researcher's position to be evident in the language and writing which is a key activity of hermeneutic phenomenology. 


\section{Criteria for Selecting PARTICIPANTS- EXPerts?}

In my preliminary design, I planned to have conversations with 'expert' gerontology nurses. That gave rise to the issue how does one define an expert nurse? My criterion for inclusion was based on solving essentially pragmatic issues. I required participants to be reflective and analytical practitioners. They also needed to have the ability and skill to articulate what it is they are doing and why. Finally, I wanted nurses who had an evident commitment to, and passion for gerontology nursing, that is those nurses who involved themselves in the professional and ongoing development of gerontology. It is questionable if the above criteria constitute what is commonly understood to be expert nursing practice.

The terms expert, advanced practitioner, and specialist are often used interchangeably. Christensen (1999, p 4) states they are distinctive but "interrelated elements of nursing practice”, Christensen (1999) then goes on to suggest a set of attributes for each of the three key terms. Benner's (1984) well known work From Novice to Expert emphasises experience as being the essential element that differentiates novice from expert within a particular scope of practice. It is not my purpose here to add to the discourse on what constitutes expert nursing practice. I believe it is nevertheless an important issue for consideration and discussion elsewhere.

Considering the above, I concluded that I had no desire to put strict parameters around the selection of participants for my study. I would not label the participants as expert gerontology nurses but instead use terms such as experienced, committed, 
and passionate when making reference to them. The critical issue for me to consider was the quality and content of the accounts from each participant. 'Experts' would give me embodied knowing, and would have the benefit of hindsight and distance thus the text would be more reflective. On the other hand, clinicians' accounts may be less crystallised but richer in terms of stories grounded in everyday practice. Therefore I decided to invite nurses to participate in the study from both worlds, those still in practice and those who are no longer practising but remain committed to gerontology nursing by being involved in nursing education or management.

\section{Phenomenology}

Having decided to explore gerontology nurses' practice, I then looked for a methodology to explore practice. At first glance, phenomenology as a form of qualitative research appeared to be the appropriate methodology for me to use given the type of inquiry I wished to carry out. As a neophyte researcher I had virtually

no knowledge of phenomenology, however, as I read more extensively of qualitative research methods my initial thoughts that phenomenology was indeed the appropriate research method to use were confirmed. There was a resonance between what I was hoping to achieve in my project and my understanding of phenomenology as both a philosophy and a research method. Phenomenology is concerned with the study of things within human existence, it acknowledges and values the meanings that people put on their own being (Guba and Lincoln, 1994). It is a study of essences that has great applicability to my project especially having made the decision to focus on the essence of gerontology nursing. 
I went through a period of being lost in the depths of ontology and epistemology. Phenomenology is within the realm of the constructivist paradigm where realities exist as mental constructs of everyday life experiences and are dependent on their meaning to the person who holds them, in other words the nature of knowledge is relative, it is unique and context-dependent (Guba and Lincoln, 1994). I became aware that van Manen's (1990) phenomenological method was suited to what I was aiming to achieve and I was now sure this was the correct path for me to follow. I did experience some difficulty though, trying to understand how to actually do a piece of phenomenological research. The main problem was, as van Manen (1990, p 30) points out "that the method of phenomenology is that there is no method". There are, however, traditions, principles, and methodical features that the researcher is required to remain faithful to in order to carry out authentic human science research (van Manen, 1990). The researcher's task is to create and develop an appropriate design and method of inquiry that is individually shaped for the project within the confines of the chosen methodology. It is a fluid, dynamic process by which decisions are made and then unmade or slightly altered, which in turn affects other aspects of the project. This fine-tuning is essential for the refinement of the project. The result is a richer content that has a complexity and depth that otherwise would be missing. The movement from the original to the end product becomes an integral element of the finished work.

\section{CONCLUSION}

This chapter has described the issues and challenges I faced in determining an appropriate topic, method, and methodology for my research project. The physical 
process of getting started has been outlined detailing the discussion groups and meetings that have taken place. I have explained the background to how I arrived at the topic of studying the essence of gerontology nursing as opposed to the art of gerontology nursing practice. Issues and challenges I faced concerning the design of the study have been chronicled and included a discussion on the concept of expert as one criterion for selecting the participants. Finally, I touched on the complexity of phenomenology as both a philosophy and research method and the difficulty I experienced in grasping the central concepts in order to proceed with the project. In undertaking this process of moving from my original ideas to the formation of a definite course of action I have come full circle and in the process have a deeper and more meaningful understanding of my work. In the next chapter, the term essence comes under scrutiny, whereby I explore its etymology and associations with both nursing and phenomenology. 


\section{AN EXPLORATION OF ESSENCE}

\section{INTRODUCTION}

As this project is about revealing the essence of gerontology nursing it is necessary to spend some time looking at the term essence. In this chapter, first I explore the etymology of essence in relation to this study. Secondly, I highlight the association between essence and phenomenology, and thirdly, I discuss the relationship that essence has with nursing. I will argue that phenomenology, being the study of essences, is a particularly apt methodology to use for this project. Then I will discuss some of the key differences and similarities between the nurses' understanding of essence and the phenomenological understanding of essence. Dictionary definitions serve as an important starting point for this discussion. Van Manen (1990, p 59) reminds us that "being attentive to the etymological origins of words may sometimes put us in touch with an original form of life where the terms still had living ties to the lived experiences from where they originally sprang”. This is certainly true for essence, which has a variety of meanings and associations, an understanding of which will help to bring a more meaningful interpretation of this research project.

\section{ETYMOLOGY OF ESSENCE}

The meanings and interpretations of the word essence have evolved over the centuries. The Oxford English Dictionary (OED) Online (1989), records that essence is derived from the Greek word ousia meaning the inner essential nature of a thing, the true being of a thing and the Latin, essentia from esse meaning 'to be'. 
According to the OED Online (1989), there are two distinct meanings for essence. I have summarised the first explanation for essence as follows: "Being, existence; the foundation of being. Specific being, manner of existing, 'what a thing is'; intrinsic nature, character. Something that is; an existence, entity. An indispensable element". The next definition of essence from the OED Online (1989) is "an extract obtained by distillation or otherwise from a plant...and containing its characteristic properties in a concentrated form. Such as perfume, flavour, or therapeutic virtues in alcoholic solutions containing the volatile elements or 'essential oil'”. For the purposes of this study, to explicate the essence of gerontology nursing, both meanings of essence as described by the OED Online (1989) are applicable. My aim is to distil the conversations, to describe in concentrated form the very nature of gerontology nursing and in doing so to reveal the fundamental nature or intrinsic characteristics of gerontology nursing, to make visible its very being or essence.

What follows is a discussion about essence, first in relation to phenomenology and then in relation to nursing, and how these two distinct entities of essence come side by side to form the crux of this thesis.

\section{Essence ANd Phenomenology}

This section focuses on essence as it pertains to phenomenology. The theory of phenomenology is discussed in more depth in the next chapter. Phenomenological research is the study of essences. Husserl (1999, p 39), the father of phenomenology wrote, "it is the peculiar character of phenomenology to analyse and conduct research into essences within the framework of a reflection that 
involves only pure seeing...”. Thompson (1990, p 38) explains Husserl aimed "to elucidate the essential meaning” of experience. Husserl's phenomenology evolved and changed over his lifetime, however, Cohen and Omery (1994) write that four constants were maintained throughout Husserl's evolving philosophy. One such constant was his study of descriptive phenomenology and universal essences.

The phenomenology of essences seeks to secure absolute insights into the what, or essence, of whatever is given intuitively in experience. The task is to elucidate the general essence of the phenomena being investigated to yield a concrete descriptive analysis. (Cohen and Omery, 1994, p 138)

My study into the essence of gerontology nursing seeks to do just that. To "secure absolute insights" into the participants' nursing practice, and to elucidate the essence or the 'whatness' of their lived experience.

Heidegger reinterpreted Husserl's phenomenology and focused on understanding human existence and being-in-the-world (Thompson, 1990). According to Walters (1994, p 138) "the focus of research projects derived from Heideggerian phenomenology is that of existence, or as Heidegger termed it Dasein". Heidegger's philosophy is outlined more fully in the following chapter, the relevance here though, is Heidegger's emphasis on being and existence, and the association that has with essence. If we return to the dictionary definitions of essence it is clear to see how essence, with its meanings of being and existence, is an integral aspect of phenomenology. As stated above phenomenology is the study of essences, and I have made a deliberate choice in using van Manen's (1990) approach to phenomenology in my pursuit to explicate the essence of gerontology nursing. Van Manen (1990, p 177) defines essence as "that what makes a thing 
what it is (and without which it would not be what it is); that what makes a thing what it is rather than its being or becoming something else”. Van Manen (1990), however, urges us not to mystify essence and maintains that essence can be seen as a description of a phenomenon. So phenomenology, being a study of essences, attempts to uncover and describe the structures of lived experience, in this case the lived experience of the gerontology nurses participating in this study.

In contrast to the phenomenological understanding of essence as a key essential 'structure' of a phenomenon, nursing literature uses the term from a more practical, literal approach. In the next section, I explore nurses' use and understanding of essence.

\section{NURSING AND ESSENCE}

Nurses' use of the word essence is in keeping with the dictionary definition, in nursing essence is the inner nature or character of something. The term essence and nursing have had a long association. Ever since Nightingale (1859, p 6) claimed "the very elements of nursing are all but unknown" nurse scholars and theorists have attempted to define and describe the intrinsic nature of nursing. In reviewing the literature, I have focused on those nurses who have written specifically about the essence or essential nature of nursing as opposed to generalised nursing theories and ways of knowing.

Henderson (1966) paid particular attention to the nature of nursing and in a subsequent paper entitled Preserving the essence of nursing in a technological age, examines what she believes to be the essence, or unique function, of nursing. Henderson (1980, p 247) posited that nursing’s basic function was to "get inside the 
skin of patients, or clients, and discover what help they need and can use...to foster independence, optimum coping behaviour, or a peaceful death”. Henderson (1980) challenged nurses to preserve the practice of humanistic nursing care while at the same time meeting the increasing need for the development of technical skills. This dichotomy is explored in chapter ten where I look at the primacy of caring for the body within a humanistic framework and is taken up further in chapter eleven where I discuss the importance of 'basic cares' in gerontology nursing.

As I highlighted in chapter one, and reiterate here, Stewart's editorial in 1929, commenting on the science and art of nursing, forms the basis of my research question. Stewart (1929) refers to Nightingale’s well-known statement that nursing is a fine art and questions what distinguishes the art from the technical skill in nursing and how nurses know what actually constitutes art in nursing.

The real essence of nursing, as of any fine art, lies not in the mechanical details of execution, nor yet in the dexterity of the performer, but in the creative imagination, the sensitive spirit, and the intelligent understanding lying back of these techniques and skills. Without these, nursing may become a highly skilled trade, but it cannot be a profession or a fine art. (Stewart, 1929, p 1)

Stewart's words although written nearly three-quarters of a century ago are still relevant today. To explicate the essence of gerontology nursing my aim is to unveil "the creative imagination, the sensitive spirit, and the intelligent understanding" of the gerontology nurses participating in this study.

Over time, in the nursing literature, the term essence was replaced with rediscovering the art of nursing practice. Humanistic nursing theorists such as Nightingale (1859), Henderson (1966; 1980), and Watson (1985) viewed nursing 
both as an art and a science, and asserted care to be the essence of nursing (Taylor, 1994). If, as suggested, care is the essence of nursing, the problem that arises is one of interpretation especially taking into account the multi-faceted nature of nursing. Caring is useful in describing the act, or the 'how', of nursing but I do not believe it is helpful in gaining a deeper understanding of the 'whatness' of nursing. As Stewart (1929) asserts, to understand nursing is to make an undertaking to gain some insight into the intrinsic nature or essence of nursing. Alison Kitson (1999a) has attempted to do just that in a two-part article entitled The essence of nursing that outlines what she believes to be the fundamental elements of nursing.

The complexity of nursing is not necessarily about the challenge of discrete tasks, rather it is the requirement of nurses to be able to undertake a whole range of practical duties in such a way that protects the humanity and the individuality of the person for whom they are caring. (Kitson, 1999a, p 44 italics added)

This has great applicability to my project because I believe, as Kitson (1999a) and Stewart (1929) so eloquently point out, that it is the underlying approach and manner in which practical nursing tasks are carried out that attests to the true essence of nursing. Next, I look at essence and nursing from a different angle, this time focusing on a particular connection between gerontology nursing and the term essence.

\section{ESSENCE AND GERONTOLOGY NURSING}

Returning briefly to the etymology of essence, there is yet another association and meaning to be explored in the context of this study. Essence, as well as being associated with phenomenology and the domain of nursing, also has resonance with gerontology nursing, in particular, to the work of the nurse. The most obvious point 
of difference between gerontology nursing and other areas of nursing is the significance of 'basic cares' in gerontology and conversely the lack of technology. A walk through any neo-natal or intensive care unit attests to the everyday use of high-tech machinery that is not present in facilities caring for old people. 'Basic cares' carries with it a negative connotation, basic, easy, simple, anybody can do it, the type of thoughts often linked to gerontology nursing. Interestingly though, the word basic can be associated with the word essence. The OED Online (1989) gives the meaning of basic as forming a base; fundamental, essential. Thus, the negativity associated with 'basic cares' and by association gerontology nursing is misplaced. The world of nursing ought to place greater importance on 'basic cares', as they are the very foundation of nursing. Gerontology nursing then is concerned with those very fundamental elements that are attributed to being the essence of nursing care. It could be logically argued that gerontology nursing itself, is the essence of nursing because it involves everyday, fundamental nursing care. However, the purpose of this study is to go beyond the everyday practicalities to see what underpins the practice.

\section{DISCUSSION}

The term essence is of great significance to this project, it is in fact pivotal to the thesis. As I have outlined above essence is closely associated with phenomenology, as well as the domain of nursing, and specifically, gerontology nursing. There are differences though, to how phenomenologists portray essence and the nursing world's interest in essence. What follows is a discussion around the differences and 
similarities between phenomenology and nursing and my justification for bringing together these two distinct components that are critical to my thesis.

I have chosen van Manen's (1990) approach to hermeneutic phenomenology as a method to conduct my inquiry, the theory of which is outlined in the next chapter. Phenomenology is concerned with seeing meaning, of looking beyond what is obvious, to see that which is not so clearly visible. The title of my thesis, More then meets the eye: Explicating the essence of gerontology nursing, is an intentional reference to two things concerning phenomenology. One is the phrase 'more than meets the eye' which refers to the phenomenological act of seeing meaning. What has emerged as being more than meets the eye is revealed in the latter half of the thesis. The second phenomenological reference in the thesis title is the term essence, which has been the primary concern of this chapter. Therefore, it is intentional that I am using a phenomenological approach for this study into the essence of gerontology nursing.

The following anecdote from van Manen (1990) illustrates the difficulty and complexity of seeing meaning that is embedded in phenomenological research. Van Manen (1990) tells the story of the unconventional Greek philosopher Diogenes, who apparently went out one day in broad daylight with a lit lantern looking as if he had lost something. When people asked Diogenes what he was looking for, he replied “even with a lamp in broad daylight I cannot find a real human being,” and when they showed him themselves, he chased them away with a stick saying he was looking for real human beings. Diogenes was looking for the nature of human being, and by searching in daylight with a lamp, he was making the point that there 
was not an easy, obvious answer. He used the lamp as a prop to demonstrate the need to see more clearly, to shed some light on the problem. By conducting this research, I am holding up the lamp to shed some light on to what it means to be a gerontology nurse, and in the process, unveil the essence of gerontology nursing, as experienced by the nurses who participated in this study.

Hermeneutic phenomenology is concerned with questions of being and experiencing the world and emphasises pre-reflective knowing (Thompson, 1990). Thompson (1990, p 234) explains this as "we live our lives by experiencing the world and not primarily by 'knowing' it”. Therefore, by focusing on everyday experiences, phenomenology seeks to uncover the intrinsic nature or essence of a thing. This is where the interface between nursing and phenomenology occurs. Both nursing and phenomenology are primarily interested in the experiences of people. Nursing is concerned with the everyday practical issues of understanding and responding to human need. The difference between nursing and phenomenology is that nursing takes a pragmatic, practical approach to understanding human experience whereas phenomenology takes a philosophical approach. Thus, phenomenology is an appropriate methodology to explore the essence of gerontology nursing because of the shared emphasis on understanding human experience.

In thinking about the similarities between nursing and phenomenology a mental picture springs to mind of Florence Nightingale, popularly known as the lady with the lamp, on the Crimean battlefields and Diogenes in ancient Greece, with his lamp searching for insights. The significance to this project is that in my study I am 
asking what are the lamps that light the vision of the passionate and committed gerontology nurses? What do these nurses see in gerontology practice that other nurses can not see? What lights the way for these nurses, so that they can see the inner beauty and qualities of gerontology nursing practice, while others are left in the darkness? Other nurses', and indeed wider society's, vision is clouded by the prevailing ageist attitudes, the dominant 'youth culture' that values above all else the pursuit of youth and beauty. The lamps that light the way illuminate the path to the essence of gerontology nursing, the lamps allow us to see what is more than meets the eye as we go deeper and deeper into the inner core of gerontology nursing practice. This study turns on the lights of the participants so that we can get a clearer view of what they see.

\section{CONCLUSION}

In summary, this research project is the search for insights into the essence of gerontology nursing. Phenomenology, as the methodology I have chosen to use, is designed specifically to pick up on essences. I have outlined the etymology of essence and briefly explained the connection to this research with phenomenology being the study of essences. Essence also has had a long association with nursing, with scholars and theorists using the term in their attempts to describe what nursing is actually all about. The next chapter explores the theory of phenomenology underpinning this project and nurses' use of phenomenology as a research methodology. 


\section{THEORY OF PHENOMENOLOGY AND THE RELATIONSHIP TO NURSING}

\section{INTRODUCTION}

The purpose of this chapter is to explicate the philosophical assumptions that inform this research project and to give a brief account of nurses' use of phenomenology in research. Increasingly, nurse researchers are being challenged to clarify and be consistent with the theoretical basis of their research (Cohen and Omery, 1994; Geanellos, 1998; Thompson, 1990; Walters, 1994; Walters, 1996). In exploring and reading background material for this section it became abundantly obvious that phenomenology, as well as being extremely complex, also has a multitude of interpretations and explanations. The very nature of phenomenology determines that there is no definition, no 'right' approach. Therefore, to establish validity it is necessary to explain the philosophy that has informed and shaped my research. My work is based on van Manen’s (1990) approach of researching lived experience. Van Manen (1990, p 2) writes that his approach is "avowedly phenomenological, hermeneutic, and semiotic or language oriented...”. This chapter then, will focus on the philosophy and history of phenomenology and hermeneutics, and then turn to explore nurses' use of phenomenology as a research methodology.

\section{The Constructivist Paradigm}

This project is grounded in the theoretical concept of constructivism. According to Schwandt, (1994, p 128) Guba and Lincoln first discussed this “wide-ranging eclectic framework" as naturalistic inquiry, however, they now refer to their methodology as constructivism (Schwandt, 1994). The ontological position of the 
constructivist paradigm is that of relativism as opposed to realism. Realities are mental constructs and are socially and experimentally based. The experience of the individual determines the form and content of the constructions. Constructs can be altered, they do not become more or less 'true', but they can become more or less informed or sophisticated (Guba and Lincoln, 1994).

The epistemological stance of constructivism is that what we know to be true is created. Schwandt (1994) explains we do not find or construct knowledge but we create it. Human beings have an awareness of the world that is passed on to us by our culture and from our interaction with the environment. Within the constructivist paradigm, knowledge and what we know to be true, is a result of perspective, it is subjective. This concept is illustrated in the following passage from the fictional writing of Barbara Kingsolver entitled The Poisonwood Bible. The story is about a missionary North American family living in the Congo in the 1960s. This passage is written through the eyes of a ten-year-old girl.

On cool mornings Tata Boanda also wears a light green sweater with a white border on the placket - he's quite a sight, with his muscular chest as manly as all get-out framed by the V-neck of a ladies'-wear sweater! But if you think about it, how would he or anyone here ever know it's a lady's sweater? How do I even know? Because of the styling, though it's nothing you could plainly describe. So is it even a lady's sweater, here in the Congo? I wonder. (Kingsolver, 1999, p 102)

According to Guba and Lincoln (1994) constructivist methodology is hermeneutical and dialectical. Constructions are elicited and refined through interaction between and among the investigator and the respondents. The final aim of an inquiry is to distil a construction that is more informed and sophisticated than any of the 
preceding constructions and as such is the reconstruction of previously held constructions.

A characteristic of knowledge within the constructivist paradigm is that it is transactional. "The investigator and the object of investigation are assumed to be interactively linked so that the findings are 'literally created' as the investigation proceeds” (Guba \& Lincoln, 1994, p 111). Polkinghorne (1983, p 2) believes that in the postpositivist tradition knowledge is not what is real. Instead, knowledge is what is accepted to be "the best understanding that we have been able to produce thus far”.

Therefore, the constructivist theory is congruent with this research project because the stories of the participants stand for what they are, the lived experience of the participants, as their reality. As the researcher, I am not claiming these stories to be true or otherwise, instead, I am saying this is my understanding and interpretation of their texts. Next, I discuss the philosophy of phenomenology before then offering an outline of the history of the phenomenological movement.

\section{Philosophy of Phenomenology}

According to Stewart and Mickunas (1974) the term phenomenology is derived from two Greek words phainomen (an appearance) and logos (reason or word) hence phenomenology means a reasoned appearance with appearance referring to anything of which one is conscious. Ray (1994, p 118) citing Heidegger, offers the following definition of phenomenology, "to show itself, to put into light or manifest something that can become visible in itself." Phenomenologists investigate whatever the content of consciousness is, and are not concerned about what is or is 
not real (Stewart and Mickunas, 1974). The philosophy of phenomenology asks the question what does it mean to be a human being, phenomenology is the study of the lifeworld and aims to gain a deeper understanding of the meaning of our everyday experiences (van Manen, 1990).

In 1967 the French philosopher Merleau-Ponty remarked how strange it was that the question 'What is phenomenology?' was still being asked half a century after Husserl's first work was published on the subject (Anderson, 1991). A quarter of a century after those comments were made Anderson (1991) remarks that the same question remains unanswered. Spiegelberg and Schuhmann (1994) describe phenomenology as a movement thereby acknowledging the ongoing changes and adaptations different philosophers have made towards the meaning and understanding of phenomenology, "the phenomenological movement seems to resemble that of an unfolding plant more than that of a river" (Spiegelberg and Schuhmann, 1994, p 2). According to Stewart and Mickunas (1974) phenomenology as a philosophic discipline is neither rigid nor uniform. However, Anderson (1991, p 26) accepting the diversity of the phenomenological tradition, believes it is still a "distinctive philosophy, theory, and method for studying the world of everyday life.” Thus, we can deduce that the phenomenology movement is not immutable, it is continuously being redefined and new meaning is continuously being layered onto previous interpretations and understandings. Although the philosophy of phenomenology is complex and varied there is, however, a shared tradition, or history that can help explain how the movement has been constructed and reworked over the years to the phenomenology that is known today. 


\section{History Of Phenomenology}

In the following section, I will present a brief account of the history of the phenomenology movement and attempt to articulate the major philosophical beliefs pivotal to phenomenology. It is important to spend some time outlining the philosophies of Husserl and Heidegger as the fundamental principles of their work are central to the current discourse on nursing research methodologies. In outlining the history of the philosophy of phenomenology, I have drawn heavily on the work of Cohen (1987) who gives a succinct account of the key philosophers and concepts of the phenomenological movement.

The history of the phenomenological movement has been comprehensively outlined by Spiegelberg and Schuhmann (1994), who identified three phases in its historical development: the preparatory phase, the German phase and the French phase. The two influential philosophers in the preparatory phase were Brentano (1838 - 1917) and his student and colleague Stumpf (1848 - 1936). Brentano is accredited with developing two key concepts important to phenomenology, the concept of inner perception, which is "the awareness of our own psychic phenomena" and the concept of intentionality - that whatever we think or believe is associated to an object, that we believe in something. Intentionality implies the connection between human beings and their world (Cohen, 1987). Stumpf was committed to reforming the science of philosophy and was instrumental in demonstrating the rigour of phenomenology as a science (Cohen 1987). Husserl and Heidegger are the two dominant philosophers in the German phase of the phenomenological movement and I summarise the key points of their respective philosophies next. 


\section{HUSSERL}

Husserl (1859-1938) was a student of Brentano and Stumpf, and is considered the father of phenomenology. Cohen (1987, p 32) comments that "Husserl was and is the central figure of the phenomenological movement, though phenomenology includes more than Husserl's philosophy, and even Husserl's philosophy was distinctly different across time”. With those thoughts in mind, some key concepts of Husserl's philosophy are now discussed as relevant to this project.

Husserl's work was in response to the then prevailing positivist paradigm of the natural sciences. He wanted to “restore the 'reality' of humans in their 'life worlds', to capture the meaning of this, and to revive philosophy with new 'humanism’ ” (Munhall, 1994 p 14). Husserl adopted phenomenology to find meaning through studying human experience (Parker, 1994). Husserl's radical philosophy was dominated by epistemology, by going to the roots of all knowledge. Subjectivity was central to Husserl's philosophy, with his popular catchphrase being “to the things themselves!" (Stewart and Mickunas, 1974, p 22).

The concept of essences was an important element in Husserl's work. As I discussed in chapter three, essence is about the inner, true nature of a thing, what makes a thing what it is (Parker, 1994). Husserl used the Greek term eidos (meaning idea) to explain his notion of essence and he "envisioned phenomenology becoming a science of essences or eidetic science” (Stewart and Mickunas, 1974, p 40). Eidetic or descriptive phenomenology aimed to uncover and describe universal essences or the structures of a phenomenon (Cohen and Omery, 1994). Van Manen (1990) claims essence refers to the whatness of things, as opposed to their thatness 
(existence). “The essence of a phenomena is a universal which can be described through a study of the structure that governs it...” (van Manen, 1990, p 10).

The 'lebenswelt' (life-world) is another important concept of Husserl's philosophy. Life-world refers to the world of lived experience that is not always accessible in the 'natural attitude'. Cohen and Omery (1994) explain that because we take for granted everyday, commonplace experiences we fail to take notice of them, and it is the task of phenomenological study to allow us to see what surrounds us. According to Walters (1994), Husserl described two attitudes - the natural attitude and the philosophical attitude. The natural attitude describes the relationship that consciousness has to everyday experience, it concerns the interaction we have with everyday things and everyday people. Another way of looking at the natural attitude is through the scientific or theoretical perspective. This attitude only looks at those objects that have material reality, it excludes the human emotions and concerns of everyday life and requires the scientist to disengage from everyday experience, in order to remove all subjectivism (Walters 1994; Stewart and Mickunas, 1974). The philosophical attitude is concerned with basic philosophical questions. The philosophical attitude does not accept the natural world, it demands rational explanations, and it questions all the presuppositions one has about the world. Husserl called the change from the natural attitude to the philosophical attitude as phenomenological reduction or bracketing (Walters, 1994).

Thompson (1990, p 232) summarises and elucidates Husserl’s phenomenology by stating it "began as a search for the philosophical foundations of logic and evolved into a study of the logical structure of consciousness.” As Husserl's career 
progressed phenomenology then "came to mean the study of phenomena, asphenomena-appear-through-consciousness” (Thompson, 1990 p 232).

\section{HEIDEGGER}

Heidegger (1889-1976) was the other influential philosopher in the German phase of the phenomenological movement. Heidegger was Husserl's student and assistant at Freiburg University and succeeded Husserl as Professor of Philosophy. Heidegger focused on the ontological issues of Being (Sein, or presence) and being (Dasein or being there). Heidegger completely reinterpreted Husserl's phenomenology, his major piece of work Being and Time was published in 1962 (Cohen, 1987). Heidegger did not believe it was possible for an observer to bracket or separate themselves from the world (Walters, 1994). Instead he sought to develop a new understanding of the meaning of Being and being-in-the-world, by studying the ordinary everyday existence of people within the context of their world (Cohen and Omery, 1994).

Heidegger's phenomenology is ontological as opposed to Husserl's phenomenology that was epistemological. Heidegger attempts to understand and find meaning in Being by exploring Dasein. Dasein or being-there, refers to the situatedness of human existence in the world. Taylor (1994, p 56) explains "Heidegger used the term Dasein to denote the exploration of an entity, as a means of finding Being”. Heideggerian phenomenology rejects the epistemological separation of subject and object and instead argues that we have our experiences in the world prereflectively, we experience them before we stop to reflect about them (Thompson, 1990). Heidegger saw time as a frame of reference and as the key to understanding Being. 
Time is the setting or matrix of our being human (Cohen and Omery, 1994). As will be revealed in chapter eight, time is of particular relevance to this inquiry, particularly the existential concept of temporality that emerged as one of the essences of gerontology nursing.

\section{French PHASE}

After the Second World War, the phenomenological movement was taken up in France. The three influential philosophers in the French phase of phenomenology were Marcel, Sartre, and Merleau-Ponty. According to Cohen (1987), Marcel (1889-1973) never called himself a phenomenologist although he saw phenomenology as being useful for the analysis of Being. Like Marcel, Sartre (1905-1980) never called himself a phenomenologist; he was an existentialist and used phenomenology as a tool for his research to reconcile issues of the object and the subject. Sartre believed that a person's existence (consciousness and behaviour) preceded a person’s essence (character) (Cohen 1987). Being literary and artistic, Sartre expanded phenomenology as an alternative method of inquiry with phenomenological writing being central to his life (Parker, 1994). Merleau-Ponty (1908-1961) was concerned with science and wanted to show that a science of human beings was possible. In his book, The Phenomenology of Perception he showed that the phenomenological approach (as opposed to the positivist approach) added valuable insight when considering an individual's experience (Cohen, 1987).

Thompson (1990) asserts that the existentialist school of thought was crucial to the development of hermeneutic phenomenology. Existentialists argued that once we have stopped to reflect on an experience, to question what and how we know 
something, we have already altered that experience. As an example, van Manen (1990, p 182) explains "our experience of anger dissipates as soon as we try to analyse it while experiencing the anger" therefore, "it is not possible to experience something while reflecting on the experience”.

Stewart and Mickunas (1974) claim three basic themes can be identified as central to the philosophy of existentialism. It must be noted though, that there are significant differences between the views of existential philosophers, however, these themes are common characteristics within existential philosophy. The themes are importance of the body, freedom and choice, and intersubjectivity, which are briefly described next.

Importance of the body is emphasised in existentialist writings because the body is our mode of being in the world. This concept has great applicability to this project given that the essential nature of gerontology nursing is caring for the body. The connection between the consciousness and the body is given great importance, particularly for understanding human reality. The body "provides situational context for conscious experience and is the source of perspective one has of the world” (Stewart and Mickunas, 1974, p 66). The significance of the body in this study is discussed in chapters ten and eleven of the thesis.

Freedom and choice refers to the notion that to exist as a person involves free choice. Freedom is not apparent through abstract thought but through an awareness of freedom. Freedom means self-determination in the choices and actions we perform and for which we are totally responsible. 
Intersubjectivity arises from the first two themes. Stewart and Mickunas (1974, p

67) succinctly describe it as follows:

To be bodily is to exist in a world inhabited by other persons.

To be with other persons is at the same time to become aware of one's freedom as well as its limitation, in that one must constantly take the other individual into account. For one discovers his own authentic humanity only by recognising the humanity of others.

A dimension of being-in-the-world is the social context, or community in which we dwell. The humanism of existentialism is centred in the belief that human beings have a central place in the universe from which meaning and value disseminate (Stewart and Mickunas, 1974). Again, this concept has particular relevance to this study given the emergence from the conversations of the nurse-client relationship as being an essence of gerontology nursing. Human interconnectedness is explored more fully in chapter nine. Having outlined the key philosophical tenets of the phenomenological movement that are relevant to this research, I now focus on the background and philosophy of hermeneutics.

\section{HERMENEUTICS}

Heidegger used hermeneutics for his analysis of Being. The term hermeneutics is derived from the Greek verb hermeneuein, which means to interpret. Hermeneuein in turn is derived from the messenger god Hermes, whose responsibility was to change the unknowable into a form that was understandable to humans. Hermes did this through the use of language and writing. Early modern hermeneutics was concerned with the interpretation of ancient documents largely theological in origin (Draper, 1996). Thompson (1990) recounts that the scope and nature of 
hermeneutics continued to expand and is now a philosophical and methodological foundation of a diverse range of fields such as comparative religion, literary criticism, and history. Contemporary hermeneutic philosophy has progressed from being mainly concerned with specific interpretative method to its current focus on existential-ontological questions. Thus hermeneutics is now associated with the human experience of understanding and interpretation with an emphasis on its social and historical context (Thompson, 1990).

Key philosophers who contributed to the development of hermeneutics include Schleiermacher (1768-1834), Dilthey (1833-1911), and Gadamer (1900-). According to Draper (1997), Schleiermacher's most significant contribution to hermeneutical theory was his recognition of the hermeneutic circle. Dilthey and Gadamer both developed further explanations of the hermeneutic circle and the theory of how we understand. Understanding is "a cognitive, affective, and practical process that is based on a sphere of shared meanings and shared experiences within a common linguistic community” (Thompson, 1990, p 243). The hermeneutic circle refers to the process of moving back and forth between an overall interpretation and an interpretation of significant parts (Walters, 1994). The metaphor of the hermeneutic circle is a way of expressing what happens when we 'understand', with understanding being a process of "moving dialectically between part and whole” (Thompson, 1990, p 243). Draper (1997, p 66) cites Palmer’s (1969) explanation as follows:

In this process the whole, and the parts of which that whole is composed, play complementary roles. A sentence, for instance, is made up of a sequence of words. Both the whole (the sentence) and the parts of which it is constructed (the 
individual words) have a role to play. We understand the meaning of an individual word by seeing it in reference to the whole of the sentence; reciprocally, the meaning of the whole sentence depends on the meaning of individual words.

Dilthey's field of interest was in the human sciences and his goal was to find a way in which knowledge could be created within this realm. He believed natural science methods were not appropriate because of the difference in subject matter. Dilthey argued that understanding was an intuitive process and was possible because cultural expressions could be understood by human beings because they had been created by human beings (Draper, 1997). Dilthey emphasised shared language and shared background of meaning as elements of the hermeneutic circle (Thompson, 1990). In that way the hermeneutic circle is integrated into my research project because as researcher, I have a shared language and background in gerontology nursing thus enabling a shared understanding with the participants. Next, I look at Gadamer's contribution to the development of hermeneutics.

\section{GADAMER}

Gadamer (1900-), a pupil of Heidegger, was heavily influenced by Heidegger's work. Heidegger's hermeneutics, rejecting the mind - body split and advancing the inter-dependence of the human being in the world, was extended by Gadamer in his book Truth and Method (Thompson, 1990). The hermeneutics of Gadamer surpasses Cartesian separatism of objectivism and subjectivism and is the study of understanding and truth (Walters, 1996). The important concept of Gadamerian philosophy is that interpretations are not seen as static, instead, understanding is a dynamic, ever changing process (Thompson, 1990). 
Gadamer provides ontological insights into understanding arguing that understanding is a way of being not a way of knowing. He described understanding as a fusion of horizons (Thompson, 1990). Gadamer asserted that understanding occurs when the horizons of the researcher intersect with the text. Walters (1996, p 97) explains that according to Gadamer "a horizon is the range of vision that includes everything that can be seen from a particular vantage point”. So, horizon can be perceived as the background of understanding or frame of reference that is adopted, it is our being-in-the-world (Thompson, 1990). This then places the interpreter as an active participant in the process of interpretation. This is a key factor for me as researcher in this project and is discussed further in the next chapter. Thompson (1990) discusses two important outcomes of Gadamer's fusion of horizons. One feature is that understanding has a practical and moral orientation that results in greater understanding and an appreciation for other views. "It grasps particular situations, and ... it has a moral sense of what should be done" (Thompson, 1990, p 247). The second outcome of the fusion of horizons is that "hermeneutic experiences always enlarge and enrich our understanding of the human condition” (Thompson, 1990, p 247).

Gadamer emphasises language as a critical aspect of understanding. He rejects the conventional idea of language, that it is an instrument or tool used to describe and make sense. Conversely, Gadamer contends that language and cultural practises are linked and are held within a historical context. Thompson (1990, p 241) suggests “...concepts are not just value laden neutral, ahistorical entities that more or less accurately mirror our world. Rather, concepts are conditioned by our historical era and by our social interests”. 
The other important concept about language that Gadamer posited was that interpreters bring to their work an established background of pre-understanding or what he referred to as prejudice. He suggested this is not a negative thing but that it is necessary to be aware of one's prejudices through a process of self reflection and argued that we can only gain access to our world through our prejudices (Thompson, 1990; Walters, 1996). Geanellos (1998, p 238) explains why this is important to research methodology as follows:

Discovery of and reflection upon pre-understandings allows interpreters to question the origins, adequacy and legitimacy of these pre-understandings in relation to textual interpretation. To not engage in the process of addressing forestructures/preunderstandings places the researcher at risk of confirming their own truth (foreknowledge, assumptions, biases, beliefs) rather than revealing the truth under investigation.

Geanellos (1998) suggests using a research diary as one way of bringing to the fore pre-understandings and assumptions in order not to foreclose early on interpretation of the texts. This is the approach I took and by documenting and analysing my initial thoughts and pre-understandings I was in a stronger position to reflect on them and acknowledge their influence on my interpretation of the texts.

I adopted van Manen's (1990) method of hermeneutic phenomenology for my project. The theoretical underpinnings of this particular method are outlined next followed by my reasons for using it for my study.

\section{VAN MANEN}

Van Manen’s (1990) approach to hermeneutic phenomenology is grounded in German and Dutch philosophies (Ray, 1994). Van Manen (1990, p 8) writes that human science research "makes us thoughtfully aware of the consequential in the 
inconsequential, the significant in the taken-for-granted”. Cohen and Omery (1994) explain the Dutch approach to phenomenology combines elements of descriptive and interpretative phenomenology. To resolve the seeming contradiction in this approach, van Manen (1990) explains that it is descriptive (phenomenological) because it lets things speak for themselves and it is interpretive (hermeneutic) because it acknowledges there are no such things as uninterpreted facts. Therefore, "the (phenomenological) 'facts' of lived experience are always already meaningfully (hermeneutically) experienced” (van Manen, 1990, p 180-181).

Lived experience needs to be captured in language that is inevitably hermeneutic in nature thus van Manen's human science is essentially a writing activity grounded in semiotics. Semiotics is the study of texts, or signs and their structural relationships that we construct of our world. So the true nature of things does not lie in the things themselves but in the relationships we construct and perceive among them (van Manen, 1990). Language and the practice of writing is an important aspect of van Manen’s methodology. According to van Manen (1990, p 127), “writing gives appearance and body to thought", it is a way of 'putting out' what we know, of making external what is internal. By writing we are putting into symbolic form what we are seeing, it allows us to see. Van Manen (1990, p 130) asserts that "phenomenological text succeeds when it lets us see that which shines through, that which tends to hide itself”. Hence, the title of my thesis More than meets the eye... is referring to the phenomenological task of revealing hidden meaning, of shedding new light on what it means to be a gerontology nurse. 
Having explicated the philosophy of phenomenology as it informs this project, next I explain my reasons for adopting van Manen's approach to phenomenology to carry out this study.

Van Manen’s (1990) human science situates itself between the differing schools of phenomenology, incorporating aspects from both phenomenological and hermeneutical methodologies and because of this, it is not a 'pure' methodology. It is a blend of descriptive and interpretive phenomenology, of describing lived experience and interpreting lived experience. One of the critical elements in undertaking hermeneutic phenomenology is to let the facts speak for themselves. That is why this approach suits my project because it allows for each participant's conversation to be meaningful for what it is - as the lived experience of that particular gerontology nurse. It is not the aim of this inquiry to create a theory or make generalities. My aim is to bring a deeper meaning to the work of gerontology nurses, to explicate the essence of their work, of their lifeworld.

Another justification for using van Manen’s (1990) hermeneutic phenomenology is because it lends itself to openness, I am not foreclosing on the nature of essence, this thesis does not represent the definitive essence of gerontology nursing. What I am saying though, is that this is what four nurses who practice gerontology chose to reveal to me about themselves and their work, and this is how I have interpreted those conversations. There are three pertinent points that help to explain why this methodology is appropriate for this particular research. First, the methodology allows for and indeed calls for, the use of multiple sources of material to be gathered for analysis, including the researchers' own position. Therefore, my 
embedded knowledge and understanding of gerontology nursing are a legitimate part of the thesis, coming together as a fusion of horizons whereby my horizon of understanding intersects with the texts to create greater understanding. Secondly, this methodology gives voice to the conversations, they can stand up and be counted for the interesting and insightful texts that they are. And thirdly, van Manen's (1990) methodology is essentially a writing activity and places a heavy emphasis on the inventiveness of the researcher that allows for creative interpretation of the texts. Therefore, it is largely dependent on the researcher's ability, by skilful use of language, to make accessible and visible what is hidden in the texts.

From a purely pragmatic standpoint, van Manen’s (1990) method offered a practical approach to carrying out a hermeneutic phenomenological inquiry. It would have been difficult to know where to start, how to actually go about gathering the material, analysing it, and writing about the essence of gerontology nursing without van Manen’s (1990) approach to follow as a guide for this work. Phenomenology has many interpretations that either diverge or converge as the case may be. Spiegelberg and Schuhmann (1994) refer to phenomenology as a movement because of its constantly changing nature. Thus, van Manen's (1990) approach was a welcome guide because it set out a clear method to follow, being mindful of course that when conducting phenomenological research it is important not to be intensely focused on method at the expense of phenomena.

Having explicated the philosophical assumptions of this project, next I explore nurses’ use of phenomenology as a research methodology. 


\section{Phenomenology AND NURSING}

The discipline of nursing and phenomenology share common beliefs, both view people as intersubjective beings whose everyday experiences are created in the context of their own worlds (Taylor, 1994). Hermeneutic philosophy, in contrast to the once dominant positivism, as a means of knowing and understanding in social sciences has steadily gained in popularity since the 1970s. As in other humanistic fields, nursing has adopted hermeneutics as a philosophy as well as a philosophical basis of research and practice (Thompson, 1990). Nursing epistemology and phenomenology have some commonalities, people are seen as whole beings who create their own meanings as they go about living their day today lives (Thompson, 1990). Using phenomenology as a way of understanding people in nursing allows us to see how people interpret their experiences of Being and also serves to illuminate the world of nurses (Taylor, 1994). According to Thompson (1990, p 228) hermeneutics is an appropriate philosophy for nurses because "it shows us that human understanding is limited and conditioned by our social interests, our values, our language and concepts, and our time in history."

In response to detractors, Lawler (1998) contends a common misconception about nursing research is that experimental, positivist research is beyond our means, or that as a group we are not committed to rigorous academic pursuit. Lawler (1998) stresses what needs to be understood is that nursing knowledge is different to other health disciplines’ knowledge - we do not seek definitive outcomes or to control events, instead nurse researchers endeavour to understand human experience. Lawler (1998) asserts that struggling to come to terms with the philosophy of such 
methods soon dispels the myth that nursing research is a soft option. In choosing a research method Munhall (1994) states it is essential to question the extent any method brings us closer to understanding what it means to be human. Munhall (1994) stresses that phenomenology is not a research method, it is a study of lived experience and how the researcher studies that experience depends more on philosophical assumptions than on the method.

As noted earlier, an important concept of Gadamerian hermeneutics is that interpretations are not seen as static, understanding is a dynamic process that will change as the researcher's interpretative horizon changes. It allows the researcher to be legitimately included in the research process, which is relevant to this particular research project given my position in the study as active participant. Walters (1996) asserts that the implications of this inclusion are that researchers must have a sense of belonging in nursing practice and this in turn raises the issue of the theory/practice/research gap. To address this issue, in chapter eleven I discuss the implications of this research on my nursing practice.

According to Lawler (1998) phenomenologies (used in the plural to indicate the discussion is inclusive and not focused on one specific method of phenomenology) are the most common choices of qualitative methodologies reported in the nursing literature. Nurses adopted the use of qualitative research methodologies in the 1960s, but it was not until the 1970s that phenomenology gained more popularity as a research method. Phenomenology was believed to fit better with the type of research nurses were doing, in other words it was believed to be a more appropriate way of exploring the lived experiences of patients and their families (Anderson, 
1991). In the 1980s nurse researchers, working toward a 'science of nursing', explored the use of phenomenology and raised important epistemological concerns in relation to methodologies and philosophical paradigms used in nursing research. Nurse researchers adopted the phenomenological approaches developed by psychologists such as Giorgi, Fischer, and Murray (1975), and Colaizzi (1978). Nurse scholars such as Anderson (1991), Munhall and Oiler (1986), Oiler (1982), Omery (1983), Parse, Coyne, and Smith (1985), Rieman (1986), Allen, Benner, and Diekelmann (1986) and others have discussed the philosophical assumptions of phenomenology and have helped to identify essential elements in phenomenological methods (Anderson, 1991; Taylor, 1994; Walters 1994).

Paterson and Zderad (1976) in describing their theory of humanistic nursing used existential phenomenology to find the meaning of nursing as it occurs in the everyday world. They described the lived experiences of nurses and patients as being mutually rewarding (Taylor, 1994). According to Ray (1994), Parse’s (1992) theory of becoming describes the interrelationship among human beings, living and health. Another prominent nurse theorist to adopt hermeneutic philosophy to underpin her research is Watson (1985). Watson's (1985) theory of caring relates to the transpersonal caring relationship that she describes as " human care processes that connects with and becomes part of the lived world of human experiences associated with health and illness” (Watson, 1985, p 18). More recently, Taylor (1994) uses phenomenology, informed by the philosophies of Heidegger and Gadamer, to explore the concept of ordinariness in nursing. Taylor (1994, p 3) views nursing as a human relationship and as such has the potential to "make sense 
of human existence” which in turn may lead to nurses understanding "themselves as humans who share commonalities with the people in their care”.

In recent nursing literature, there is discussion on nurses' ability to appropriately apply phenomenological methodologies to their research projects. Benner's work in particular, and others have been critiqued for not remaining true to the philosophical foundations of their work (Walters, 1996; Crotty, 1998). Geanellos (1998) states nurses are increasingly using the philosophy of hermeneutics, however, the extrapolation of philosophy as a research method is proving to be problematic. Lawler (1998) concurs with this view, writing that although phenomenologies are fashionable in nursing there are methodological issues that need addressing. A fundamental issue that has yet to be addressed "is the appropriateness, with direct reference to nursing's knowledge base(s) and in the interest of nursing scholarship, of choosing one particular methodology over another” (Lawler, 1998, p 105). In doing so, not only will the validity and value of nursing research be preserved but nursing scholarship will also be advanced.

\section{CONCLUSION}

My research project is about investigating the essence of gerontology nursing using the methodology of hermeneutic phenomenology. Phenomenology is fundamentally a study of essences, which as explicated in chapter three, is very relevant to my research. I have described the philosophies of phenomenology and hermeneutics as they inform this study, and in particular van Manen's (1990) approach. To conclude, I now summarise the main theoretical points underpinning my research. Phenomenology is the study of human experience and aims for a 
deeper understanding of the meaning of everyday experiences. Hermeneutics is the theory and practice of interpretation. The Husserlian epistemological phenomenology is rejected and it is argued instead that our experiences are not characterised by the separation of object and subject but that we life our lives by experiencing the world and not by knowing it. Hermeneutic phenomenology, informed by the philosophies of Heidegger and Gadamer, is ontological and existentialist in nature. Interpretation and understanding are linked to being and our experience in the world, with a focus on language as a medium to experience the world. The hermeneutic circle, fusion of horizons, and the concept of preunderstandings are essential elements of hermeneutic understanding and interpretation. I chose to use van Manen's (1990) approach to explicate the essence of gerontology nursing because it is a blend of descriptive and interpretative phenomenology that focuses on lived human experience. Having explicated the theoretical underpinnings of my research, the next chapter moves on to the design of the project. 


\section{GETTING STARTED - RESEARCH DESIGN}

\section{INTRODUCTION}

In the previous chapter I focused on the philosophy that informs this project, now I turn to the practicalities of the research and detail the design of the study. The issue of intersubjectivity is discussed and then I cover the recruitment of participants, criteria for inclusion, establishing trustworthiness, consultation with Mäori, and ethical concerns. Following that, I focus on the interview process I used to gather the material for my study. In particular I outline Minichiello’s et al (1990) method of in-depth interviewing that I found useful to follow.

\section{INTERSUBJECTIVITY}

The intersubjective nature of the project requires me to make explicit my own story, and my position and involvement as researcher in the study. I was an integral part of the interactive inquiry process, I was inextricably involved. In the words of Guba and Lincoln (1994), I was the "passionate participant”. Walters (1994) suggests the relationship between the researcher and the participants recognises the shared experiences we have with each other as an important source of new knowledge. Hence, my experience as a gerontology nurse is very much part and parcel of the inquiry process and influences all aspects of the project. It should be emphasised that "the person most likely to inquire about a phenomenon is the one most likely to have a great deal of knowledge about it...” (Sandelowski, Davis, and Harris, 1989, p 78). Therefore, it would be very difficult not to be a passionate participant! My story is included in the next chapter with the participants. 


\section{Selection of PARTicipants}

As a gerontology nurse, I have an established network and relationship with gerontology nurses within my locality. On hearing of my research interest, these colleagues indicated a positive and enthusiastic response to this project in its formative stages. Therefore, it was logical to use this knowledge in recruiting participants for the study. I recruited four gerontology nurses to participate in the research. I explore in more detail below the criteria I used to recruit these particular gerontology nurses.

In order to capture a variety of accounts with which to work I decided to include nurses from a variety of work environments and with differing roles and experience. Thus I interviewed nurses who were either still working in clinical gerontology nursing or who were no longer practising but still in some way committed to, and actively involved in gerontology nursing.

\section{CRITERIA FOR INCLUSION}

It was necessary to set some parameters and criteria for inclusion in the project. The first factor was that the participants had to have a commitment to, and a passion for, gerontology nursing. I decided this would be most evident in their employment history (outlined in the following chapter).

I also believed their commitment to professional nursing would be demonstrated by their undertaking of academic study beyond that of on-the-job training courses such as wound care or managing dementia. Therefore, I decided to include participants 
who were working toward or had completed either a bachelor or masters degree in nursing.

A further criterion was that I felt it necessary for the participants to have experience in reflective practice and to have the ability to articulate their knowing. It was necessary for me to make a judgement as to their level of expressive expertise. Van Manen (1990) suggests when recruiting participants, representativeness is not of primary concern in human science research. What is important though is the ability of the participants to articulate themselves. Again, I believed involvement in postgraduate study or in nursing education would more than likely indicate that a prospective participant could meet this criterion.

I chose participants who worked in a range of roles as I sought a breadth of experience as opposed to depth or length. The result was that I interviewed nurses whose experience in gerontology nursing ranged from five years to twenty-five years experience.

Finally, I limited the geographical area for inclusion to the study to my local area for reasons of practicality both personal and economic. It was not necessary to go further afield to recruit participants to meet the above criteria however, should it have been necessary I would not have hesitated to do so.

My decision to use just four participants had implications for the outcome of the study. My findings into the essence of gerontology nursing were limited to what those four nurses chose to reveal to me during the one-hour conversation I had with each of them. So that then is a limitation of the study, because my findings are based on the perspectives of the nurses I recruited, if I had recruited four different 
nurses then I would expect to find their perspective on the essence of gerontology nursing to be different. Conversely, it could be argued that limiting the study to four participants is a strength of the research because it is keeping within the methodology. I am not searching for universal truths, I am looking for meaning and understanding of lived human experience, as experienced by the participants.

\section{ESTABLISHING WORTHINESS}

Given that phenomenological research is so rigid and yet so loose - the researcher determines the structure of the project, how then can the work be judged for rigour? Van Manen (1990, p 17) claims that "human science operates with its own criteria for precision, exactness, and rigour.” In general terms, rigour in research allows for the project to be scrutinised for credibility, methodological accuracy and worthiness (Roberts and Taylor, 1998).

The terms validity and reliability are used to judge the scientific rigour of quantitative research. Although no less rigorous than quantitative research, different words are used to measure the accuracy and worthiness of qualitative research (Sandelowski, 1993). Hill-Bailey (1997) writes that some qualitative researchers use the process of validation to authenticate their research. Validation is achieved by adjudication by both the consumers and fellow researchers. The essential component of this process is that the researcher must make their research process visible and auditable.

Establishing rigour in phenomenological research is dependent on the philosophical underpinnings of the project being clearly identified. Walters (1994) warns nurse researchers to ensure that the language and indicators used to position rigour are 
congruent with the ontological foundations of their research. For example, if a project was based on Husserlian phenomenology it would be appropriate for the researcher to guard against bias and to seek external validation of the interpretations. On the other hand, if the methodology was Heideggerian "objectivist attempts of scientific rigour would not be appropriate" and the researcher would make clear where the researcher is situated within the research process (Walters, 1994, p 139-140). As I declared earlier, I am inextricably involved in this research as a 'passionate participant' which is congruent with Heideggerian philosophy.

Next, I address consultation with Mäori and then the ethical considerations pertaining to my research.

\section{CONSULTATION WITH MÄORI}

As my research had Mäori participation, I checked the Guidelines for Researchers on Health Research involving Mäori 1998 (Health Research Council of New Zealand, 1998) for advice regarding the consultation process I ought to undertake. According to the guidelines, “...consultation should take place if Mäori are to be involved as participants in a project or the project relates to a health issue of importance to Mäori” (Health Research Council of New Zealand, 1998, p 7). They then go on to state the nature and extent of consultation is dependent on a number of factors and advise "the extent of any consultation should be appropriate to the scale of the intended project, its relevance and significance to Mäori health...” (Health Research Council of New Zealand, 1998, p 8). After discussion with the Mäori 
participant, and in accordance with the guidelines, we decided it would not be necessary to seek any further consultation given the scope and nature of the project.

\section{ETHICAL CONCERNS}

In carrying out research involving human participants, the researcher must attend to certain moral obligations to ensure no harm is done to any person involved in the study. The Victoria University Human Ethics Committee, subject to some minor amendments that were duly addressed, approved the research proposal for this study.

Three principles underpin most research standards: beneficence, respect for human dignity, and justice (Roberts and Taylor, 1998). These three principles are now discussed in relation to this study.

\section{Beneficence}

The overriding aim of the research should be to 'do good'. The study must benefit individuals or society in some way. Gerontology nurses may benefit from this project by having the complexity of their work made explicit. The wider nursing profession may benefit by gaining a deeper insight into the area of gerontology nursing, which in turn may assist with recruitment and retention of nurses to this area of nursing.

Strengthening gerontology nursing may benefit the older population by the development of a workforce who are not only professional in carrying out their duties but who have a more profound understanding and knowledge of the role they are undertaking. 
I considered the potential for harm or exploitation of the participants. We are all gerontology nurses, the researcher included, and the only area of potential harm or conflict of interests would be in the inter-relationships with each other. However, I decided this was not an issue as we were working for different organisations and in different roles. There would be no opportunity for exploitation, or abuse of power between the researcher and the participants.

\section{Respect for Human Dignity}

The second principle, respect for human dignity, is the participants' right to selfdetermination, the right to participate or withdraw from the study at any time without penalty. Two elements of this are information and consent that were covered in the consent form (Appendix A). I telephoned the participants and invited them to be involved in the research project. They all agreed and were duly sent out an information sheet (Appendix B) and a consent form (Appendix A). The information sheet explains the nature and purpose of the project, how the transcribed conversations will be used and addresses issues of confidentiality and anonymity. Time was allowed for them to consider whether or not to participate and to ask any questions. The consent form was signed at the first contact with the participant with a copy given to the participant and one filed by the researcher.

\section{Justice}

The principle of justice refers to the right of the participants to be treated fairly and respectfully throughout their involvement with the research. Partial anonymity was maintained as I knew the participants but used pseudonyms to conceal their identity to outsiders. Confidentiality was upheld by storing the audiotapes and research data 
securely. The typist who transcribed the tapes was required to sign a confidentiality agreement (Appendix C). No other person other than my research supervisor and myself had access to the tapes or transcripts. A transcript of the tapes was sent to the participants to give them the opportunity to confirm and verify the data for accuracy. A copy of the completed thesis will be available for the participants to read should they so wish.

\section{GATHERING MATERIAL - THE CONVERSATIONAL INTERVIEW}

The process of data collection, as in other research design concepts in phenomenology, is not as straight forward as it first appears. The word 'data' is suggestive of the positive sciences and is not entirely congruent with human science research. Other terms such as gathering or collecting lived experience material is more in keeping with phenomenological methods of inquiry (van Manen, 1990). The conversational interview is one method to gain access to material for interpretation. According to van Manen (1990, p 66), the hermeneutic phenomenological interview serves two specific purposes:

(1) It may be used as a means for exploring and gathering experiential narrative material that may serve as a resource for developing a richer and deeper understanding of a human phenomenon, and (2) the interview may be used as a vehicle to develop a conversational relation with a partner (interviewee) about the meaning of an experience.

Van Manen (1990) refers to what he calls the personal life story as a means of gathering accounts of personal experiences. By having a conversation with a participant in which they relate stories, anecdotes, incidents and so on will enrich the account of their life experience and in turn enrich the study. For the purposes of 
this project, I chose the unstructured, in-depth interview as means of gathering the nurses’ accounts of their lived experience.

One of the foremost people who write structurally about the way of working with indepth interviews is Minichiello et al (1990) who is a social science researcher. His way of conducting in-depth interviews keeps within the tenets of hermeneutic phenomenology and is complementary to van Manen's (1990) approach to hermeneutics.

Minichiello et al (1990, p 93) states this form of interview, whilst taking on the appearance of a normal conversation, is in fact "always a controlled conversation, which is geared to the interviewer's research interests”. It should be acknowledged that to remain true to the phenomenological tradition the researcher must avoid adhering to a rigid set of predetermined rules or techniques in case the method overtakes and controls the natural course of the phenomenological study. To conduct a meaningful interview as researcher I needed to be aware of, and paid attention to, various elements of the conversational interview which are discussed below.

\section{Establishing Rapport}

Establishing rapport is a prerequisite to conducting an interview. Rapport with another person is the understanding and matching of their world (Minichiello et al, 1990). Munhall (1994) suggests being aware of the body and posture of the interviewee as well as trying to match their mood. Munhall (1994) is referring to what I know as mirroring and Minichiello et al (1990, p 111) claims "this can be done effectively by matching the perceptual language, the images of the world, the 
speech patterns, pitch, tone, speed, the overall posture and the breathing patterns of the informant”. By doing this I found it helped me to remain focused on the person I was talking to and to convey to them that I was indeed interested and listening to what they had to say.

Prior attention to details such as where the interview is to take place, comfort measures and addressing any issues concerning audiotaping the interview all assist in creating a conducive environment in which to establish rapport with the participant. The participants were offered a choice of venue for their interview and three chose to come to my home at a time and day mutually agreeable. It also allowed me the opportunity to ensure comfort, privacy and to easily offer refreshments. The fourth interview took place in a room organised by the participant at her work place, as this was convenient to her, and as it eventuated, was a suitable venue for the interview to take place.

One participant found the audiotaping of the interview somewhat disconcerting. At her request I stopped the recorder and attempted to minimise her discomfort by covering the machine with a cloth. We discussed the necessity of having the conversation taped and I emphasised that she was talking to me and not the machine. Despite these measures, I believe she remained hesitant and was possibly not talking as freely as she would have without the tape machine on. Conversely, the other participants were very comfortable with being audiotaped which I think can be attributed to their participation in post graduate study whereby all the sessions are taped routinely which brings about a familiarity and certain disregard with the process of being recorded. 


\section{Remaining Oriented to the Topic}

Prior to starting the interview process the researcher must be focused and have a clear intent. I began each conversation by outlining the purpose of the research and of the interview. The participants had previously read the information sheet and so were familiar with the topic. A model of interviewing called the recursive model is an unstructured form of interviewing that allows the flow of conversation to direct the research process. The value of this model is that it enables the researcher to focus on the uniqueness of each individual's situation (Minichiello et al, 1990). The recursive model then is in keeping with the interpretative approach to research and is in alignment with van Manen's (1990) methodology. Each of the four conversations took slightly different paths whilst remaining true to their initial intent. On reflection, it is now apparent to me that who the participant is, is just as important as what they are. So, by allowing the conversation to flow naturally it also allowed the participant to reveal more about who they are in their own world.

The downside to the recursive approach is the difficulty in keeping the conversation on track. My first conversation had a tendency to veer off track, I was unaware of this during the conversation but it was very obvious when I received the transcript. I edited out the irrelevant parts of the conversation before sending it back to the participant for verification. This experience taught me a valuable lesson for the other three conversations that were more controlled and kept within the time frame of about one-hour. Van Manen (1990) advises that to avoid ending up with an overabundance of tapes or transcripts and the accompanying unmanageable text, it is important for the researcher to be strongly oriented to the research question. To 
keep myself focused I developed an interview guide that reinforced my purpose. I noted down some key aspects that I wanted to cover and also some key words for myself to serve as reminders such as 'keep focused' and 'be specific'.

Preparation work before starting the interviews is important. Being familiar with the topic and having knowledge and understanding of associated areas as a background to the research project enabled me to bring a depth of knowledge and intelligence to the interview. I know gerontology nursing, therefore I could take an active part in the conversation and was in a position to raise points elicited from a review of the literature and by being cognisant of the social and political context of gerontology nursing. Therefore, the task of remaining oriented to the topic came naturally and I could readily follow the train of thought of the participant.

\section{Style of Questioning}

As noted above I favoured the unstructured style of interview. My questions had no specific order and were largely in response to what the participant was saying. I started each conversation by asking the participant to recount their work history and how they became involved in gerontology nursing. At some point in the conversation, I explicitly asked, "What is the essence of gerontology nursing?”

Van Manen (1990) urges the human science researcher to remain close to the lived experience of the participant. One strategy to achieve this is to ask for specific, concrete examples of generalisations that may have been made during the conversation (van Manen, 1990; Munhall, 1994; Minichiello et al, 1990). When it became necessary to refocus the conversation, I did so by asking specific questions such as "You mentioned earlier about ...can we explore that further?" Minichiello 
et al (1990) suggests the use of probing questions to elicit more information from the participants. Probing questions differentiate the research interview from that of normal everyday conversations. It is a method of elucidating, clarifying, and gaining more meaning during the conversational interview and according to Minichiello et al (1990, p 123) is "an indicator that the researcher is aware that he or she cannot take for granted the common sense understanding that people share..." I prompted and probed the participants for details by asking questions such as "Can you give an example?” “Can you remember how you felt about that?” and "What was it like?" which helped the participant to explore their lived experience to the fullest.

\section{Listening}

In the interview process, the art of listening is an important element of conducting a phenomenological interview. Conversation is a two way process and as such the researcher must let the participant know, by verbal and non verbal means, that what they are saying is being paid attention to. According to Minichiello et al (1990), effective, empathetic listening can be readily indicated during the conversation. By nodding, 'smiling' eye contact, and making 'listening noises' the participants received positive feedback and it also helped to minimise any anxiety they might have been feeling. I found whilst interviewing that I had to curtail the urge to express my own opinions at the expense of listening to the participant. I had to find the balance between engaging in a conversation and encouraging the participant to air their thoughts and opinions. 


\section{DisCUSSION}

This chapter has detailed the design of my research and the process I took to interview the participants. Overall the design worked well for me, I had no major issues with gaining ethical consent and the process itself went smoothly in terms of recruiting the participants and carrying out the interviews.

There are two points that need highlighting in relation to the recruitment of the participants, and the impact that these two issues had on the outcome of the thesis. The first issue is the criteria I used for inclusion and the second issue is the number of participants I used for the project. I adopted a fairly pragmatic approach to the recruitment of the participants, with one of the primary criteria for inclusion being their ability to articulate their knowing in nursing. By taking this approach, I knew that I would get a certain quality of material to analyse. The participants were all engaged in postgraduate study and had a confidence in their ability to reflect on and discuss, not only their practice, but also themselves. Therefore, although the nurses were from varying roles and backgrounds, there was a degree of sameness about their conversations, being mindful of course of their uniqueness as human beings. So, when I began the process of listening to the tapes, and reading the transcripts, I found no real surprises, because I belong to the same 'category' as the participants. So, my prior knowledge and thinking about the topic was in line with what the participants were saying to me. Given the intersubjectivity of the project, and my position as a passionate participant, this was not a problem to overcome, as it was congruent with the methodology I had chosen. My challenge though was to dig deeper, to drill down to the core of the conversations to extract the essences of the 
participants' practise, with my own knowledge being a legitimate additional source of data. Conversely, if I had opened the criteria for inclusion to embrace nurses who were not in post graduate study, I would have had very different conversations, possibly more 'raw' in nature, and perhaps not so sophisticated in the articulation. It would nevertheless have resulted in a different outcome for the thesis, an outcome that we can only speculate about.

The second point concerning the recruitment of participants is the number of nurses I used, as the outcome would have been different if I had recruited more than four participants. The consequences of narrowing the study in this way meant I ended up with four perspectives on the practise of gerontology nursing. Having six, eight or ten participants might have revealed differing perspectives and given me a broader base with which to work with. Again though, from a methodological stance, taking this approach was appropriate because phenomenology does not seek to create generalities, instead, it is concerned with gaining insights into everyday lived experience. Therefore, although the decisions I made about the recruitment of participants has limited the study they are in keeping with hermeneutic phenomenology and I believe overall have had a positive outcome for the project.

The project is clearly limited in scope but because of that it has been a manageable task and I think it has afforded me the opportunity to really dwell in the data. I have been able to work very intimately with the texts that has resulted in a deeper sense of understanding than if I had more to manage. So, I feel the structure and design of the study fits and works well for the question in hand. Most importantly, it has allowed me a way to get to what is more than meets the eye. To get to the essence 
of the nurses' conversations it was necessary for me to move to the inside of their stories, to stand on the inside world of the nurses and their lives and their practise. This is explicated more fully in the following chapter but I want to emphasise that it was how the study was designed and structured that has allowed me to stand on the inside of the nurses' world of gerontology nursing to explicate the essence of their practise. This is what hermeneutic phenomenology is about, the search for essences and the interpretation of the meaning of lived experience.

\section{CONCLUSION}

This chapter signals the end of the 'thinking' and planning aspects of my research. I started the process by reviewing the literature around my topic of gerontology nursing. This was presented in chapter one as background and justification for the research. Having settled on van Manen's (1990) approach to phenomenology as being an appropriate methodology to use for my inquiry, I then focused on the substantive question, and the pivotal nature of essence within that. My aim is to explicate the essence of gerontology nursing and it is an assumption of the research that the way I have used phenomenology addresses essence. As outlined in this chapter, my primary mode of gathering material to analyse was by conversational interviews as informed by Minichiello et al (1990), which required paying attention to establishing rapport, remaining oriented to the topic, appropriate questioning technique and listening. I have discussed my insights as to how this process worked for me in the earlier section, overall though Minichiello’s indepth interviewing style worked well within the phenomenological framework of the research. Minichiello's unstructured form of interviewing allows for the flow of the 
conversation to take precedence in the research process which then leaves room for the participant to reveal what they wish to without being caught up in boundaries or preconceived ideas about what I was wanting them to say. In this way, the uniqueness of each participant is allowed to shine through, which is compatible with van Manen's method of phenomenology that focuses on collecting personal accounts of human experience.

I now move into the next phase of the research which is meeting the participants and their stories and understanding the world from their perspective. In the following chapter, I introduce the four participants as well as offering my own lived experience as a gerontology nurse, as a further source of lived experience. 


\section{INTRODUCING THE PARTICIPANTS AND REVEALING MYSELF}

\section{INTRODUCTION}

Not surprisingly, given the design and methodology of the research as discussed in previous chapters, the conversations reflected the unique nature of each individual participant. This was their lived experience and, accordingly, their conversations were grounded in their being-in-the-world. Their past experiences, both from a personal family perspective and from the professional influences they have been subjected to, shaped how they viewed gerontology nursing. Each participant expressed a different focus, a different way of seeing things, and highlighted unique interpretations of their working lives. Within that, however, commonalities clearly emerged and these are discussed in the following chapters. First, though, I want to acknowledge each of the four participants' unique contributions by telling their stories of who they are and how they came to be the gerontology nurses they are today.

This chapter then, introduces Jean, Madison, Tärati, and Dorothy. I have altered some of the details to preserve anonymity. Then, my own experience and reflections on my practice are presented.

JEAN

Jean started nursing in 1979 as an enrolled nurse in the area of continuing care for people over 65 years old. She recalls the experience as being very task oriented and that she knew very little about older people and actually felt a sense of guilt for 
"what she was doing to this other person”. After a few years, she moved to Australia to gain further experience, that as it turned out was not particularly positive, as Jean explains, "It was while I was in Australia I saw some of the most incredibly atrocious acts on older people that I've ever experienced”.

In the mid 1980s Jean returned to Aotearoa and worked in a religious and welfare facility for three years. Jean recognises that she was inspired by some staff there who enjoyed gerontology nursing and who had "really good values around older people and around what was good nursing care". However, she also challenged some care practices with which she was uncomfortable with, even though making a stand cost her personally as she was ostracised and her working life was made difficult. The experience did serve as a motivation though to do her comprehensive nursing diploma in order to work in gerontology.

Jean's first job as a registered nurse was as a staff nurse in a continuing care ward for a public health care provider. She was promoted to Acting Charge Nurse, and then moved into the psychogeriatric field in a variety of nurse management/team leader roles accumulating as clinical nurse specialist. Jean then worked as Clinical Nurse Specialist during the difficult merger of the acute medical ward for over sixty-fives and the Assessment, Treatment and Rehabilitation unit. Currently Jean is involved in nursing education.

Jean started her nursing career as an enrolled nurse in 1978, gained her Diploma in Nursing in 1988, then about ten years later her Bachelor of Nursing and is currently working towards her MA (Applied) in Nursing. 
Humanistic nursing is the central premise of Jean's philosophy of nursing and she values the interpersonal relationship. She has a strong sense of social justice and sees advocacy as an important element of her practise. She stresses the importance of being with someone and being present in the relationship. To be able to do this Jean believes “it’s very much about knowing who I am as a person”. Jean refers to Stephanie Dowrick's book Forgiveness and Other Acts of Love (1997) that has influenced the way she inter-relates with people. Dowrick writes about six human virtues - courage, fidelity, restraint, generosity, tolerance and forgiveness that Jean says impact on her relationships with clients.

When prompted, Jean described gerontology nursing as a colour - deep blue "because for me its warmth. You need warmth, and that warmth is about caring, nurturing the relationship...and its about feeling safe. She also sees the colour red, “for happiness, I think the bright, light colour red which is vibrant, that's what it's all about”.

\section{MADISON}

Madison commenced her training as a comprehensive nurse in the early 1990s, and was 20 years old when she graduated with her diploma. While waiting for her results Madison worked as a caregiver in a long-term care facility and then as a staff nurse once she gained her registration. Madison remained at the same hospital for about two years before moving to live in a different city.

After a short stint working as an agency nurse, Madison gained a staff nurse position at a religious and welfare continuing care hospital. Currently, she works at that same facility but has been promoted to the role of care co-ordinator. This is 
indicative of her commitment to excellence in gerontology practice to have reached this senior position in a relatively short nursing career.

In the five years since graduation Madison completed one paper towards her Bachelor of Health Science and then after locating to a new city, successfully completed her Bachelor of Nursing.

Madison has made a commitment to a career in nursing and in particular is dedicated to gerontology nursing. She also has an interest in palliative care and end of life issues, but has never worked in any other clinical setting since graduating.

Her interest in old people has been long standing. When she was about 11 or 12 years old, she recalls "I wanted to go into resthomes and have chats with older people and find out about their lives”. Once she started her training, Madison knew immediately after the first clinical placement that "it was definitely gerontology."

Madison was a slightly reticent participant and hence our conversation was shorter than the others, but nevertheless exceedingly rich with content. She has a heartfelt passion about gerontology nursing which was apparent in statements such as, "I guess that it comes down to my heart being in the job” and, "I know deep down that I really love my job”. Our conversation revealed Madison’s deep-seated compassion for the clients in her care. The compassion and dedication surfaced in the practice exemplars she cited and when I asked her to talk more about these feelings she said, "I’ve never really thought about it, its just what I do”. 


\section{TÄRATI}

Tärati is of Ngati Porou descent. The principles of Te Tiriti o Waitangi partnership, participation, and protection are inherent in her personal and professional philosophy and who she is as Mäori is an integral part of her being-inthe-world. Tärati's parents belonged to the generation of Mäori that was characterised by what is known as the urban drift, the move from rural areas to the cities. Every school holidays as a child, Tärati took the two-day journey back to the East Coast to be looked after by her grandmothers. This was significant because they instilled in her the reason for her becoming a gerontology nurse and are the foundation of her practice. "It was my grandmothers who were very adamant that the ground that we stood, and the space that we held, was precious. That there is a place for everybody”. The gift of time is another value that Tärati has inherited from her grandmothers and has influenced her practise, "they had a lot of time for us”.

Tärati’s very first job was in a rest home at the age of fourteen doing dishes two days a week in the evening. It was during this time that her desire to be a nurse was confirmed. She has always wanted to be a nurse and has always been clear that she would be a gerontology nurse. Tärati believes this clarity came from her childhood, " it comes from the nurturing of the women, the healers, and the carers in my family”. Her nursing career began as an enrolled nurse and then on completion of her comprehensive training, started her first job as a staff nurse in 1989. Then, according to plan, she gained experience in surgical, medical, and rehabilitation nursing both in Australia and Aotearoa, before returning in the 1990s to resume her 
interest in gerontology. Remaining in the same organisation, a large public health provider, over a period of six years she moved through a succession of roles from staff nurse, advanced nurse practitioner, to nurse specialist. Tärati is a nurse lecturer in a Bachelor of Nursing programme and is actively involved in supporting Mäori nursing students, as well as studying part-time towards her MA (Applied) in Nursing.

The essence of Tärati's conversation with me arises from her Mäori being-in-theworld and the influence of her grandmothers when she was growing up. "I use the word older adult because that is the term we use in everyday nursing language, but it is always switched in my head that its kaumatua. My beliefs around kaumatua health are because of the experience and the knowledge and who they are and who they have been in their life...that is the honour of the status that they have in their older years”. Tärati sees herself as an investigator and a bridge so that as a gerontology nurse her role is to figure out, using a variety of means, how to best meet the needs of the people she is caring for and making the all important connection with her clients. This inter-relates with her strong focus on holistic care,

“ I never see a person with a disability. I see them as a whole person. Even if a person has a memory loss I treat them as if they have all the innate powers of being”.

\section{DOROTHY}

Dorothy knew she wanted to be a nurse from the age of about ten. To that end she worked as a voluntary nurse aide whilst she was still at boarding school. Every Saturday she did an eight-hour shift at a hospital run by a religious and welfare 
organisation. This experience enabled her to be accepted into a nurse training programme straight from school. Dorothy was in one of the early drafts of Polytechnic trained nurses and throughout her training held nurse aiding jobs in aged care as well as surgical wards. She was devastated when she was appointed to her first position as staff nurse in 1989 at an aged care assessment and rehabilitation unit. She felt she had already done her bit for aged care after about four years of nurse aiding. However, it was during that first job that she realised "the huge amount of satisfaction” she got from working with old people. Before committing herself to gerontology she decided to try out other areas of nursing and discovered “it didn’t really matter where you went, you were nursing aging people and I didn’t really get the same satisfaction out of those other areas”.

In the early 1990s, Dorothy worked as a staff nurse/team leader in a religious and welfare continuing care hospital. She stayed there for just over a year but left disillusioned with the quality of care and vowed to get some more education and experience in gerontology in order to be in a position to create change. She then joined a large public health provider in 1994 and has worked in the same organisation in a variety of roles and settings including staff nurse, community resource nurse, clinical nurse specialist, and currently is in a nurse management position. Dorothy is studying toward her MA (Applied) in Nursing and is involved in a number of gerontology advisory roles and professional development groups.

The way Dorothy regards old people with unabashed admiration and her positive attitude to aging comes through strongly in her conversation, “I’m in awe of older people - I think its just amazing”. Dorothy talks with real enjoyment about 
gerontology nursing, and she genuinely likes being around old people. She gets obvious pleasure from spending time and getting to know her clients. "My office is just outside the ward and when I'm having a bad day I put a chair out opposite my door. As the patients come around, they see the chair, and if they need to sit down its right opposite my door, then I can whiz out in the corridor and sit and just have a chat”.

Gerontology nursing reminds Dorothy of rainbows "of different colours coming together to make a wonderful whole where you can't quite see the beginning and you can't quite see the end". She is also reminded of supportive hands setting butterflies free as she sees aged care as giving people new life, "helping them into a new phase and supporting them to blossom into their old age stage of life”. The hands are symbolic of the supportive, nurturing hands of nursing " offering the opportunity to really lift off and experience...”

\section{MY LIVED EXPERIENCE AS A GERONTOLOGY NURSE}

I began my nurse training at thirty-one years of age, being fortunate to be included in a two-year programme especially designed for students who held previous tertiary education. My first placement as a student nurse was in a continuing care hospital run by a religious and welfare organisation. After working two or three shifts, I recall saying to the charge nurse that, "I didn't think this area of nursing would be right for me”. As it turned out those words, spoken in ignorance and naivety, couldn't have been further from the truth.

Throughout my training, I supported my income by doing agency home care work and nurse aiding in a local rest home. These positions allowed me the opportunity 
to form relationships with old people, the overriding memory I have from that time is feeling incredibly privileged to share in these people's lives. I became involved with old people who were living in their own homes. I planted silver beet as instructed and under close supervision; discussed the results of horse racing and the balance of the TAB telephone account; and learnt about the experiences of being a White Russian during the early part of the twentieth century. From those who were institutionalised, I became aware of the endless waiting and the learnt helplessness typical of so many old people 'in care'. These early nursing experiences undoubtedly shaped my worldview of aging, of old people, and of the role of the gerontology nurse.

My view of old age is influenced by the old people I have known, not only in a professional capacity but also through the medium of the arts, the books I read, the movies I see, and the images I am exposed to. In my day to day life I look around me and see old people, perhaps I see old people more readily than others given it is my chosen career interest. I want to see and observe and notice old people. The following passage from a novel by Doris Lessing (1984, p 21) The Diaries of Jane Somers eloquently expresses this:

I walked beside her. It was hard to walk so slowly. Usually I fly along, but did not know it until then. She took one step, then paused, examined the pavement, then another step. I thought how I rushed along the pavements every day and had never seen Mrs Fowler, but she lived near me, and suddenly I looked up and down the streets and saw - old women. Old men too, but mostly old women...I had not seen them.

I am inspired and moved by the old people I have nursed. More often than not, it is knowing that we have connected in some way, that I have been able to make a 
difference to their lives. I am reminded of a man who was in long-term care when I was Principal Nurse Manager. He had Alzheimer's type dementia and the staff found him challenging to care for because of his insistent questioning about his university study. He had been a schoolteacher and in his retirement had commenced a course of study in economics, unfortunately his failing memory prevented him from ever completing his degree. In his world though, he had outstanding assignments and was concerned about getting them submitted on time. This caused him considerable agitation and worry and resulted in him being unsettled for most of day. I intervened and gave him a notebook and set some due dates for his assignments. He responded well to this, diligently working on his university studies, often coming to see me for progress reports and clarification of due dates. Luckily, I was in a position to liberally grant extensions! As expected he became more settled as he now had some sort of structure to his day that was familiar to him.

What was significant to me about this story was not the success of the intervention but a note I found on my desk one day which said, in spidery sloping handwriting, "Dear Anne, thank you for the paper". This reminded me that it is the small, seeming insignificant actions that have the most impact on the people we come into contact with. It meant very little to me, but obviously was important to this man. Having access to paper, and everything that having paper meant to him, was somehow fundamental to this man's being-in-the-world. What touched me was the hand written note that I have kept as a memento as it reminds me of my purpose as a gerontology nurse. That if we remain open and in 'receiving mode' we have the 
unique opportunity to connect and respond to people's needs in such a way that brings enjoyment and satisfaction to their lives.

In reviewing my work history, I graduated in 1992 and since then have had a variety of roles in a variety of settings. I have held positions as nurse aide, home care assistant, staff nurse, community nurse, and nurse manager. I have worked in private and public hospitals, and in private homes. This has allowed me to experience the role of the gerontology nurse in many diverse ways and brings a deeper understanding of the work of the gerontology nurse.

\section{CONCLUSION}

This chapter marks a transitional point in the thesis as I have moved from being in the academic world to now embracing the more human part of the study. Introducing the participants brings the personal aspect of the research to the forefront of our attention. This is a significant move because now we are standing on the inside world of these nurses and their lives and their practice.

So, this chapter opens the door from which I go on to explore their practice through their texts. Because it is through their texts that we are seeing their practice world, and from that we can explore the essence of gerontology nursing, and by standing on the inside of their stories I can elicit what is more than meets the eye.

The crucial aspect of this chapter about the participants is that it reinforces the place that these four particular nurses have in this research. Other nurses might bring other stories, other dimensions, and other essences, but it is Tärati, Dorothy, Jean, and Madison who have shared their practice and participated in the conversations 
with me. So this chapter, by introducing the participants in the study as unique individuals with unique stories to tell, is reiterating the central role they have in this study.

I have worked with the texts, spent time getting to know the material and in so doing, getting to understand the world from their perspective. This is what van Manen (1990) refers to as dwelling in the data, and is concerned with immersing oneself in the texts to gain a deeper sense of meaning and understanding. In the following chapter, I elaborate on this more fully. As part of this process of analysis, I had returned the transcribed conversation to each participant for validation and also to provide the opportunity for further insights to be added. In this way, we have been exploring the essences of gerontology nursing. The five of us, four participants and myself, adventured into the realms of gerontology nursing to explore our stories, our histories, in order to get at the essence of our practise. Thus, by delving into our practise we were able to gain some insights into what the essence might be. From this point onwards, I am on the inside of the texts, this is the inside story that will unveil what is more than meets the eye in gerontology nursing. So we are no longer looking in from the outside, we have repositioned ourselves to sit on the inside to see the world from their perspective and from that view to explore the essence of gerontology nursing.

Thus, this part of the thesis about the participants themselves, serves as a bridge from the academic side to the human side. We are going from the design of the study to whole people and whole histories and then once we get to the other side of the bridge we are standing on the inside of their practise. The first thing to become 
apparent when standing on the inside of the texts was the four elements that emerged as the heart of gerontology nursing. These four elements are true acceptance, personal knowing, being present, and being alive and are explicated more fully in the next chapter.

To summarise, this chapter is a bridge from the academic side of the study to the human side. It has focused on the participants, emphasising who they are as the key to unlocking the essence of gerontology nursing. My own details and experience as a gerontology nurse are included thereby making explicit my involvement and position in the study as an active participant. Next I turn to my process of analysis and discuss the four cardinal elements that initially emerged from the conversations, as well as discussing other sources of lived experience that shed some light onto the essence of gerontology nursing. 


\section{PICKING UP THE GEMSTONES}

\section{INTRODUCTION}

The intent of this chapter is twofold, firstly to outline how I went about analysing the conversations and secondly to make explicit my initial thoughts to serve as a starting point for the further analysis which is detailed in the following three chapters. This chapter then, describes my first level of analysis of the texts, using van Manen's process of thematic analysis. I am now positioned on the inside of the texts, looking for what emerges as being the essence of the participants’ practise.

The four elements, true acceptance, personal knowing, being present and being alive are the foundational things to emerge from the inside of the conversations that then give rise to the three essences that are discussed in chapters eight, nine and ten. I have considered very carefully what term to use to describe these four aspects of the relationship. On the one level they are themes, but that is too superficial and does not accurately reflect the essentialness of their position in the search for essences. These four things represent the foundational frames of reference from which I explore deeper to see their essences. I eventually settled on using the term cardinal to depict these four essential things. According to the OED Online (1989) cardinal means on which something hinges, fundamental, important such as cardinal numbers being one, two, three and so on, or cardinal points of the compass being north, south, east and west. Thus in terms of this project, it seemed appropriate to have true acceptance, personal knowing, being present and being alive as cardinal elements. They are cardinal elements because explicating the essence of 
gerontology nursing hinges on exposing the deeper qualities, or essences, of those four foundational elements.

Next in this chapter, I describe how I actually went about doing the thematic analysis and then move on to describe the four cardinal elements as fundamental starting points for the further analysis that follows.

\section{ThEMATIC ANALYsis}

In this section I have drawn heavily from van Manen’s (1990) process of thematic analysis, which is the process of reflection and analysis of the text of a lived experience. According to van Manen (1990), themes are the structures of experience and so by conducting thematic analysis my purpose was to discover the experiential structures that could be said to be the essence of gerontology nursing.

My first level of analysis began by having the conversations that I had taped transcribed by an independent typist. I then listened to the tapes with the transcript and checked for accuracy. At this stage, I also edited out any repetitions, false starts to sentences, irrelevant sidetracks, and words such as "you know" or "um". Pseudonyms as chosen by the participants were inserted at this point.

I had requested that the first tape be transcribed verbatim. This turned out to be an error as it contained too many what I refer to as empty words, as well as my listening and encouraging words and phrases such as "mmm”, “okay”, "go on”. It was a distraction having them in the text when reading the transcripts. For the subsequent transcripts I instructed the typist to leave out such words and I found these transcript much quicker and easier to check for accuracy as well as enabling 
the conversations to flow better on paper. I sent the edited transcripts to the participants for validation and, having had a period of time for further reflection, to provide the opportunity for them to make any additions or deletions to their original conversations. I completed all the interviews before embarking on the actual analysis.

The first stage of the thematic analysis was familiarising myself with the material. The editing process helped me to become well oriented with the text as it involved listening to the conversation as well as reading it and working with it. Listening to the tape allowed me to be immersed in the conversation without having to be thinking of other issues. I was getting a feel for the stories, understanding the nurses and who they were, and what they did. I could hear the tone and colour of the words and note the pauses, points of uncertainty, the humour and so on.

After dwelling in the data by reading and listening to the tapes several times, I was ready to look for themes. I had listened to the stories and I understood them, they made sense to me. I worked with them as a whole and then worked with them individually, and by then the strong points came through from the texts. The approach I used for isolating themes entailed asking myself, "What statement(s) or phrase(s) seem particularly essential or revealing about the phenomenon or experience being described? These statements we then circle, underline, or highlight” (van Manen, 1990, p 93). The responsibility of the researcher is to carefully sort through the material gathered in this study through the transcribed conversations, and extract the essential elements of the experience of the 
participant. Taylor (1994) describes this process as salvaging the essence of the meaning of the experience and writes it as:

...reminiscent of searching for gemstones of a certain type; some gems are of the desired type, others are precious but they are not the type being sought, and some of the other stones are clearly pieces of gravel stones and grit. (Taylor, 1994, p 187)

Taylor's metaphor was very useful for me in a practical way, the conversations brought forth a wealth of experience that I wanted to capture and use for my research, I thought I had struck gold! But by limiting myself to the "gems of the desired type” I could remain focused on my topic and not get overwhelmed and buried in the texts. Throughout this process, I was conscious of retaining a strong orientation to the question at all times. As a prompt, I had written on a piece of paper, "What is the essence, essential nature, characteristics, lived experience of gerontology nursing?” This also helped to keep my research question sharply in focus whilst I was working with the transcripts.

I made note of the emerging themes by writing statements detailing the main points and lifting out key phases that I felt illustrated or captured the essence of the theme. I repeated this process with all the texts and whilst doing so I was looking for thematic commonalities as well as for areas of discordance. There was no obvious conflict between the conversations, if anything the opposite is worthy of noting in that they were remarkable for their shared content.

So, it was in this way, by capturing the themes of the conversations I was able to elicit the four cardinal elements that are at the heart of the interpersonal relationship in gerontology nursing. 


\section{OTHER SOURCES OF LIVED EXPERIENCE}

Van Manen (1990) urges the human science researcher to go to a range of other sources to obtain a variety of lived experiences that may be outside the realm of our own everyday experiences. By turning to literature, music, or art we may be given the opportunity to gain insights that help us to understand and interpret our topic more fully. Therefore, when the opportunity arose for me to discuss my research project with a group of gerontology nursing colleagues it seemed appropriate, with their permission, to use the discussion we had as a further source of data. I saw the group discussion as a valuable addition to the one on one conversations that I had with the participants. It also gave me the opportunity to sound out my thoughts so far, to get a feel from the group as to if I was on the right track with my initial thoughts. The process also helped me to clarify my thinking and to order my thoughts in a logical sequence.

It was also significant from a methodological standpoint because it was an indication of the worthiness of the study thus far. So, by presenting my analysis to the group of gerontology nurses I could get some idea as to if I was achieving my task of phenomenologically describing gerontology nursing. I was looking to see if my work had resonance with the group. From their feedback and the discussion we had as a group, I felt confident that my interpretation and description was validated. The following section is a description of my initial analysis that derives from a combination of sources. It represents my initial analysis of the four conversations I originally had, and then is reworked to include the ideas and discussion I had with 
the group of gerontology nurses. The analysis that follows in the next three chapters arises from these four cardinal elements.

\section{INITIAL THOUGHTS: CARDINAL ELEMENTS OF GERONTOLOGY NURSING}

The first essence or essential element in nursing is the philosophical and moral recognition of nursing as a personcentred activity. With this acknowledgment comes a set of beliefs and values. (Alison Kitson, 1999a, p 44)

In discussing Kitson's statement with my colleagues there was unanimous agreement that it is the interpersonal relationship that is indeed the core of gerontology nursing. And furthermore, it is the particular beliefs and values of the gerontology nurse that form the foundation, and is the essence of, gerontology nursing. What follows, is my description of the structure of the nurse-client relationship that forms the framework of gerontology nursing. I have organised the structure for reasons of clarity into four categories, that as I discussed earlier, I refer to as cardinal elements. Each of the four cardinal elements, true acceptance, personal knowing, being present, and being alive, are interconnected and informed by the other, and therefore should be read as a whole and not as parts. This then serves as the foundation for my further analysis into the essence of gerontology nursing in the ensuing chapters.

\section{True Acceptance}

This is the unconditional acceptance of clients for who they are in their unique context. It is the acceptance of what space and time they are in now and where they have come from. Gerontology nurses have an opportunity to validate their clients' being-in-the-world, to say this is who you are and I accept that. We must have an 
awareness of history and the values and beliefs held at that time. We also accept that we will never share time with our clients, we will never experience the experiences they have had such as living through the Great Depression of the 1930s. It is beyond our realm of knowing, however, we can accept that this experience is part of who this person is that we are now nursing. For the relationship to be authentic, it is reliant on honesty and an openness to be a part of that relationship. Acknowledging that we all have weaknesses and faults is part of accepting others and knowing your self. Forgiveness is an integral part of an interpersonal relationship, it allows for the nurse and the client to move on and develop a deeper understanding of each other and helps to avoid getting caught up in a cycle of negativity that is known to happen in long term care situations. To forgive is to be tolerant, and tolerance is much more than false acceptance as Stephanie Dowrick (1997, p 237) points out:

Tolerance is not a neat and tidy virtue. In its bonsai forms it certainly allows people to be nice, compliant, patronising, pleasant, hypocritical, blind, unreal, and half-alive. But where it lives and breathes, sweats and weeps, grows and soars, it is anything but nice. It is comforting, flexible, blatant, humorous, sometimes harsh, always encompassing, truthful, demanding - and real.

Dowrick (1997) is referring to the authenticity in a relationship, the 'realness' of the person to person interaction. The notion of true acceptance is about being true not only to our clients but also to ourselves. Nurses, particularly those not well versed in care of old people, have a potential to approach their clients in a false, patronising manner. Examples of this are often seen in depictions of nurses in popular culture, the too loud, over enunciated "How are we today" type of comment. This bonsai form of tolerance as Dowrick (1997) refers to it, is easy to 
see through and can be downright insulting to the client. By not communicating with the client in a genuine way, it denies a person the right to be accepted for who they are.

\section{Personal Knowing}

To be part of a therapeutic, interpersonal relationship it is important to know your self. You have to know who you are and what you bring to the relationship, warts and all. It is an awareness of the becoming who we are, knowing that it is a changing dynamic process and being open to seeing and learning new ways of being and knowing who we are. The use of self as a means of personal knowing is a nursing concept that has been promoted by theorists such as Carper (1978), Watson (1985), and Chinn and Jacobs (1987). "Personal knowing in nursing concerns the inner experience of becoming a whole, aware self” (Chinn and Jacobs, 1987, p 8). Moch (1990) describes three components of personal knowing:

1. Experiential knowing- becoming aware through participation or being in the world.

2. Interpersonal knowing- increased awareness through intense interaction or being with the other person.

3. Intuitive knowing- immediately knowing something without use of reason. (Moch, 1990, p 156)

It seems to me that all three of the above aspects of personal knowing are relevant in gerontology nursing. I think the second aspect, interpersonal knowing is particularly relevant especially given the long term nature of the nurse-client relationship in gerontology nursing. The nurse can often be caring for the same patient for years and years, day in and day out and this contributes to the intensity of the relationship to which nurses in other areas of nursing are not privy. 


\section{Being Present}

An essential element of interpersonal relationships is the nurse's ability to 'tune in' with the client, to be present. Nurse theorists such as Peplau (1952), Paterson and Zderad (1976), and Watson (1985) have written about this as being an aspect of humanistic nursing. It means to be ready, focused, and alert to where the client is in terms of their being, time and space. Being present is aligned with existentialism, and is manifested in nursing by the nurse 'being with' the client, not 'doing for' .

The following narrative and reflection is extracted from a journal entry I made when working as a staff nurse in a continuing care facility. I have included it here as an illustration of being present from my practise.

I was nursing a man who had been a farmer all his life and through an unfortunate series of events ended up being in institutional continuing care in the city. He was in his early eighties, and suffered from dementia. He was aggressive and violent towards other residents and staff. I came to the conclusion he was alienated and angry by his situation. This man hated being cooped up inside, being a farmer he loved being outdoors, in fact it was more than that, he needed to be outside. I arranged to get him a pair of gumboots and a swandri that enabled him to go outside and poke around in the garden. With assistance from the nurses he did this twice a day, regardless of the weather. By putting on these familiar clothes and having some routine and meaning in his day, his anger subsided and consequently his aggressive behaviour was minimised. It had been suggested that a chemical restraint be used to control his violence but by knowing this man and being attentive to who he was as a person, to his being-in-the-world, the use of medication was avoided. 


\section{Being Alive}

This structure of the nurse-client relationship was difficult to conceptualise, it is about appreciating the day for what it brings, having fun, enjoyment, sharing in the finer things that life has to offer. It is the appreciation of feeling the warmth of the spring sun on your back after a dreary winter. It is taking time to smell the roses. Gerontology nurses have a large part to play in their client's living and often it is up to the nurse to make time and enable the client to experience life to the full. Being alive is the sharing between nurse and client, being involved in each other's ups and down, the good and bad, and the sheer mundane. For it to be authentic, the nurse brings her own living to the relationship in order to maintain the balance of the partnership. I worked with a nurse who used to bring her preschooler into work every afternoon for about fifteen minutes until her partner came to pick the child up. This arrangement was much to the enjoyment of the residents, some of whom would take a very real interest in the child's well being. It was the nurse's willingness to share her child with the residents that was so special. This is also an example of mutuality and reciprocity that Turkel, Tappen and Hall (1999) found in their study about nurses providing home-based care which is discussed more in chapter nine.

\section{CONCLUSION}

In this chapter I have revealed my first level of analysis of the conversations. Once I got a feel for the texts, got to know the nurses and their practice from their perspective, I was in a position to stand inside the texts to see what was there that was more than meets the eye. Basing my exploration of the texts on van Manen's 
(1990) process of thematic analysis I discovered four cardinal elements; true acceptance; personal knowing; being present; and being alive. The cardinal elements are at the heart or core of the interpersonal relationship in gerontology nursing.

As I noted earlier in this chapter, Taylor's (1994) metaphor of searching for gemstones had particular resonance for me. To extend the metaphor further, the cardinal elements are the certain types of gems I was searching for, and now having spotted those gems, and picked them up I am going to look at them more closely to find their quality, their beauty, their essence. Searching for their inherent characteristics, their colours, hues and tones, will reveal what is more than meets the eye in gerontology nursing.

I am drilling down in to the centre of the gem to expose its very essence and that is how I am going to approach explicating the essence of gerontology nursing. We have picked up the gems, the cardinal elements, and after further analysis and reworking from the inside, the cardinal elements give rise to three essences of gerontology care. These essences are the centrality of temporality, the centrality of interconnectedness and lived human relationship, and the centrality of the lived body, corporeality. The following three chapters are devoted to explicating each of these three essences. 


\section{THE CENTRALITY OF TEMPORALITY}

\section{INTRODUCTION}

The previous chapter revealed the four cardinal elements of the interpersonal relationship as being at the core of gerontology nursing. In describing how I went about analysing the conversations, I used the metaphor about picking up gems to illustrate how I thematically analysed the conversations. To extend that metaphor even further, we now have the four gems in our hands and are looking deep into their inner core to see and appreciate their visual quality, their uniqueness, or in other words their very essence. This chapter and the two following chapters focus on the essences that arise from the four cardinal elements of true acceptance, personal knowing, being present and being alive. So the cardinal elements were the foundational essences that I have looked more deeply into in order to see what their essential qualities are. It is from the further drilling down to the very heart of gerontology nursing practice that the essences of gerontology care are unveiled. The essences are centred in the concepts of temporality, relationality, and corporeality and this then, is what is more than meets the eye in gerontology nursing practice.

An integral part of the nurse-client relationship, was the concept of time. It was a like a thread running through the fabric of the conversations and emerged to be an underlying and critical element of the work of gerontology nurses. The participants' perspective and understanding of lived time was a key element underpinning their practise as gerontology nurses, and that sets gerontology nursing apart from other fields of nursing. There are two aspects to this concept, the first is 
concerned with the lived time of the clients, and the fact that they have lived in another age different to that of the nurse. And the second aspect is the nurses' knowledge and appreciation of past events in the clients' lives, and how that knowledge and way of knowing is therapeutically employed in daily practise. Thus the existential concept of lived time, or temporality can be seen as the setting for gerontology nursing, against which all action takes place. And, within this setting of temporality is the interpersonal relationship between nurse and client. The following section outlines the concept of existential temporality before then briefly discussing subjective and objective time in relation to nursing in general and then specifically to gerontology nursing.

\section{TEMPORALITY}

Exploring lived experience can be structured in terms of four fundamental lifeworld themes or existentials which are lived time (temporality), lived space (spatiality), lived body (corporeality), and lived human relation (relationality). Each existential informs the other and is interrelated with the other, and although it is possible to differentiate each existential they can not be separated (van Manen, 1990).

The existential phenomenologist Merleau-Ponty (1962) analysed time and temporality within the concept of subjectivity. He believed time was not objective, and that the past and the future are embedded in our present-time being (Spiegelberg and Schuhmann, 1994). Spiegelberg and Schuhmann (1994, p 567), in describing Merleau-Ponty’s philosophy on subjectivity and temporality write,

Merleau-Ponty finally characterises "time as the subject and the subject as time". By this he means that the subject is not 
simply in time, for it assumes and lives time and is involved (engage) in time: it is permeated with time.

So, temporality is subjective, it is how an individual perceives time, for example going on a car trip may seem to take forever getting there, but the return trip might appear really quick although the actual distance travelled has been the same there and back. Time can either fly, or be as long as two wet weeks depending on how it is perceived. Subjective time is particularly pertinent in nursing. The bed-ridden client with little or no diversions has a very different perspective on time than a nurse responsible for the care of many clients. For the client waiting for the call bell to be answered it is an eternity, and yet the nurse, being busy, believes she has been quick in answering that particular call. It is all a matter of perspective.

Within the realm of researching lived experience, van Manen (1990) explains temporality is concerned with lived time and the dimensions of past, present, and future. To explore the temporality of a person's lifeworld is to ask about their past and their hopes for the future. It is about knowing the past and how that will influence or inform the future.

\section{Nursing and Objective Time}

Time can also be objective, if the clock says it is midday then we accept that it is midday. Objective time can also be readily associated with nursing and is pivotal to the daily work of a nurse. It seems the watch is some sort of unofficial symbol of nursing, and could even be interpreted as being the tool of our trade. Fob watches are handed down from one generation of nurses to the next, or are gifted on 
graduation and are subsequently worn with pride and may even have a deeper significance than just a device with which to read the time.

The nursing shift is structured around time, getting four hourly observations done on time, getting the patients ready for theatre on time, administering medications on time and so on. As a student nurse we are told our shifts will get easier, and that they will be more manageable and organised with effective time management. We muddle on, forgetting things, rushing to and fro in an effort to get everything done on time. With experience we learn to manage time to our advantage and it becomes second nature. It is a skill we learn, and as nurses we value in each other, it is good working with colleagues who can manage their time well. Time management is something we are appraised of and judged on in our role as being an effective nurse.

In relation to gerontology nursing time has tended to dictate the work of the nurse. In the past rigid schedules were developed around task oriented cares that were usually better suited to meet the needs of the nurse or the institution as opposed to the client. Koch and Webb (1996) refer to this style of care as 'routine geriatric style' that is characterised by conveyor belt care and resulting in the clients unable to express their needs and being dominated by the ward schedule. If it should be morning tea time then the resident had to wait until after tea to be taken to the toilet, or if it is time for your shower too bad if you are tired and would rather stay in bed for another hour or so. The nurse had a set of tasks to get through during the shift and the patients had little choice but to fit into that time-focused regime.

The imposition of time centred schedules could be attributed to the heavy workload of the nurses. And the heavy workload is due to the very nature of the work. Old 
people who are in institutionalised care are usually there for a very good reason. They require varying levels of assistance to meet their daily needs and often the assistance will take on a dual purpose of maintaining a certain level of function, so the gerontology nurse is focusing on assisting as opposed to 'doing for'. This is time consuming, it may be a lot quicker to 'do for', for example to wheel somebody to the toilet than to walk them, however, it may more therapeutic for the client to be walked. It is not dissimilar in assessment and rehabilitation wards, as the name suggests, the focus is on rehabilitation which again takes time. Furthermore, when nursing old people, other age related changes must be accommodated, such as if a client has deteriorating eyesight it will take them a longer time to do things than if they have good eyesight. Thus in meeting daily living needs, time becomes a very real issue in gerontology nursing in more ways than one.

The following anecdote from Dorothy eloquently illustrates how taking some time to spend with a client can be of lasting therapeutic value to the client and captures the essence of the nursing use of time.

...there was a lady there who wasn't particularly popular. She had never been married, she lived with her sister until she went into care and it's very difficult to know exactly why she ended up needing care but she certainly didn't mobilise well and over time she lost her mobility but didn't have any sort of diagnosis as such, she just became incredibly fragile. But the staff found her very annoying because she was quite demanding, she used to ring the bell a lot and always wanting attention, was occasionally incontinent. Because she didn't have a diagnosis they decided that she was probably putting it on and that she was perfectly able. Then she was transferred up to [another unit] and a couple of months later I also transferred and she was really pleased to see me and I was so pleased to see her. She was nursed very, very differently at this new place. She had a continence assessment done and she was put on a toileting regime that 
met that need, so she was never incontinent. And what they discovered was that her hips had just crumbled from the arthritis, so that was why she was no longer able to walk and she had also been involved, many years before that, in what they call now home invasions and she was extremely scared of being alone. I used to spend a lot of time with her and she was down in one of the rooms, down the far end and when we discovered through talking to her, eventually it came out that she had been attacked in this home invasion many years ago. So we bought her round and put her by the office so that it didn't matter what time of day it was, she could always see somebody passing and she settled right down and she was really happy.

When she died her sister brought in a doll that she had won at a fair and gave it to me and this patient had written it in her will that this particular doll was to go to me and I think for me that was, because she had never said anything to me, but I think that was the reinforcement that I had obviously done a good job. (Dorothy)

This story from Dorothy raises the issue of the 'expert' or committed nurse's use of time. She invested her time into finding out about the patient's previous experiences and meanings by developing and maintaining a sympathetic interhuman relationship. This anecdote is a powerful illustration of the interweaving of all four lifeworld existentials. The lived body is represented by the crumbling hips, that were not known about by staff in the first ward the patient was in and subsequently caused the nurses to attribute judgemental interpretation of the patients behaviour. Lived time is in the patient's lifetime, her past history that is so significant to her story. Also the registered nurse's use of time, and then as well, the patient demanding of the caregiver's time. Lived human relation was the vehicle for, first, aligning the interpretations of the patient with the staff and secondly, lived human relation was the vehicle for more effectively using time available because the patient was not demanding of so much time. The fourth 
existential, lived space was employed as a solution once the nurses had an accurate interpretation of the patient's situation. Moving the patient to a different space proved to be an effective intervention. Thus, whilst temporality is manifested in the story in different ways, the interconnectedness between all four existentials is also amply demonstrated.

This section has explicated the connection between nursing and time, particularly as the work of the nurse is governed by objective time. Next, I turn to temporality within gerontology nursing, looking how the lived time of the clients influences nurses’ practice.

\section{TEMPORALITY AND GERONTOLOGY NURSING}

It is not surprising, then, given the connection between nursing and time as discussed above, that temporality emerged as one of the essences of practice of the gerontology nurses participating in this project. The conversations revealed the nurses' appreciation of the lived time of the clients, and of having a sense of history and how what has gone on in the past informs the client's present time. These two themes are discussed below while the other side of the relationship, the lived time of the nurse, is discussed more fully in chapter ten.

\section{Lived Time of Clients}

A unique feature of gerontology nursing that sets it apart from other areas of nursing is that the nurse and the client can never share time. Gerontology nurses care for people who have lived in another time, a time that the nurse will never experience. For example, the Great Depression of the 1930s will never be repeated, 
there may be other similar depressions but if so, it will be in another time, and therefore, it would be in the context of that time, not the 1930s and everything that living in the 1930s meant. Although the nurse and client cannot share time, the participants, each in their unique way, expressed an appreciation of the knowledge old people have simply from having lived through time.

...they've taken the journey, they've travelled through their life and I haven't, there's possibly more to go for me! And I don't think we value the wisdom of their journey. No matter how crabby the person might be, or whatever, they're still somewhere where I am not. I think ...there is still wisdom there no matter what, there has to be because they've taken the journey, they're ahead of me. (Jean)

Old people accumulate knowledge and wisdom throughout their lives that the nurse does not have access to because she has not lived through the same experiences as that person. A nurse in tune with her client appreciates and values the lived time of the client and what it means for the client to have being somewhere the nurse has not.

\section{Appreciation of the Past and IMPact on Present}

...having the knowledge about where that person is, what their previous lived-experiences have been, what experiences they bring with them in their 80 or whatever years. (Dorothy)

Even though the nurse can not share the same time as the client, the nurse does however, need to have an awareness of history and how it might have affected the person she is caring for. For example, another person might read about or listen to people talking about being a prisoner of war and although not directly experiencing it, is still able to imagine what it might have been like for that person. This second 
hand knowing is useful within the realm of gerontology nursing in enabling the nurse to gain some insight and understanding of a client's behaviour in the present time. Accepting the premise that there is a reason behind every behaviour, the more awareness a nurse has of history and in particular the client's personal history, the easier it is for her to use and apply that knowledge when caring for clients. Caring for an ex-farmer, for example, as I described in chapter seven, might alert the nurse to the fact that person enjoys spending time outdoors and not being cooped up inside day after day. In the following excerpt, Madison points out the difficulties in caring for someone when their past is not readily known and she reveals in her conversation how much she relies on having knowledge of the past in order to care for people appropriately.

There's only so much that families may be able to tell you about their history and also we've got several clients where they've got dementia and they don't have family that visit and I suppose that's one sad thing that you never get to know what they were like when they were younger. You just don't know. I try and imagine what it might have been like from little snippets that I might get told or whatever, but it's a shame really that we can't turn back the time, or have a magic ball to look back and see what they were like. (Madison)

The above excerpt shows the practical aspect of temporality, that the concept of temporality is not just a theoretical concept but that it has valid application in daily nursing practice. Going deeper though, it also reveals how as a nurse Madison values the past history of her client and in doing this, values her client now in the present. To return to the gem metaphor, Madison picks up the gem and looks deeply for the essence of the lived time of the client. She does this even though the lived time is clouded by dementia or absent family. Even though she is not able to communicate or know the client because of the deterioration of mental function, she 
is nevertheless eager to know that person. It is about seeing the person in their past, present and future, as temporal beings, and as such, we may not be in the present but it does not diminish who we are as people.

\section{CONCLUSION}

The lifeworld theme of temporality is about the timeframe in which we live our lives. The world of gerontology nursing is seated in temporality. Everything we do is against the backdrop of time. It is important to acknowledge objective time because of its role in the daily work of the nurse, we simply can not avoid time. So temporality governs what the nurse does, it governs the practice.

On another level, time in its phenomenological (subjective) sense, is relevant for nurses working with old people who have lived in a different time to the nurse because it is about the inbeddedness of the past and future in our present time consciousness. Temporality can be seen as a timeframe of life with nurses taking an active role, and participating with their clients. There are two aspects that illustrate what is more than meets the eye. One is the nurse's act of participating in the client's lifetime, and the second aspect is the valuing of the client's lifetime. These two aspects go toward explaining how temporality is the essence of gerontology nursing.

The first aspect of temporality is the nurse's act of participating in the client's lifetime. Gerontology nurses know that it is more than likely that the old person they are nursing will die whilst in their care. However, gerontology nursing is not about dying, or waiting to die, it is about living and doing everything possible to enable the client to live well. It is the temporality of the moment, of knowing there 
is a past and taking somebody into the future. Gerontology nurses are engaged in the process of participating in someone's evolving life, where we are in the present but the past and the future are very much intermingled with the present time. This is the essence of the practice, of being part of another being's lifetime.

The second aspect of temporality is the value that gerontology nurses put on an old person's lifetime. The centrality of values within the nurse's practice is further discussed in chapter ten. The gerontology nurses I spoke to for this study, the four participants as well as the nurses in the collegial group I consulted with, all shared a genuine, positive regard for old people. The value is demonstrated by their not falling into the common traps of ageism, instead, of seeing the 'true worth' of old people. This returns us to one of the four cardinal elements discussed in chapter seven, true acceptance which is about authentic acceptance of the client. To truly value someone's lifetime is to value who they were, who they are now and who they will become in the future. Ageism is a barrier to that happening because instead of focusing, as I described above on the temporal being, the focus is on the negative stereotypes of old age such as disability and uselessness. This is an easy trap to fall into, however, it was very clear from the conversations, that the gerontology nurses in this study first and foremost saw the person before the disability, or the pressing need. They not only see the person but they are looking for who that person is, the roles and relationships that person might have had, son, father, grandfather, soldier, artist, and so on. The nurse is mindful of, and participating in, that persons lifetime and interpreting what that might mean in the here and now. Thus, one of the essences of gerontology nursing is the participation 
and value that nurses place on the lifetime of the old person for whom they are caring.

As I mentioned above, temporality is one of the four existential lifeworld themes that van Manen (1990) believes structures and informs all human experience. The existentials of temporality, relationality, corporeality and spatiality are inextricably linked and inform each other. However, van Manen (1990) states for the purposes of research it is appropriate to differentiate the existentials, which is the course I have taken in order to explicate the essence of gerontology nursing. It is interesting to note that in my reworking of the texts after my first level of analysis, in my search for more than meets the eye, I did not pick up on the existential of spatiality, although it is clearly evident in Dorothy's story that I quoted in this chapter. Some possible reasons for spatiality not rising from the texts is discussed in chapter eleven.

The next chapter moves on to the interconnectedness of the lived human relationship as being another essence of gerontology nursing, and then chapter ten focuses on corporeality being the third essence. 


\section{INTERCONNECTEDNESS: LIVED HUMAN RELATIONSHIPS}

\section{INTRODUCTION}

If a person can't see then let them know here is a doorway, ... If they can't walk that fast because they are so crippled up with arthritis then slow down. (Tärati)

The above extract from Tärati's conversation illustrates the lived body and the human relationship between registered nurse and client. Her words demonstrate the relationship between nurse and client, the interconnectedness that binds the two together, and that is what this chapter is about. The excerpt shows how the nurse works, her way of being with the client that nurtures the relationship. Tärati amply demonstrates her modus operandi, how she gets alongside with her clients, falls into step with them, and in such a way that preserves their sense of self. How this nurse works is the complete antithesis to the so-called 'routine geriatric style' of care that I discussed in the previous chapter. That particular style of care was characterised by unmet care needs and was dominated by ward schedules (Koch and Webb, 1996). However, the style of care demonstrated by this nurse is the way she knowingly adjusts to the client, not the client having to fit in with the nurse. Furthermore, it is characterised by the nurse making a connection with the client at the client's pace. So this chapter is about the interconnectedness between nurse and client. From an existential viewpoint, it is about the lived relationship, the experiencing of the other and the relation we maintain with others (van Manen, 1990). The exemplar above also calls forth the lifeworld existential of temporality, Tärati is in time with her clients, she walking with them in their present time. And 
so again this is how the existentials interface with one another, in this instance, the concepts of temporality, lived body and relationality intermingle with each other.

Nurse theorists and scholars such as Henderson (1980), Watson (1985), and Kitson (1999a; 1999b) claim the interpersonal relationship is central to the nursing process and that there are many factors contributing to the effectiveness of the interaction between nurse and client. Having immersed myself in the texts from the conversations I had with the participants, the essential nature of the gerontology nurse-client relationship emerged. The conversations were surprisingly similar in that common concepts or themes came to the fore that could describe the nurseclient relationship. In order to see the interpersonal relationship more clearly I have identified and focused on the following four themes: commitment; presencing/giving of self; connecting; and knowing the client holistically. These are the gemstones that I described picking up in chapter seven and now I am going to try and describe their colours, hues, and tones that go to make up their essential quality.

The concepts are not unique to gerontology nursing, however, they are key factors in the nurse-client relationship and as such have unique features particular to gerontology nursing. It is the practical application of these factors within the gerontology setting that set them apart from nurse-client relationships in other areas of nursing. In particular, as discussed in the previous chapter, it is against the setting of lived time that is the point of difference.

It must be made very clear that the four concepts are all inter-related and connected to each other. The manifestation of one element is determined by the other 
elements and there is a general blurring and interconnectedness of the outlines. It is only for the purposes of this description that I have tried to isolate the components in order to see the greater picture that is the interpersonal relationship. In other words, I have focused on the parts in order to make more visible the whole. This is true for my entire analysis of the essences. I have explicated my description in parts, however, in reality they are all melded together as a whole.

What follows is a representation of each element of the interpersonal relationship with illustrations from the conversations. I have made no attempt to describe all aspects of the interpersonal relationship or indeed to claim a comprehensive description of each individual element. Being true to the phenomenological method, this is a reflection of the lived experiences of the nurses I spoke to, with the intention of capturing the essence of their particular experience.

\section{COMMITMENT}

I believe with patients you have to have a commitment, a total and utter commitment. And that commitment is not just to do with I'm your nurse for the day sort of thing. It's a commitment to everything, every interaction you have with that person. (Jean)

The above extract from Jean's conversation eloquently illustrates the significance of commitment in the nurse-client relationship. Commitment underpins everything the nurse does with the client, it is the responsibility the nurse has to the client.

I suppose if the clients ask me for something, then they can pretty much rely that I'll do it for them ... I mean it might be something as simple as a phone call that they want made or a relative has called and wants me to pass something on to them and it's very seldom that I forget, and I know that if I did 
forget I would find it hard to forgive myself. (Madison)

Commitment in the relationship is also about the nurse being emotionally involved with the client. Gerontology nurses have the opportunity to become emotionally involved with their clients because of the long-term nature of the relationship that often spans many years. Over a period of time, the nurse shares significant life events with clients such as the loss of a spouse, as well as celebrations like birthdays. This sharing of intimate life events brings a closeness that leads to a deepening of the relationship. It somehow makes the relationship more real or genuine, at the end of the shift the nurse knows that the next day, and the day after that, and the month after that, and even the year after that, she will be nursing the same person. Therefore, there has to be a large degree of honesty in the relationship otherwise, it would be too difficult to maintain and eventually it would founder or become superficial. Like any other relationship, the nurse-client relationship is developed deeper, and is strengthened, because of the giving and the taking, the shared ups and downs, the good days and the bad.

The next three excerpts illustrate how the nurses view their nurse-client relationship. They unashamedly talk of their emotional connectedness to their work. This is a precious thing in gerontology nursing that is highly valued.

To me they are a part of my family and even though I know they are not my family - I realise that but I think that part of the territory as a gerontology nurse especially in a continuing care setting is that there is a sense of family and it's a family that I get given the invitation to be in. (Tärati)

To a degree, I feel that work is kind of like my second family in a way. (Madison) 
How do you not get emotionally involved to some degree? I think you have to don't you. Because that's what building interpersonal relationships is all about, you become involved, when they leave if you've been involved, you've become a part of their life, how can they not become a little part of yours? (Dorothy)

Becoming a part of their life and them becoming a little part of yours, as Dorothy says, is what sustains the relationship. There is more than meets the eye in these relationships, they transcend the commonly accepted boundaries of nurse-client relationships in other areas of nursing. The difference is that in gerontology nursing it is legitimate to have an emotional attachment, to feel a sense of family. It is not only allowed to happen but it is something that these committed practitioners strive to achieve because it gives meaning to our practice, it nurtures and sustains us in our work.

The following anecdote from Tärati illustrates the great lengths and personal cost she went to in order to honour the commitment to her client. It is also noteworthy as a fine example of advocacy.

A few years ago, I was the primary nurse for a woman in her middle to late eighties and she had never been married. She had come in in her middle years in her forties and grew old in the institution. At the time that I met her I would say that she had been in about twenty years and I ended up striking up a conversation around "What would be something that you would really really want?" and she said "I want some dentures'. This woman was able to tell me that "I would really really want some dentures" and I said to her "Can you remember when you last had some?" and she said no I don't know because she had never had dentures. So we went down the path of getting her a new set of dentures and it was a hard task really because I was intent on being her advocate. I was really clear - this is what she wanted I checked out her finances and she had enough money. Got hold of her niece advocate. That's fine whatever my Aunty would like, that's 
fine with me just go ahead.' I took her to the dental technician. He goes "there is no way she is going to wear a denture. Her gums are too receded basically and she has had a CVA so she'll have difficulties with the weakness in the side of her mouth actually holding the suction to keep the plate in. I think it's a really unwise investment. That's all he's seeing you know - the money thing. I had to explain to her a few more times in the weeks following and she was still quite clear that this is what I want and so we carried on. We went ahead with it and the staff on the ward who had been there for quite sometime thought that it was so ridiculous - a frivolous waste of money it was so hard to keep to the honour - keeping my word to advocate and maintain the honour of this particular woman. So anyway we got her dentures and everything the technician had said was true - she couldn't wear them, and whenever I was on looking after this woman I would go through the pain of "I want my dentures in" so we would have to put her dentures in, you know like rinse them put them in her mouth and she would get halfway through breakfast and say I need to take them out. But then she would always carry them in her handbag, so she carried them around in this handbag and when she died I was adamant that we had to send her dentures and even though she couldn't wear them in her life she would have them with her on her death. So the story around that is to be honourable. If I say that I am going to do something and even though I might have a lot of doubting people saying that "it's wasted money" or whatever, I think that the value is to honour what is the desire of a person, and even if you have to get a bit beaten up over it as a practitioner. (Tärati)

This story is what the essence of gerontology nursing is, and there is more to it than meets the eye. The nurse got the dentures for the patient over and above what everyone said was practical and the patient ended up taking them with her to her grave. That is the "creative imagination, sensitive spirit and intelligent understanding” underpinning the practice. The nurse withstood all that technical information and instead chose to stand with her patient. This is how other nurses do not understand gerontology nursing because creative imagination is not highly valued in nursing. You need to have creative imagination to see why it is important to have dentures when it clearly is not a practical thing to do. Everybody else's 
eyes saw the gums and the money where as the nurse saw something else. The dentures had a symbolic meaning, the client took them with her to the grave in her handbag. The dentures had a hermeneutic, a meaningful reference for that client that the nurse, in her connectedness with the client, was able to pick up.

Another perspective to the commitment that the participants expressed is concerned with dedication to the job. It may be stating the obvious, but a prerequisite to the nurse working with commitment toward her clients is that the nurse has to like her job, to actually want to be at work. Unfortunately, particularly in the field of gerontology nursing, this is not always the case, as Madison said

And then there are those that have chosen it as just a job and I don't really like being around people who see it as just a job. It's negative and you don't get very good vibes and they don't want to be there and it sometimes comes across to the residents. (Madison)

I came across this lack of commitment personally in my role as nurse manager. There was a very clear distinction between those nurses who wanted to be in gerontology and those who did not. Those nurses who did not have a commitment were difficult to motivate, disinterested, and often disruptive to the team environment. This was manifested in medication errors, careplans not done, and so on. Nurses who had performance issues such as above would fall into two categories, those who were happy to be working with old people would lift their performance, and those who didn't want to be there quite simply could not improve their performance over a sustained period of time.

Commitment to the job and to being a gerontology nurse was a dominant theme throughout the conversations. It sustained and motivated the nurses and resulted in 
mutual beneficence to nurse and client. Turkel, Tappen and Hall (1999) refer to this mutuality and reciprocity in a study designed to explore long-term care nurses whose roles were redefined from providing in-patient care to providing home based care. Turkel, Tappen and Hall (1999) found that having the opportunity to establish long-term relationships was a positive experience for the nurses who gained personal satisfaction and subsequent renewed enthusiasm for their work. Below, Tärati and Dorothy talk about how affirming it is to make a difference to someone’s life.

I get so excited when I see a little smirk on the person's face or see the eyes flicker or something like that. And I think gosh I have created a moment where I have actually made a small difference because I have been able to connect. (Tärati)

Knowing I've done a real good job, I've made a difference with that person, I've made things better for that person. (Dorothy)

In this section I have shown how commitment is an integral aspect of the nurseclient relationship. In order for the nurse to be committed to the relationship she has to be present and that is the next aspect of the nurse-client relationship that I explore more fully.

\section{Presencing/Giving of SelF}

Snyder, Brandt, and Tseng (2000) claim presencing as a concept of nursing has been around for centuries and that it has been developed and discussed in the nursing literature since the 1960s. According to Doona, Haggerty, and Chase (1997), Vaillot (1966) introduced presence to nursing basing her work on Marcel’s existentialism, however, since then the concept has "accrued multiple and mixed 
meanings”. Doona, Haggerty, and Chase (1997, p 3), in their paper exploring the use of presence in nursing, offer the following definition:

Nursing presence is an intersubjective encounter between a nurse and a patient in which the nurse encounters the patient as a unique human being in a unique situation and chooses to "spend" herself on his behalf, while at the same time the patient invites the nurse into his experience.

They go on to explain the philosophical dimension of nursing presence and its existential nature.

Presence can only be known from within, in the tension of the moment, because presence proceeds from the source of the self immersed in and involved in its existence. Presence is eminently subjective. Thus a nurse cannot be taught presence...the nurse learns to be a presence as she is present to herself, in the tension caused by possibilities in her situation and her freedom to choose her future among those possibilities. (Doona, Haggerty, and Chase, 1997, p 7)

Therefore, given the existential focus of this inquiry, particularly in regard to the analysis, nursing presence is a prominent theme, a dimension of gerontology nursing that underlies the practice. As Doona, Haggerty, and Chase (1997) point out nursing presence can not be taught, it is one of those intangible qualities of gerontology nurses that you can't quite put your finger on but you know when it is there. When a nurse is a presence in a relationship, the quality of the interconnecting is enhanced and enriched. The following excerpt illustrates nursing presence, it reveals the nurse giving herself in the relationship, of being there for the client and choosing to participate in her client's situation.

It was that personal me that I bring to the relationship. Somehow within continuing care that is something that is allowable, also keeping in mind that there is no ownership here for me... I believe the sincerity and the honesty and the integrity that I bring in myself in the way that I practise is professional, ethical, and safe. (Tärati) 
Presencing is more than the nurse being with the patient physically, it requires a deliberate focus to the other person and involves the nurse being attuned to the patients’ needs and concerns with their whole being (Snyder, Brandt, and Tseng, 2000). Doona, Haggerty, and Chase (1997, p 11) do not see presence as a nursing intervention or technique, instead they state presence is based in philosophy. Jean's practice is grounded in theologian Martin Buber's philosophy of human relationships and the concepts of I-Thou and I-It. 'Being With' and 'Being There' are terms used to describe the nurse-client relationship.

And to be present is to not leave yourself behind. You're always aware of yourself but you're open to their reality, of what's happening for them and that's what we don't do. And that's when we see the not so good nurses, they're the ones who fly into the dining room and fling out the meals and they're not with the clients, they're not watching, watching and seeing what the client's reality is, as you put the meal in front of them and the fright because you've come up on the side and just dumped it on their tray. They don't see any of that. Because they're not there, actually they are, they're physically present but they're not emotionally and spiritually there. They're only acting from their own reality, which is stress, under paid, low staff numbers and all that sort of thing. (Jean)

Presencing and giving of self is, I think, one of those rare gems that are hard to find and so when the real thing is found it is both precious and valuable. There may be lots of imitations around but because of its philosophical nature, presencing is difficult to grasp hold of. Presencing requires the nurse to be present first to herself and then to her client. Therefore, presencing is about the interconnectedness between the nurse and the client. Making that connection is the next concept I look into as being one of the major factors of the nurse-client relationship. 


\section{CONNECTING}

But it's capturing - It must be so exquisite, because it's about capturing moments that are of value to where the person is that I have been given responsibility to care for. It's around finding those connections and making it complete or making it true for that person. That's the essence. (Tärati)

As in any relationship, effective communication is the key. Tärati eloquently refers to it as making a connection with another person. Connecting implies a two-way link, the image of an electrical connection comes to mind. All the necessary technical support may be in place, all the wires correctly assembled and the cord plugged in but without the essential power there is no connection, nothing happens. The same could be said about communication, there might be two people needing to make a connection but for the communication to actually to place the power has to be switched on, and in nursing, it is the nurse who is the power source.

As Tärati points out, the nurse has the responsibility to make the connection with her patient. Normal age related changes or pathological causes can lead to sensory loss with the result that communicating non-verbally is often the challenge facing gerontology nurses. In such relationships, the nurse's experience and keen observation skills are brought to the fore. Tärati explains how she communicates non-verbally.

...Memory loss and the loss of language is a huge thing to lose and yet I believe that I have developed very sharp skills on looking at the way a person is, looking and finding some words to reflect back or observing body language to see if there is a yes/no response and maybe that's the track that I need to go down with this person. I have always felt that I am the nurse in the role as investigator, I am the detective, I am trying to figure out what is the story here that is unfolding before me because this person can no longer tell me with words so lets have a conversation around the body language and I put up 
the words or I put up the responses or make body gestures to see if that's what's of value here. (Tärati)

Australian researchers Pincombe, O’Brien, Cheek, and Ballantyne (1996, p 675) used critical incident technique to identify critical aspects of nursing in aged and extended care. They found "as a theme, the ability to communicate and to be seen to be listened to ranked high as a component of most of the critical incidents reported”. Pincombe, O’Brien, Cheek, and Ballantyne (1996) go on to list listening, advocacy, and team work as components of communication. The extracts below from Dorothy and Jean show how listening and advocacy are key aspects of communication.

Plus I think ...the fact that you can be honest in the way you listen, it's going to be really difficult to explain. You know how you can talk to somebody and you just know damn well that they are nodding and shaking at the right places but they are just not hearing what you're saying. Well I think, I believe that I'm a very good listener so I'm very honest about the way I listen and hear and so I will clarify and check that I've heard right and that I've understood and I'll prompt and those sorts of things so that at the end of the conversation that you've had, hopefully they feel that they've actually been legitimately listened to and understood. So I think that's an honesty in a way, I don't think it helps them if somebody says yes oh yes yes isn't that terrible and oh good and oh great when in fact they are not hearing what is actually being said to them. (Dorothy)

There are so many of the nice things happen when you're working with older people. That's what keeps me, sustains me as well. You know it's just lovely little things. We had this little woman who came in and I only knew her for two days, but I think a lot of it, is being open to people yourself. Being very open with your clients, and making a connection and having a relationship with them is so huge for me. And that's what it's all about. In these two days, I met this woman, she came in, she had cancer in different sites throughout her whole body. Why I know that is because I went to the clinical thing in the next ward and they showed the x-rays of this woman. She was only in for two days. With older people, you've got to 
have fun as well, not just doom and gloom. We built up this really good relationship in just two days, and that was built up by me being open with her and just hearing her. Hearing what she had to say, how it was for her and all that. And then I came back on the Monday and she'd died. She had a massive haemorrhage on the Saturday night but before I went home on the Friday, I'd gone round to say goodbye and she gave me a really good hug and just held my hand really tight, and she said I hope it's all going to be okay Jean. (Jean)

Honest listening and being open with the clients is indicative of how the nurse sees a client. Hirst and Raffin (2001, p 25), in an article entitled I hated those darn chickens, write about the power stories have to "advance the well-being of older adults”. They believe that nurses can show how they value an older person by listening to their stories, accordingly, attentive listening is the key. By listening and truly hearing what the client is saying in their story, the nurse is validating and affirming the worth of the client. Hirst and Raffin (2001, p 27) urge gerontology nurses to "invest significant effort in the listening" in order to achieve maximum therapeutic value for the client. The following excerpt from Dorothy reveals how she uses storytelling to promote quality nursing care.

I think that it's very very therapeutic if you can tell your story and somebody hears it. [a colleague] tells a story where a Resthome were having difficulty with a man's behaviour and they called her in to give some advice and consultation and she went in and had a talk to this gentleman who would not shower. And it turned out it related back to the war and he'd been on a ship that had been bombed and sank and so he'd spent a lot of time under water and in the water and so he was terrified of the sensation of water on his head made him feel like he was drowning. So he simply told his story and that was really an important story for him and so then she was able to go back and say don't shower him, this is why you can't get his head wet and so they bathed him. Problem solved. And then they progressed and over time he was able to tolerate the hair washing and so on. But he just needed somebody to listen to his story and actually validate it and make sure that that 
information was used to benefit him. I think that is a lot of what we do. (Dorothy)

Dorothy's story reveals yet another concealed quality of gerontology nursing. There is always more than meets the eye to a client's 'challenging' behaviour. Knowing the client's story, knowing his past, was the key to unlocking the present difficulties. This is another example of how temporality is an essence of gerontology nursing. But this story is also about validating this man's very existence, of sensitively understanding why he was behaving in the way that he was. The easy solution would have been to ride roughshod over him, maybe even use medication to make him more compliant, but this was avoided because the nurse simply made an effort to find out the reason behind the behaviour and in so doing made a valuable connection with him.

The last aspect of the nurse-client relationship to emerge from the conversations is knowing the client holistically which is really an accumulation of the previous three. As I noted earlier, all of these components are interrelated and informed by each other and knowing the client can not be possible without first the nurse being committed, present, and making a connection with the client.

\section{KNOWing THE Client Holistically}

Knowing yourself you may get to know somebody else. (Jean)

It is widely accepted, as Jean's statement above suggests, that in order to know somebody else you must first know yourself. Carper (1978) introduced personal knowing as a fundamental pattern of knowing and characterised it as "the kind of knowing that promotes wholeness and integrity in the personal encounter, the 
achievement of engagement rather than detachment, and it denies the manipulative impersonal orientation” (Carper, 1978, p 20). As I discussed in the section on personal knowing in chapter seven, Moch (1990) further developed the concept of personal knowing, identifying three components of knowing - experiential, interpersonal, and intuitive knowing. It became evident from the conversations that all the nurses experienced a degree of personal knowing, “discovery of self-andother arrived at through reflection, synthesis of perceptions, and connecting with what is known” as described by Moch (1990, p 159). Each participant, in their unique individual way, expressed an understanding of how their past experiences determine and shape how they practised as a nurse, this is discussed more fully in the next chapter. Personal knowing puts the nurse in a position to see and to know the client as a whole person. As this story from Dorothy illustrates, knowing the client within a holistic framework brings rewards and satisfaction for the nurse as well as the obvious benefits for the client. Gerontology nursing, by its holistic nature, affords the nurse the opportunity to really become involved and make a significant difference to somebody’s wellbeing.

I remember one episode in the Neurology Ward where there was a woman who had a subarachnoid haemorrhage and she was transferred to us from ICU when it was obvious that she wasn't going to recover. She was in a basically unconscious state, a lot of brain damage from it, and she would have been about 60 -65, and she had no spouse or family of her own, but she had an elderly mother who was coming in each day and the mother said to me, I don't know how I'm going to cope, you know there was nothing the hospital could do, she really needed to go home or go into care and the mother wanted her home and she didn't know how she was going to cope and whatnot. And I said we need to get the Social Worker involved and help set up cares and I remember going and talking to the charge nurse about this and saying I'm really concerned about how the family are going to cope and they don't have the 
support and the mum's very old and has arthritis and the charge nurse saying that's not our job, we've done our bit, it's time for her to go. Somebody else can sort that out and I decided that I didn't actually like that way of nursing when you only look at one little bit and then the rest gets left. And it was at that time that I thought, blow this, if I'm going to look after older people, I want to look after the whole person and consider the whole social network and family and so on. (Dorothy)

The value in knowing the person you are nursing brings a richness and depth to the relationship. It extends the boundaries of the professional nurse-client relationship and becomes a person to person relationship. Being involved with the client and getting to know them was evident in the interpersonal relationship by the commitment, presencing, and connecting that has been discussed above. It is a holistic approach to care in which the nurse never loses sight of the personhood of the client, of knowing who the client is, as the following excerpt describes.

Because even though someone may have had a stroke and lost their movement or be going deaf or losing their sight, or lost their memory, I never ever look at that person as a partial person, they are always very whole and complete. Even though I know a person has a disability, or if they wear thick glasses say so you know they are visually impaired, even though they have a difference in their body, or in the way they are in the world, I never see a person with a disability. I see them as a whole person. Even if a person has a memory loss I treat them as though they have all the innate powers of being. Even though I have to make allowances by the way I talk or my actions that's just automatic. That's how I accommodate the disability, that's me as a bridge. I bridge the way I have to be to meet a need, but I never ever see them as anything less than a wholesome person. (Tärati)

The nurses spoke of going beyond the physical, mastering the so-called 'basic cares' and utilising all the nursing skills to meet the needs of the person. Working with old people is all encompassing, the task of carrying out physical cares for a client was placed within the interpersonal relationship, what is important is how the 
nurse carries out the physical care whilst maintaining the integrity of the client as a whole person. This holistic approach to knowing the client has been identified as humanistic nursing by Paterson and Zderad (1976). Brouse and Laffrey (1989) explain that Paterson and Zderad's Humanistic Nursing Theory is based on Buber's existential view of the person wherein the person relates with the rest of the world through the body. This is what the lifeworld existentialist concept corporeality is concerned with and is the focus of the next chapter. A central component of the Humanistic Nursing Theory is intersubjectivity, with the nurse and patient both being active participants in the relationship. Humanistic nursing does not ignore the physical aspects of nursing practice but goes beyond it to incorporate the being with aspects of care.

Holistically knowing the client, therefore, is an amalgamation of all that it means to be a nurse, it recognises the primary importance of physical cares within the bounds of the nurse-client relationship.

\section{CONCLUSION}

This chapter has looked at how the nurse works, of how the connection is made between nurse and client as an expression of the lived human relationship. It is through this expression of interconnectedness that we can see the essence of gerontology nursing.

Back in chapter seven where we were picking up the gemstones, the centrality of the human connectedness was paramount. By going deeper, looking more closely to see what was not so obvious I was able to unveil some key aspects of the nurseclient relationship. I have broken done the parts of the interpersonal relationship, 
seen as the core of gerontology nursing, and described each component so that a more complete picture of the whole is made. In doing so, I have been able to make more visible what underlies the practice, and that is how the essence of gerontology nursing is explicated.

Seen within the context of the thesis, interconnectedness is one of three essences to arise from my second level of analysis. The initial analysis, searching for gemstones, spotted and picked up four cardinal elements of gerontology nursing: true acceptance; personal knowing; being present; and being alive. I then reworked those four cardinal elements to reveal their inner quality, with temporality, relationality, and corporeality emerging as being central essences of gerontology nursing. The following chapter focuses on the corporeality of the nurse, on her embodied lifeworld and the corporeality of the old people whom she is nursing. 


\section{CORPOREALITY OF THE NURSE AND THE NURSED}

\section{Introduction}

The significance of the lived body is the third essence that emerged from the conversations. Alongside temporality and relationality sits corporeality as the three central essences of gerontology nursing. This chapter has a dual focus, first I look at the corporeality of the nurse, as it is through the body that the nurse expresses herself. Secondly in this chapter, I focus on the corporeality of the nursed, whereby I discuss the nurse's perception of the client's lived body and how that influences her work.

The nurse's being-in-the-world, who the nurse is, is shaped by past experiences, both professional and personal. And how the nurse sees the world determines how she inter-relates in nursing practice. Therefore, what follows is a closer look at the attitudes and characteristics of the gerontology nurses who were engaged in this study. My intention is to make known the hidden qualities and characteristics that are unique to gerontology nursing. As stated previously, it is important to emphasise yet again the individuality of the lived experience of each participant. However, within that, commonalities can be drawn out so that we can get a better picture of what gerontology nursing looks like. By focusing on the body, through the lived experience of the nurse, it is possible to get a more meaningful understanding of the essential nature of gerontology nursing itself.

\section{DisTINGUISHING CHARACTERISTICS}

It's a personality thing, some people like jam, and some people like vegemite. (Dorothy) 
Dorothy's pithy comment aptly describes what this section is about. In the earlier discussion about commitment in the interpersonal relationship, I introduced the notion that gerontology nurses have to actually like their work to enjoy job satisfaction which in turn enables them to approach their work with dedication and commitment. Not all nurses have an aptitude for gerontology nursing, however, there are nurses who do choose, and enjoy working, with old people. This raises the question of what predisposes a nurse to want to work with old people, why does one person choose gerontology and another choose an acute care setting to practise nursing? Cheah and Moon (1993, p 1614) claim there are "specific attitudinal characteristics which characterise and distinguish the elderly care specialist nurse”. They go on to explain the relevance of nurses who consciously choose to work in gerontology as opposed to those who work in the area in order to meet their employment needs of the time. It is suggested that a "key attitudinal factor may be elderly care nurses' singular liking for older people and greater acceptance of this group of people as valued members of society” (Cheah and Moon, 1993, p 1614). Their opinion is certainly supported by the nurses I interviewed, with the following excerpt from Dorothy being a representative example.

I think the fundamental thing for me in gerontology nursing is that you actually have to like older people...You have to actually like them and have to like spending time with older people and you have to really respect them and I have a huge admiration and respect for older people because of the experiences that they bring with them. Even now, I look at the older people and always think wow, look at what they've done, look at where they're at, isn't this amazing. And I have this real respect and admiration. (Dorothy)

Not only did the participants enjoy the company of old people, they also revealed a longstanding interest in old people and their care. A common element amongst the 
participants was their working in rest homes prior to starting their nurse training. I was left with the prevailing impression that it was a logical and fitting conclusion for them to end up working in gerontology nursing, there was a sense of belonging, of being where they should be. Madison actually went to rest homes when she was a teenager and sought out old people to have conversations with, wanting to know more about their lives, and getting to know them as people.

Jean and Dorothy spoke of negative earlier experiences, of being shocked by the less than adequate standard of care, and as this quote from Jean illustrates, used that as motivation to make things better for old people.

But that was my passion, that was where I wanted to be [in gerontology nursing] because I had this huge sense of how with older people they miss out everywhere. So I was thinking I'm going to try and do what I can. (Jean)

It seems these nurses have taken on the responsibility of raising the standard of care, a responsibility they have approached with altruism and conviction. They demonstrated a strong sense of social justice, of putting themselves on the line for their clients. Advocacy is one of those qualities that require a certain degree of hardiness, it takes a special person to make a stand and then follow that stand through. The story that Tärati told about the woman with the dentures in chapter nine highlights the scorn she was subjected to when advocating for her client. However, Tärati continued to walk along side her client and because she was in step with her, achieved an outcome that was, as it turned out, right for that woman.

Having a sense of social justice is determined by who you are as a person, your values and beliefs. Gastmans (1999) puts forward the argument that nursing care, 
being more than a set of tasks and competencies, is a moral attitude that is derived from the way nurses commit themselves in the caring relationship.

The ethical significance of the caring attitude lies mainly in the fact that nurses express in this way that the patient is of value to them. Only by expressing a caring attitude do nurses endow a sick human being with a moral value. Nurses build up a caring relationship with a patient because they consider the patient to be important as a person. (Gastmans, 1999, p 218)

Seeing the patient as an important person would seem de rigour in nursing, however, as Tärati points out it is not always the case when it comes to caring for old people.

I was happy to look after the older adult, whereas with some people that I worked with it was "oh no here's the oldies again" and all those shocking derogatory labels that get put on the older adults because of the culture of the nurses. People don't have the same values that I have towards the older adults. Because I don't see it as a group of people who just because they are getting old they are of no value to society, I have never felt like that and that's from my upbringing. (Tärati)

How the nurses see and accept old age directly impacts on their practice, for example, what do they see when they walk into a room with an old person lying in the bed? Do they see a frail old person with a broken hip needing help to get dressed or do they see the person first and then tasks that need to be seen to. The following excerpts from Tärati and Dorothy clearly show the value and esteem in which they hold old people. The heartfelt passion is also palpable.

I can't understand why everybody doesn't love it. It doesn't make any sense to me. I'm just in awe of older people, I think it's amazing. I think it's incredible that you can look at a 93 year old on the ward and anyone else might walk in and think oh look at that decrepit old lady, but they don't realize that until she broke her hip, she was still walking 10 kilometres a week to do her groceries, and had no home supports and you know was knitting jersey's for the grandchildren and it's just 
amazing. I don't see old age as being a sickness or a disease, which I do think a lot of people do. They see aging as being a deformity to avoid it all costs. (Dorothy).

It's the age group of the person, it might be because they are older adults. I use the word older adult because that is the term we use in our everyday nursing language, but it is always switched in my head that it is kaumatua. My beliefs around kaumatua health are because of the experience and the knowledge and who they are and who they have been in their life - because they have been a child, an adolescent, an adult, they might have had children, married, careers...if they need some sense of looking after, or caring or nurturing or management or whatever it is, they have actually earnt that. That is the honour of the status that they have in their older years. (Tärati)

The words that these two nurses have chosen to use when talking about old people and old age are very telling of the nurses’ positive and enthusiastic attitudes towards old people. Words such as awe, amazing, incredible, experience, knowledge, honour, and status. By using those particular words these nurses are showing us what personal values are underpinning their practise, and in so doing are exposing what is more than meets the eye. It is the embodiment of their values and who they are as moral beings in the world that inform their positive attitudes and approach towards old people in their nursing practise.

Another facet of the corporeality gem is how the gerontology nurse views the world and the fact that gerontology nurses have chosen to work in an area where machinery and technology are not a significant factor (as opposed to neo-natal or intensive care for example). The conversations revealed that gerontology nursing afforded the participants the opportunity to practice in a way in which they were most comfortable. It is probably difficult to know how this comes about, is a nurse good at her work because it suits her personality and therefore she excels, or is it the type of work that attracts her in the first place, which she then finds she enjoys and 
succeeds in. Either way, it is of importance for the nurse to find the right fit, to have enough self-awareness to know what suits her as a person in order for her to nurse most effectively. As I discussed in the previous chapter, if there is no fit there is no commitment or connecting between nurse and client which results in a non therapeutic relationship.

Jean and Madison both made a point of mentioning that they were the only ones in their nursing classes to choose gerontology.

I chose to go to [continuing care Hospital] for my elective, I was the only one in the class who had chosen the older adult area. (Jean)

Out of about 120 students there was me and a friend of mine who was interested in gerontology - I was definite and she was tossing up between that and psychiatric nursing and they wanted to know why, they thought we were strange because they were all going off to surgical and A \& E and all that. I felt comfortable. I suppose anything like surgical and theatre and those types of nursing don't really interest me. Gerontology is, although more hard work, is the comfort zone for me really. (Madison)

These two participants have about twenty-five years separating them in terms of when they were doing their nurse training. So, it is noteworthy that within that time span gerontology is still not a first choice for most nursing students. This would be a worthwhile topic to research more. As I highlighted back in chapter one in the literature review, gerontology nursing is troubled by its stereotyped negative image. Given the predicted population demographics, gerontology nursing must attract more nurses, and within that, more nurses who are choosing to go into gerontology because they have an aptitude for it. More needs to be known about gerontology 
nursing and that is aim of this study, to shed some light on what it means to be a gerontology nurse so that it might open the door for other nurses.

Retsas and Wilson (1997) compared how three groups of nurses (gerontology nurses, critical care nurses and other nurses) perceived effective nursing practice within their specialty areas. The results of their study showed that the constructs caring, compassionate and empathetic, positive affect, enacts values, and holistic view of care are more characteristic of gerontology nurses than of critical care nurses, who were characterised by the constructs knowledge base, clinical skills, teaching skills, and achievement orientation. They argued that nursing can not be regarded as homogenous and concluded that context is important in distinguishing the nature of nursing. So it is not surprising then, that the essences to surface in this study are congruent with the characteristics that Retsas and Wilson's (1997) research revealed.

\section{LIVED BODY OF THE NURSED}

The previous section of this chapter explored the corporeality of the nurse, next I turn to the lived body of the client, and the nurse's perception of the body as being an essence of gerontology nursing. The existential lifeworld theme of corporeality or lived body refers to the fact that the body is a viewing platform with which to view our relationship with the world (Spiegelberg and Schuhmann, 1994). Van Manen (1990, p 103) explains that lived body "refers to the fact that we are always bodily in the world. When we meet another person in his or her landscape or world we meet that person first of all through his or her body". 
The body, and the tasks associated with the body, were not dominant themes in the conversations. This was because I had clearly stated that my focus was on the essence of gerontology nursing - not on the practice itself but the underlying things that make up and support the practice. However, the body was ever present in the conversations as a given fact, not often spoken aloud, because our common knowledge of the central importance of the body in gerontology nursing enabled the conversations to move outside the body.

In the following quote from Dorothy's conversation, we were talking about how nurses in other fields of nursing see the old body, and how that perception is different to the way gerontology nurses see the body.

I don't think that they acknowledge where that person has been and where they are going. I think that they see them as a body that's not working that's breaking down and slowing down rather than seeing the father and the grandfather and the son and the brother that that person actually is. (Dorothy)

Dorothy's words reminded me of a poem that was pinned on the notice board at my first job as a staff nurse in a long-term care hospital. I photocopied it and have kept it in my practice journal. It is well known in the gerontology nursing world, however, there are varying accounts of where it actually originated from, and how it became so well known. Apparently, a woman called Kate, surname unknown, who was in a nursing home in Ireland wrote it. After her death, the poem was found in her locker by one of her nurses.

\section{'What do you see?'}

What do you see, nurses, what do you see? Are you thinking when you are looking at me, A crabbit old woman not very wise, Uncertain of habit with far-away eyes, 
Who dribbles her food and makes no reply, When you say in a loud voice

'I do wish you'd try'

Who seems not to notice the things that you do, And forever is losing a stocking or shoe, Who unresisting or not lets you do as you will With bathing and feeding the long day to fill, Is that what you're thinking,

Is that what you see?

Then open your eyes, nurse, you're not looking at me. I'll tell you who I am as I sit here so still, I'm a small child of ten with a father and mother, Brothers and sisters who love one another, A young girl of sixteen with wings on her feet, Dreaming that soon now a lover she'll meet; A bride soon at twenty, my heart gives a leap, Remembering the vows that I promise to keep; At twenty-five now I have young of my own Who need me to build a secure and happy home. A young woman of thirty my young now grow fast, Bound to each other with ties that should last; At forty my young ones now grown will soon be gone, But my man stays beside me to see I don't mourn; At fifty once more babies play round my knee, Again we know children my loved one and me.

Dark days are upon me, my husband is dead, I look at the future I shudder with dread, For my young are all busy rearing young of their own, And I think of the years and the love I have known.

I'm an old woman now and nature is cruel, 'Tis her jest to make old age look like a fool.

The body it crumbles, grace and vigour depart, There now is a stone where once I had a heart:

But inside this old carcass a young girl still dwells, And now and again my battered heart swells, I remember the joys I remember the pain, And I'm loving and living life over again, I think of the years all too few - gone too fast, And accept the stark fact that nothing can last. So open your eyes, nurses, open and see, Not a crabbit old woman Look closer - see ME. 
This woman is imploring nurses to see her for the person she is, not the body she has become and everything that her body now means. Her self-awareness tells her that her body is 'an old carcass', moreover, she knows that her body is the focus of attention to the nurses at the expense of her whole self. The gerontology nurses who participated in this study stressed how they worked within a holistic framework, of going beyond the physical, of mastering the so-called 'basic cares' and utilising all the nursing skills to meet the needs of their client. The task of carrying out physical cares for a client was placed within the interpersonal relationship, so what is important is how the nurse carries out the physical care whilst maintaining the integrity of the client as a whole person.

An example of placing the cares within the relationship is the task of bathing. Just as there is more to gerontology nursing than meets the eye, there is more to having a bath than just meeting hygiene needs. Hektor and Tuohy (1997, p 15), in an interesting article exploring the history of bathing claim "rather than being a therapeutic and satisfying experience for older persons, bathing in institutions becomes routine, depersonalised, and often harmful. Attention to the aesthetics of the bath could return bathing to its prior status as therapeutic intervention”. Having a bath is an intimate, private thing to do, we often association it with relaxation, with pampering ourselves, and with fun. From a nursing perspective it is an opportunity to observe the client's skin, and general physical condition. More importantly though, it can be a time for intimacy between the nurse and the client. This brings to mind a woman I nursed who had her daily bath in the evening partly to soothe her arthritic knees and partly to relax her prior to going to bed. She had Alzheimer's disease and spent all day on her feet, very rarely did she sit still. What 
I enjoyed most about those baths, aside from the aromatherapy, was the intimate time we had. Because the focus was on relaxation, it was important for the entire bathing process to be at ease, it would have defeated the purpose to be in a rush. I learnt from trial and error how to bathe her in a way that she enjoyed and was therapeutically of value to her. Therefore, it was the bathtime that enabled us to form a meaningful relationship, were we could truly connect. It was through the body that we made that connection.

\section{CONCLUSION}

This chapter has focused on the body as a means to reveal further essences of gerontology nursing. It is through the body that the fundamental characteristics of gerontology nursing are revealed. The nurse's lived world, who she is as a person is embodied in her nursing practice. And so how the nurse sees the world, her moral attitude, is an elusive quality of gerontology nursing. This chapter has shown that having a positive regard for old people and the aging process determines the essence of gerontology nursing. The most effective way to describe this, is in Jean's words that are her response to my question "In a creative sense, what would the essence of gerontology nursing be for you?”

It would be blue and it would be a deep blue, because for me it's warmth. You need warmth, and that warmth is about caring, nurturing the relationship. See when I think of warmth, I think of being wrapped up and being with, and being safe, it's about safety. I believe older people should be nurtured and I don't mean that in a patronising way I mean nurtured as in they have a place in our society that needs to be nurtured. I thought of blue and red, and red would be the happiness. Associated with from being old you know that it's not all bluh and blarr and so I think the bright, light colour red which is vibrant... When I see or am with some older people that I nurse, a lot of them have vibrancy. They have vibrancy 
but we do not see it sometimes because we are not looking for it. What we're looking for is decrepitness, you know broken bones, bent and all that and that's just crap. But when you see some spark in some old person's eye, the little look they might give you, there's vibrancy there and there's wanting to get out and be and live that. And then they say it's time for your wet round, time for your meal and so on. And out goes the spark. We don't ever allow for the vibrancy, very rarely. We do occasionally but not often enough because of the tasks, and the management and the money and the dollars and they will over rule that. (Jean)

It is through colours that Jean has unveiled what is more than meets the eye in gerontology nursing. The warm, nurturing, caring blue that Jean refers to resonates with the Retsas and Wilson (1997) study in which they identified caring, and compassion and empathy as characteristics of gerontology nursing. But then Jean goes on to say she associates bright red with old people, and to her that means happiness. It is unusual for old people to be associated with the colour red. Red is usually sexy, youthful, vibrant, which we as a society do not often associate with being old. Furthermore, happiness is not often associated with old age, more often loss, grieving, pain, hardship, and the suchlike bleak, depressing feelings are linked to being old. Therefore, Jean, through how she sees the world, through her lived experience has unveiled what is more than meets the eye in gerontology nursing. And what she has revealed in her conversation is that gerontology nurses see old people so differently to others, they see red when other people maybe see grey or black.

Dorothy's response to the same question "In a creative sense, what would the essence of gerontology nursing be for you?” is also remarkable in that it reinforces how differently she sees old people.

Well, two things come to mind, I'm quite a visual person. I actually see rainbows when I think of gerontology nursing with 
lots of different colours coming together to make a wonderful whole where you can't quite see the beginning and you can't quite see the end but there is this wonderful excitement of colours and all melding together. But I also think of butterflies when I think of aged care, I think of hands with the butterfly and the butterfly just taking off. I think probably the hands are nursing and the butterfly is...I think of it more as rather than where others might see aged care as dying, I see maybe aged care as giving people a new life. Helping them into a new phase and supporting them to blossom into their old age stage of life. The hands are not holding them down, I see them as cradling and giving the butterfly the lift to go and experience this new and wonderful thing that is aging. Maybe the ultimate is the hands with the butterfly and the rainbow. I don't know, but I do think of the hands for me, that is the nurturing hands of nursing, supporting not claustrophobic, not constricting but just supporting and offering them the opportunity to really lift off and experience...And I think sometimes of the butterfly just having come out of the cocoon and maybe it's that acknowledgment that this is a new stage in life. Rebirth of a new stage in life. And it may not always be positive for everybody, you've got to remember that, but aging isn't a positive experience for a lot of people, but maybe the nursing hands are still the hands that can support and offer as much help as possible so that they can get as much benefit out of life, as much quality and experience out of life as they possibly can. (Dorothy)

Talk of excitement of colours, butterflies, and new life is more common in a maternity ward, not an old person's continuing care ward. This re-iterates that gerontology nurses have a worldview distinctly different to others. Dorothy's view of old people is embodied in her hands. She talks of the nurturing, supportive hands, as opposed to the oppressive, holding down hands usually associated with nursing old people.

This chapter has completed the trilogy of essences. First was temporality, focusing on the centrality of lived time in gerontology nursing, then relationality and the interconnectedness of the nurse and client, and thirdly in this chapter, explicating the essence of gerontology nursing through the lived body of both the nurse and the 
nursed. In the next chapter, I bring it all together in a final analysis of the essence of gerontology nursing. 


\section{MORE THAN MEETS THE EYE: EMERGENT ESSENCES}

\section{INTRODUCTION}

My purpose for this chapter is to bring the research project to a close, to bring it all together as a whole to explicate the essence of gerontology nursing. Van Manen (1990, p 13) reminds us that it is not appropriate to expect a conclusion from a phenomenological study, as in poetry, it is the "primal telling” of the research itself that is the end result. Therefore, having come thus far, and if I have achieved my aim, the reader ought to have already been moved to a deeper understanding of gerontology nursing.

It is necessary to reiterate that in order to describe the essences, I have had to arbitrarily break them down into parts. The need to do this demonstrates the limitations of using a written thesis to describe artful practice. However, working within these limitations, I have attempted to describe the essences as separate entities, whereas, in real nursing practice the essences all meld together, they are inextricably linked, all informing and inter-dependent on one another. This intermingling of the essences is clearly manifested in the excerpts from the participants that I have quoted throughout the thesis. To illustrate a point I have had to pay attention to particular facets of the texts. Most of the excerpts I used could have just as appropriately been used to illustrate another quality of the essence elsewhere in the thesis, this serves to reinforce the connectedness and wholeness of the essences. Returning to the gem metaphor, I have cut through the gems to expose different planes and angles, and in illustrating a certain point, I have been 
focusing on just one plane of the exposed gem. I could have just as easily shone my light onto another plane to reveal its inner beauty.

So, having focused on the parts in the previous chapters, I now go back out to the whole. First, I discuss some practical issues about the research process, the view from within, before then looking more closely at the emergent essences of gerontology nursing that are more than meets the eye, these are caring for the body, the act of seeing, and the joy of care. To conclude the chapter, I stand back on the outside and discuss the limitations of the study and finally offer my insights from the study.

\section{THE VIEW FROM WITHIN}

I started looking for what was more than meets the eye by positioning myself on the inside of the conversations, to see what was there from within. Using Taylor's (1994) metaphor in searching for the essences of meaning, I was on the look out for a specific type of gemstone, and only picked up those gems that would shed some light on my chosen topic, the essence of gerontology nursing. If I had a slightly different focus, then my analysis and my thesis would be different to what it is. For example, I could have looked at excellence embedded in the practice of the participants, or I might have explored the art of gerontology nursing. Either of these two slight shifts in focus would have resulted in my picking up different gems from the conversations, which in turn would have meant the lamp illuminating different qualities and essences to explore. Therefore, what I have got reflects the conversations I had with those four nurses at that time, and it also reflects the way they were thinking at the time and what they chose to talk with me about. 
Furthermore, this thesis reflects how I was thinking at the time and how I was working with the texts. Therefore, elements of space, time, and relationality exist procedurally as well as substantively in gerontology nursing.

Van Manen (1990) states all lived experience can be structured into four fundamental lifeworld themes, or as he refers to them, existentials. From my study, the existentials of temporality, relationality, and corporeality were clearly evident. Conspicuous by its absence is the fourth existential, spatiality or felt space that is "the world or landscape in which human beings move and find themselves at home" (van Manen, 1990, p 102). This didn't emerge from the conversations possibly because it was not a dominant factor for the particular nurses I interviewed, or possibly, because the questions I asked did not bring it to the fore. However, I did not specifically ask questions about the other three existentials either, their presence was felt in the conversations without any prompting. As I noted in chapter eight, spatiality was present in the conversations, an example being in the excerpt from Dorothy. Therefore, if I had been actively looking for spatiality in the texts my analysis would probably have taken a different form. I do believe that spatiality is relevant to gerontology nurses, because lived space is about how we feel about home and the space around us, which would have great applicability given the predominantly institutional workplace of gerontology nurses. Therefore, I think this is an under explored area of the research.

The last point I wanted to make about coming from the inside of the conversations is that this study is very much about the nurses who agreed to participate in the study. Chapter six is about the participants, and this study is about their lived 
experience. Therefore, this is not a rigid analysis, it is a phenomenological study whereby we ask the question what is the nature or meaning of this particular phenomenon (van Manen, 1990). Ask the same question to another person and naturally, the answer would be different because we are talking about human experience. So the research can not be generalised, instead, I sought to describe the hues, colours, and qualities of the gemstones that I chose to pick up and explore further in order to find and explicate their inherent characteristics, and in so doing unveil the essence of gerontology nursing. What is more then meets the eye in gerontology nursing is discussed next in my final analysis of the emergent essences.

\section{EMERGENT ESSENCES}

Standing on the inside of the conversations and sorting through the gems I discovered four cardinal elements. I use the word cardinal because it means on which something hinges, or a fundamental thing. The four cardinal elements of true acceptance, commitment, presencing, and connecting formed the foundational frames of reference for the second level indepth analysis that revealed more than meets the eye. Thus, explicating the essence of gerontology nursing is dependent on, or hinges on, those four cardinal elements I described in detail in chapter four.

Continuing with the gem metaphor, arising from the cardinal elements or gemstones that I lifted from the conversations, were three essences. I picked up the gems to see what was inside them, noticing their particular inner qualities or essences. I drilled down to expose their beauty and their luminescence. And what I found to be at the inner core, or heart of gerontology nursing was the centrality of temporality, the centrality of human interconnectedness, and the centrality of corporeality. And 
now, having exposed these essences as explicated in the previous three chapters, I can further reveal what is more than meets the eye in gerontology nursing. For the nurses who participated in this study, the act of seeing, caring for the body, and the joy of care is the essence of gerontology nursing that underpins their actual nursing practice and these are described in more detail next.

\section{CARING FOR THE BODY}

Gerontology nursing is a field of nursing where the care of the body is a fundamental aspect of the day to day work of the nurse. However, the body was not a dominant topic in the research conversations, primarily because I had made it explicit that I was not focusing on the body. Nevertheless, it was there in the conversations as a silent omnipresence that demands attention because as Lawler (1997, p 46) asserts, “nursing is inescapably concerned with, among other things, the physical body and its malfunctions”. According to Lawler (1997) there are two reasons as to why the nursing knowledge and much of nursing practice about the body has been silenced. One is the taboo nature of nursing work, that in Western culture the body is private and not spoken about. The second cause is that formalising and articulating ways of knowing the body and embodiment in nursing are inadequate and problematic. I would add a third reason pertaining to this discussion and that is how nurses see and cope with old bodies. Nurses caring for old people come face to face with the future. They see the normal age related changes such as wrinkles, and sagging skin, as well as witnessing loss of bodily function, and loss of control of the body. The existential concept of temporality helps to explain this, nurses are confronted with their future in the present time. A 
possible reason that some nurses find caring for old people difficult is their own fear of aging, of loss of bodily function, control and appearance. This issue of prematurely coping with the ageing process could be dealt with in nursing education. Preparing student nurses with the reality of aging and ensuring they have the ability to work through any issues or fears they have about their own aging might assist them to see their clients in a more positive light.

Another aspect to this discussion on the body, and in particular old bodies, is about how nurses interpret the work of caring for the body. It is seen as being simple and basic, therefore anyone can do it. An example of this is in the home care arena, whereby largely untrained staff are performing what is termed nursing cares such as administering suppositories. It is not my intention here to discuss that issue any further but to draw attention to the popular view that anybody can do basic nursing care, resulting in minimising and devaluing the task and by association, gerontology nursing. It is possible, by examining the terminology, to see why 'basic cares' are not seen as worthwhile, adopting the word primary though, indicates the value of the work. The relevance of this to my study is that holistic care is implicit in gerontology nursing and no discussion about the essence of gerontology nursing would be complete without paying attention to the body and the care of the body.

\section{Basic Care - Primary Care}

I am not convinced that the term 'basic care' most accurately portrays the essential personal care that is the foundation of nursing. Exploring the etymological roots of basic may provide an explanation for the low status associated with the word. According to the OED Online (1989) the word basic is derived from the French 
word base which originates from the Greek basis meaning stepping. Base is given to mean the lower or supporting part, the fundamental principle, or the foundation. So basic means forming a base; that which is fundamental, essential. There is, however, another meaning of base derived from a different source. Base, derived from the Latin bassus meaning short, means morally low, cowardly, or menial. An association can be made between the two different derivations of base, both refer to being lowly or lower. It can be deduced then that 'basic cares', whilst undoubtedly fundamental and essential to the practice of nursing is always going to associated with being on the bottom rung of the ladder, or viewed as a stepping stone.

The continued use of the word basic is a hindrance to the progression of acknowledging the essential tasks of nursing care. I suggest the word primary may be more appropriate. The OED Online (1989) gives the meanings for primary as earliest, primitive, original; of the first or highest rank, that which claims the first consideration; chief. Thus, the term 'primary cares' give the impression of great importance. It refers to the cares to which the nurse must give first consideration. 'primary cares' can be described as those fundamental aspects of client care that when practised within a holistic framework, meet the essential needs of the client. Essential needs are not only physical requirements but also include emotional and spiritual comfort.

The worth that nurses place on 'primary cares' is contrary to the worth attributed to them by clients. Bjork (1995) claims that although patients consider practical skills to be a vital part of good nursing care these skills have a diminishing importance in nursing. Bjork (1995, p 8) reviewed research findings over a forty year span and 
summarised, " the patients have more or less maintained a stable perception that good nursing care reveals itself first of all through the practical, technical or manual aspects of physical care”. Hudson and Sexton (1996) exposed the different ranking given to care-giving activities between old people and nurses. Old people gave priority to physical comfort whereas nurses gave priority to their observing and monitoring role. This demonstrates the disparity between the perceived importance of 'primary cares'. If nursing is, as it claims to be, client centred, then we need to pay heed to the importance of physical care in the nursing process.

\section{The Act OF SEEING}

Time and time again throughout this thesis, I have made reference to sight by using words such as seeing, looking, and focusing. The title, More than meets the eye...is an intentional allusion to the fundamental tenet of phenomenology - the act of pure seeing, phenomenology is about seeing meaning in everyday ordinary things. More than meets the eye is also as reference to the words of Isabel Stewart that I quoted in chapters one and two, and repeat here:

The real essence of nursing, as of any fine art, lies not in the mechanical details of execution, nor yet in the dexterity of the performer, but in the creative imagination, the sensitive spirit, and the intelligent understanding lying back of these techniques and skills. Without these, nursing may become a highly skilled trade, but it cannot be a profession or a fine art. (Stewart, 1929, p 1)

What I have concluded from my study, is that there is a great deal more to gerontology nursing than most nurses think. It is like we are the Cinderella of nursing, hard working, dowdy, largely unnoticed and facing a dreary future unless of course something magical happens. As the participants have revealed, the magic 
can and does happen but it is the nurses themselves, not a fairy godmother, that makes it happen. It is the nurses' readiness and acceptance of entering into the nurse-client relationship that provides the opportunity for something magical to happen. I have called it the 'joy of care’ which is discussed more fully next.

\section{THE JOY OF CARE}

The gerontology nurses who participated in this inquiry were noteworthy for their passion and commitment to their work. But there was something else, an ' $x$ ' factor that was difficult to grasp and define, this is more than meets the eye. That ' $\mathrm{x}$ ' factor is the sheer enjoyment they have for their work. The joy of care can only come about once the hard work has been done. The interpersonal relationship has to be created and nurtured, the techniques and skills have to be mastered, and then you can take a step back and enjoy the moment for what it is, to delight being with another person. The nuances of the interpersonal relationship have been discussed in detail in chapters eight, nine, and ten, but it is worthwhile reiterating that it is the genuine, authentic relationship - human to human that is so special. The taking of valuable time to get to know someone, the intimacy and sharing of life events that is so precious and rare, therein lies the magic and the joy of gerontology nursing.

There is no getting away from the hard work of caring for old people, it is physically demanding and emotionally challenging. To think of it as being enjoyable seems unreal but it was a palpable presence during the conversations. The joy was evident because the participants know the job so well, they go looking for what is not always obvious, and when they do find it, they are transcended to a different level. It is like a marathon runner coming to 'the wall', whereby they are 
exhausted and feel they simply can not go any further, but if they carrying on and break through the pain barrier they find a second wind that enables them to continue in a way they never thought possible before hitting 'the wall'. In the same way, that is how gerontology nurses experience the joy of care, they know the potential of a relationship and look for what might be there, and go to extraordinary lengths to find it, resulting in lifting their practise to higher, more satisfying levels.

It is apparent to me those magical moments derived from the joy of care, are a closely kept secret. As I discussed in chapter one, it is well documented that gerontology nursing is unpopular and has a negative image amongst nurses. The reasons for this being attributed to ageism, and its historical roots in Britain where it was stigmatised and denigrated (Snape, 1986; Treharne, 1990; Norton, 1990; Robertson and Cummings, 1996; Bernard, 1998). In New Zealand, aged care providers bear the brunt of the nursing shortage, with recruitment and retention of suitably qualified nurses an ongoing issue. All four participants mentioned feeling different in choosing gerontology as well as at times working with nurses who were neither suitable nor inclined to work in the field of gerontology. Whilst, as I pointed out in chapter ten, working with old people is not for everyone, I do believe it is generally misunderstood and maligned. This could be attributed to past experiences with old people which is discussed more fully below, or maybe, if nurses had the opportunity to know more, it might open their eyes to the rich possibilities that exist in gerontology nursing.

The following story illustrates this point. I have a pot plant on my kitchen table that looks like an ordinary, if rather ugly plant. In fact, it has huge significance for me 
as a symbol and memento. An old Russian lady, Maria, broke off a piece of her plant and gave it to me one day when I was employed by her to do housework while I was a nursing student. I probably learnt more from her about nursing relationships than in the classroom. Maria died, but that piece of plant has flourished, and means so much more to me than I can put into words. My point, is that most people take that plant at face value for what it is, only, I know differently. Once others do know the story however, they too see the emotion and meaning not previously understood by them. I urge gerontology nurses then, to share their insights, to make it known to the nursing profession what is so magical about gerontology nursing. My recommendation is for more and more research to be conducted about the art of gerontology nursing. There is already an abundance of research into the practical details of caring for old people, what is now needed is a foundation of artistic nursing knowledge to reveal and make public the true potential of gerontology nursing.

Having explicated the essences of gerontology nursing that emerged from the conversations, I next reposition myself, and standing on the outside, I look at some of the issues arising from this project.

\section{THE VIEW FROM THE OUTSIDE}

The findings of this study are limited by the method that I chose to use. As I noted at the beginning of this chapter, the thesis would have taken on a different slant if I had done things differently, or if I had picked up different gemstones to explore more fully. Therefore, the study is limited to what the four participants and myself 
talked about in our one-hour conversations about the essence of gerontology nursing.

Had I spoken to different nurses, my findings would have been different, other essences would have emerged. For example, if I had spoken to four passionate novice gerontology nurses I am sure, not only would the conversations have been different in tone and sophistication, but also the content would have been radically different. The conversations I did have indicated the nurses’ reflective practice, and in three of the four participants, they demonstrated the benefit of hindsight. The participants were looking back at years of practice, and could see how they used to practise, and compared that to what they know now, especially in terms of knowing themselves. Novice practitioners do not have the accumulated knowledge that years of experience brings and so if I had interviewed them, I would have got more 'raw' data to analyse.

Similarly, had I asked different questions, different essences may have emerged. I have already noted earlier in this chapter, the non-emergence of spatiality in the conversations. Had I used different prompts during the conversations spatiality may well have come through as an essence underlying the practice of the participants. Although the conversations were unstructured, I allowed them to go where the participant was heading, I nevertheless remained focused on the word essence and as necessary directed the conversations back to that main focal point. In doing so I was thinking of the phenomenological sense of essence, the very nature of something, as well as the nursing sense of essence, the intelligent understanding, creative imagination, and the sensitive spirit lying behind the practice. Therefore, although the conversations were unstructured, they nevertheless remained true to 
the topic of essence. If on the other hand, I was exploring the art of gerontology nursing for example, I would have got more creative responses perhaps and the thesis would have reflected that. So this research project is very much limited by the methodological and design choices I made in the early stages of the study.

The final issue I want to highlight is my use of the literature in the thesis. As I said in chapter one, the vast amount of the literature about gerontology nursing is focused on practice issues and issues concerning its negative image and the varying reasons for that. In terms of this study then, the available literature served as a very useful background for the study. I have used it to set the scene, as a backdrop for the project. For that reason, it was presented in the first chapter, because I wanted the reader to know the background to the study and to have some awareness of the issues surrounding gerontology nursing. The issues I focused on were gerontology nursing's negative image, ageism and nurses attitudes to caring for old people, and its role as a speciality domain in nursing. I was not able to find any literature addressing the essence of gerontology nursing. I did find, though, essence in terms of nursing in general, but not specifically essence and gerontology nursing (Stewart, 1929; Henderson, 1980; Kitson, 1999a; 1999b).

Because of the lack of literature about the essence of gerontology nursing, I decided to leave it in chapter one, as a backdrop to the study, and instead of using literature to support my findings, to allow the texts to speak for themselves. This is congruent with human science research, it is afterall, about lived human experience. It is not dissimilar to assessing pain, if a patient says their pain is eight on a scale of ten, then as nurses we accept that and ensure the patient receives adequate pain 
relief. It is the same situation with the conversations with the four gerontology nurses, I accept what they say as being their lived experience. It is not right or wrong, it does not need validating or refuting, its strength lies in the fact that it is this particular nurse's lived experience. In this study the texts speak for themselves, and it is the words of the participants that are the strength of study. It is through their words that I have been able to see what is more than meets the eye and explicate the essence of gerontology nursing.

\section{INSIGHTS FROM THE STUDY}

Now that my study is completed, I can return to the thoughts I had at the beginning of the research, to the things that were my motivation to do the study, and offer some reflections and insights that I have gained from the research. In the phenomenological way, I am returning to the things themselves, returning to the roots of the study, to examine what I am now able to see that was not so clear to me at the beginning of this project. Accordingly, what follows in this section are some thoughts as to how this study might inform my future practice.

One of my reasons for carrying out this study was to gain a deeper understanding of gerontology nursing because, in my position as Nurse Manager, I experienced ongoing problems with the recruitment and retention of registered nurses that were both willing and able to work with old people. This study has emphasised for me the need to explore very carefully prospective employees’ attitudes, not only toward old people, but also toward the actual work that gerontology nurses do. Caring for the body emerged as being one of the essences of gerontology nursing, therefore, 
how gerontology nurses go about doing that work of caring for the body becomes a critical factor in their day to day practice.

As I discussed earlier in this chapter, the participants revealed that they viewed caring for the body to be of prime importance, and when they carried out bodily tasks they did so within a holistic and humanistic framework. Therefore, in interviewing applicants to care for old people, I would want to know how they see caring for the body. I would be looking for nurses who could appreciate the primacy of carrying out the cares that are fundamental to all nursing in such a way that preserves the integrity of the whole person they are caring for. A nurse may demonstrate proficiency or even mastery of the task itself, but I would be looking for someone who could carry out the task with the intelligent understanding, sensitive spirit, and creative imagination that Stewart wrote of in 1929.

Another aspect I would be more aware of when recruiting nurses for gerontology nursing would be finding the right 'fit', of ensuring that the nurse I was going to employ had an aptitude to work with old people. The study highlighted to me the importance of having the right nurse for the right job. It is not a matter of right and wrong, or better or worse, but a case of the right job for the right person. A person who is an excellent neo-natal nurse may be only mediocre at gerontology nursing and vice versa. Therefore, I would be looking for someone who has an appreciation of history, who can walk along side an old person and not rush past, someone who likes to stop and smell the roses. A nurse who has an awareness of these things, and values them and incorporates them into her daily practice would fit well into gerontology nursing. 
My research has highlighted to me the need to know more about the art of gerontology nursing practice. Having spent a considerable amount of time searching for relevant literature for this study, I can see now that gerontological nursing research has in the main focused on practical concerns. Whilst these concerns are undoubtedly important, I think it would be useful for the specialty of gerontology nursing to balance the books and to explore the artful side of practice in order to complement the already large body of research that addresses the technical side. Again, I return to Stewart's (1929) words, unless we want gerontology nursing to become a highly skilled trade, then consideration must be given to what lies behind the skills and techniques. Therefore, this study emphasises to me the need to know more about the art of gerontology nursing. I can see a need to encourage and facilitate discourse on the art of gerontology nursing in order to build up the body of knowledge. It is necessary for me to disseminate the findings from this study to serve as impetus for such discourse by presenting my findings at conferences and seminars for gerontology nurses.

I think there is also a need to explore the art of gerontology nursing from its grass roots and one way of doing that would be to probe with other gerontology nurses what they consider to be the essence of their practise. This could be done as part of inservice training or more widely in courses and seminars. The purpose would be to encourage gerontology nurses to explore their practice, to pick up their own gemstones and peer deeply into the heart of their own practice. Gerontology nurses need to find their own metaphoric language to describe their practice. I see this ongoing professional development as benefiting those nurses whose practice is less than whole, whose nursing maybe is lacking in sensitivity and creativity. 
Encouraging nurses to become more aware of this aspect of their practice would have a direct, positive outcome for the old people in their care. Furthermore, it may assist in the retention of staff, if nurses had a deeper awareness and understanding of what they were doing it might help them to see and appreciate their job more fully, and consequently enjoy more job satisfaction.

I can also see the need to disseminate my findings to the broader nursing community, which would serve yet another purpose. One of my reasons for doing this study was because I believed the difficulty in recruiting and retaining appropriate nurses to gerontology was because of its negative image and low status in nursing. I still believe this is the case, gerontology is the Cinderella of nursing, the 'poor cousin'. I think there are two ways that we, gerontology nurses, could change our image. First, as I stated above, more research needs to be carried out into the art of gerontology nursing practice, a complete picture needs to be built up depicting all the dimensions of practice. All sides of the picture need to be made visible, so that those on the outside looking in can see the whole, not just a part. By making the art and the science of gerontology nursing more widely known, it will give other nurses the opportunity to understand what working with old people can offer. It would bring a deeper meaning and understanding to what gerontology nursing is all about.

The second way to address the low status of gerontology nursing is through education. There needs to be a positive focus on caring for old people right at the start of nursing education. As two of the participants pointed out, it was interesting to note how few nurses elect to enter into gerontology nursing straight from their 
training. I think it is safe to assume that somewhere along the way, these student nurses have been exposed to negativity towards gerontology nursing. This would be an interesting and critical area to explore in future research. Therefore, I think it is appropriate for nursing educationalists to address this issue by confronting ageism as being the obvious starting point. However, I think more could be done in raising awareness relating specifically to nursing. The use of language in nursing is one such area that negative attitudes towards gerontology nursing could be challenged. As I have already discussed in this thesis, we need to look closely at how 'basic cares' are interpreted and valued and that changing the label to 'primary cares’ might bring about a more positive approach to those nursing tasks that are central to gerontology nursing. Furthermore, challenging student nurses to question their own thoughts and feelings about seeing gerontology nursing as a career option might be an interesting exercise in raising awareness. An effective way of uplifting the profile of gerontology nursing amongst student nurses would be to expose them to passionate and committed gerontology nurses, acting as role models and mentors. I believe if gerontology nursing is to attract the best people nursing has to offer, then it is our duty to nurture and care for beginning practitioners in such a way that will enable them to learn and gain experience in a supportive and encouraging environment.

The next chapter summarises the research project and concludes the thesis. 


\section{CONCLUSION}

I set out to explore the essence of gerontology nursing, to reveal what was more than meets the eye in the daily practice of nurses caring for old people. My motivation to do the study was the difficulty I experienced in recruiting and retaining committed gerontology nurses. I wanted to know what was it about gerontology that turned some nurses away yet conversely attracted some of the most able, passionate and professional nurses around? By talking to those nurses who have chosen gerontology as their specialist field, my aim was to make visible the essence of gerontology nursing, or in adopting Stewart's (1929) words, "the intelligent understanding, the sensitive spirit, and the creative imagination” underlying their practice. I wanted to look beyond the tasks to reveal the essential structure and meaning of gerontology nursing.

Through the generosity of four nurses who worked with me, as well as input from a group of gerontology nurses engaged in postgraduate study, we explored gerontology nursing practice. Using van Manen’s (1990) framework of hermeneutic phenomenology and some indepth interviewing guidelines from Minichiello (1990) I conducted unstructured interviews that exposed such rich texts and that carried with them wonderful stories and accounts of practice.

Having carried out a process of thematic analysis based on van Manen's (1990) method, four cardinal elements emerged, these were true acceptance, personal knowing, being present, and being alive. I termed them cardinal elements because they formed the basis of my further analysis of the conversations. The second level 
of my analysis was dependent on having initially identified those four cardinal elements, and after further reworkings and more indepth analysis, three central essences or qualities were revealed. These three essences were the centrality of temporality, the essential nature of human relatedness and the significance of the lived body, or corporeality, which when come together to form a whole, are the essence of gerontology nursing.

These three essences or qualities work together to give us the particular hues, colours and shapes that underpins the work of the gerontology nurses who participated in the study. The qualities of temporality, interconnectedness, and the lived body are manifested in the philosophy, and the frameworks of actual practice.

Under the traditional ageist framework, nursing care of old people may be reduced to routine-orientated tasks, and is largely misunderstood and troubled by its negative image. However, for the nurses who participated in this study, through their act of seeing, their joy of care, and the way in which they were able to utilise temporality, corporeality, and human interrelatedness, made the difference to their way of practising gerontology nursing. Furthermore, it provided a framework for the shape and scope of their practice, and for their way of working, of being gerontology nurses. Together, these elements are more than meets the eye, for as to the casual observer gerontology nursing may be a dreary, bleak, endless task, but to these nurses, as I have amply demonstrated, there is a sense of vitality, of enthusiasm and passion, and a moral attitude to care that dominates their practice. Their high regard and positive outlook towards old people as well as the aging process itself, were significant factors that set them apart from nurses working in 
other fields. In particular, the placement of physical cares within a holistic, humanistic framework was more than meets the eye because of the primary importance the participants placed on meeting these needs. It is the mastery of the so-called 'basic cares', and the value placed on these more aptly named 'primary cares', that enables the nurse-client relationship to transcend to another level.

Van Manen’s (1990) framework proved a helpful model in which to explore the lived experiences of the study participants. It worked well for this study not only because of its practicality but more importantly because of its openness, as the texts speak for themselves, they are given a voice. Given the nature and scope of my project, it was appropriate to have the texts take a central place in the thesis. However, more research needs to be done using van Manen's model or with broader audiences and perhaps other theoretical models could be tried. Indepth interviewing as informed by Minichiello (1990) worked well with van Manen's (1990) hermeneutic phenomenology.

The study was limited by recruiting and interviewing four experienced gerontology nurses hence, the findings are limited to what was revealed to me by those four particular nurses in their conversations with me. The analysis comes from the inside of their stories, different nurses would have told different stories that would have revealed different essences. Rigour in the research was bound up in the worthiness, the transparency of the findings and the overt workings of the analysis.

I am confident that this study will contribute to the wider body of nursing knowledge and serve as a starting point for further inquiry into the artful practice of gerontology nursing. If gerontology nursing is to shrug of its negative image and 
attract more willing and able practitioners then more research is needed to bring into the spotlight what lies behind the practice. We must give as much attention to the art of gerontology nursing as we do to the science. Further research is needed to explore this largely unknown aspect of gerontology nursing.

This research should be of interest to gerontology nurses who are wanting to develope more insight and depth to their practice. In particular it should interest nurse managers responsible for the recruitment and retention of registered nursing staff caring for old people, because this study reveals the special nature and characteristics of gerontology nurses. Furthermore, it should be of interest to all nurses by way of bringing some meaning and understanding of gerontology nursing to the wider domain of nursing thereby making a contribution in alleviating its negative, 'poor cousin' image.

Lastly, I wish to thank the nurses who participated in my project, and who explored the essence of their practice with me. Their enthusiasm for their job, their passionate caring for old people and their professionalism is truly awesome. It is a comfort to know, that the ongoing development of caring for old people is in their very capable and safe hands.

The final words must go to an old French woman for no other reason than what she had to say was amusing and it feels right for an old woman to have the last word.

The oldest documented human being was French woman Jeanne Clament who died in 1997 at the age of 122 . Clament gave up smoking at 120 . "It was becoming a habit," she said. Asked at 115 how she saw the future, she replied. "Short, very short”. (O’Hare, 2000) 


\section{APPENDIX A}

\section{CONSENT TO PARTICIPATE IN RESEARCH}

"More than meets the eye: Explicating the essence of gerontology nursing"

I have been given a copy and have read the information sheet about this research project. I have had the opportunity to ask questions and have had them answered to my satisfaction. I understand that I can ask further questions at any time.

I understand that I may withdraw myself, or any information I have provided for this study, at any time up until the analysis is complete without having to give a reason.

I understand that I will participate in at least one interview with the researcher that will be taped and at a later date transcribed. The time and place of the interview will be mutually agreed upon.

I understand the information will be kept confidential to the researcher and the transcriber of the tape. The data will be stored securely and will be disposed of as soon as it is no longer necessary to retain.

The data I provide will only be used for the thesis and the dissemination of the findings by journal and/or conference papers.

My confidentiality and anonymity will be maintained throughout the project and in any published results.

I understand the nature, purpose, and requirements of the study and I have chosen to participate.

\section{I would like a summary of the research findings when it is completed.}

Name of participant

Contact address

Contact phone number.

E-mail address if available.

Signature of participant

Date

Name of researcher.

Signature of researcher

Date...................... 


\section{APPENDIX B}

\section{INFORMATION SHEET}

I am a student of Victoria University studying toward my MA in Nursing. In order to fulfil the course requirements I am conducting a research project. The working title of my thesis is "More than meets the eye: Explicating the essence of gerontology nursing".

The aim of the study is to look beyond the practical tasks and skills of gerontology nursing in order to explicate the quintessential nature of gerontological care. I want to try and surface those things that underlie the practice and the interventions, the heart and soul of gerontology nursing. By doing this I hope to bring more knowing and understanding to not only gerontology nursing but also to the wider nursing profession.

I am inviting four to six gerontology nurses to participate in this project. It is necessary for the nurses to have the ability to articulate their reflective practice and for practical reasons to live within the Wellington area. I expect the project to take no longer than twelve months from start to completion.

Should you choose to participate your involvement would be as follows:

The first step would be a preliminary meeting with me to discuss the research, answer any queries and discuss consent for you to participate. We will then arrange a time for us to meet and have a conversation that will be of one-hour duration and will be audiotaped and then transcribed. A further meeting will be arranged for you to have the opportunity to read the transcript and make alterations or changes should you wish. At the completion of the project a summary of the research findings will be made available to you. A copy of the completed thesis will also be available for you to read should you so wish.

The only people to have access to the data from the taped conversations with you will be the research supervisor, the typist who transcribes the tapes and myself the researcher. The data will only be kept for as long as necessary and will be destroyed at the completion of the thesis and once the findings have been disseminated through conference and journal papers.

Anonymity and confidentiality will be maintained at all times throughout the process of the research project. The use of a pseudonym will preserve your anonymity and will be used in any subsequent publications or presentations of the findings of this study. A professional typist will transcribe the conversations and this person will be required to sign a confidentiality agreement. During the study the data will be kept secure in a locked cabinet. 
If you no longer wish to participate in the study you may withdraw at any time without giving any reason and without any consequence to you.

Should you require any further information please contact me either by e-mail anne.schumacher@vuw.ac.nz or by telephone 04 384-6140.

Or you may contact my research supervisor Chris Wilson, Research and Teacher Associate, Department of Nursing and Midwifery, Victoria University of Wellington. Chris Wilson may be contacted during working hours on 04 237-3103 ext 3732 or by e-mail c.wilson@whitireia.ac.nz

Thank you for considering participating in this study. 


\section{Appendix C}

\section{Transcriber confidentiality agreement}

I understand that the tapes I am to transcribe are to be kept confidential. No other person will have access to the tapes or typed transcripts while they are in my care.

I agree to maintain confidentiality by not discussing or disclosing at any time during, or after the project, any aspects of the tapes or typed transcripts with any other person other than with the researcher.

Tapes, transcripts and the computer disc will be returned to the researcher as soon as they are completed.

Printed name:

Signed:

Date: 


\section{REFERENCES}

Allen, D., Benner, P., \& Diekelmann, N. (1986). Three paradigms for nursing research: Methodological implications. In P. L. Chinn (Ed.), Nursing research methodology: Issues and implementation (pp.23-38). Rockville, MD: Aspen Publications.

Anderson, J. (1991). The phenomenological perspective. In J. Morse (Ed.), Qualitative nursing research: A contemporary diagram (Rev. ed.), (pp. 25-38). Newbury Park, Ca: Sage.

Benner, P. (1984). From novice to expert: Excellence and power in clinical nursing practice. Menlo Park, Ca: Addison-Wesley.

Bennett, G. (2001). Benefits to patients and practitioners in adopting the guidelines for the prediction and prevention of pressure ulcers. Primary Intention, 9 (3), 121-123.

Bernard, M. (1998). Backs to the future? Reflections on women, ageing and nursing. Journal of Advanced Nursing, 27, 633-640.

Bjork, I. T. (1995). Neglected conflicts in the discipline of nursing: Perceptions of the importance and value of practical skill. Journal of Advanced Nursing, 22, 6-12.

Brouse, J., \& Laffrey, S. (1989). Paterson and Zderad's humanistic nursing framework. In J. Fitzpatrick \& A. Whall (Eds.), Conceptual models of nursing $\left(2^{\text {nd }}\right.$ ed.), (pp.205-225). Norwalk: Appleton and Lange. and Row.

Butler, R. (1975). Why survive? Being old in America. New York: Harper

Carper, B. (1978). Fundamental patterns of knowing in nursing. Advances in Nursing Science, 1 (1), 13-23.

Carr, K., \& Kazanowski, M. (1994). Factors affecting job satisfaction of nurses who work in long-term care. Journal of Advanced Nursing, 19, 878-883.

Castledine, G. (1997). There is no such thing as a menial task in nursing. British Journal of Nursing, 6 (7), 407.

Cheah, Y.L. \& Moon, G.M. (1993). Specialism in nursing: The case of nursing care for elderly people. Journal of Advanced Nursing, 18, 1610-1616.

Chinn, P. (1991). Ageing and ageism (editorial). Advances in Nursing Science, 13 (4), vii.

Chinn, P., \& Jacobs, M. (1987). Theory and nursing. St Louis: C V Mosby. 
Chinn, P. \& Watson, J. (Eds.), (1994). Art and aesthetics in nursing. New York: National League for Nursing Press.

Christensen, J.C. (1999). Integrating the terminology and titles of nursing practice roles: Quality particularity and levelling. Nursing Praxis in New Zealand, 14 (1), 4-11.

Cohen, M. (1987). A historical overview of the phenomenology movement. Image: Journal of Nursing scholarship, 19 (1), 31-34.

Cohen, M., \& Omery, A. (1994). Schools of phenomenology: Implications for research. In J.Morse, (Ed.), Critical issues in qualitative research methods (pp. 136-156). Thousand Oaks, Ca: Sage.

Colaizzi, P. (1978). Psychological research as the phenomenologist views it. In R. Valle, \& M. King, (Eds.), Existential phenomenological alternatives for psychology. New York: Oxford University Press.

Courtney, M., Tong, S., \& Walsh, A. (2000). Acute-care nurses' attitudes towards older patients: A literature review. International Journal of Nursing Practice, 6, 62-69.

Crotty, M. (1998). The foundations of social research: Meaning and perspective in the research process. St Leonards, Australia: Allen and Unwin.

Doona, M., Haggerty, L., Chase, S. (1997). Nursing presence: An existential exploration of the concept. Scholarly Inquiry for Nursing Practice: An International Journal, 11 (1), 3-16.

Dowrick, S. (1997). Forgiveness and other acts of love. Victoria: Penguin Books Australia Ltd.

Draper, P. (1996). Nursing research and the philosophy of hermeneutics. Nursing Inquiry, 3, 45-52. Routledge.

Draper, P. (1997). Nursing perspectives on quality of life. London:

Dunning, T. \& James, K. (2001). Complementary therapies in action: Education and outcomes. Complementary therapies in Nursing and Midwifery, 7 (4), 188-195.

Elzubeir, M. \& Sherman, M., (1995). Nursing skills and practice. British Journal of Nursing, 4 (18), 1087-1092.

Ersser, S., Wiles, A., Taylor, H., Wade, S., Walsh, R., Bentley, T. (1999). Measuring the sleep of older people: Tool development and use in the evaluation of therapeutic massage. NT Research, 4 (1), 55-65.

Firn, S. (1995). Core truths. Nursing Times, 91 (41), 54. 

214-222.

Gastmans, C. (1999). Care as a moral attitude in nursing. Nursing Ethics, 6,

Geanellos, R. (1998). Hermeneutic philosophy. Part 1: Implications of its use as methodology in interpretive nursing research. Nursing Inquiry, 5, 154-163.

Giorgi, A., Fischer, C., \& Murray, E. (1975). Duquesne studies in phenomenological psychology. Pittsburgh: Duquesne University Press.

Guba, E., \& Lincoln, Y. (1994). Competing paradigms in qualitative research. In N. Denzin \& Y. Lincoln (Eds.), Handbook of qualitative research (pp.105-117). Thousand Oaks, Ca: Sage.

Hartshorn, K., Delage, J., Field, T., \& Olds, L. (2002). Senior citizens benefit from movement therapy. Journal of Bodywork and Movement Therapies, 6 (1), 55-58.

Health Research Council of New Zealand. (1998). Guidelines for researchers on health research involving Mäori 1998, Auckland: Author.

Hektor, L.M., \& Touhy, T.A. (1997). The history of the bath: From art to task? Reflections for the future. Journal of Gerontological Nursing, 23 (5), 7-15.

Henderson, V. A. (1966). The nature of nursing: A definition and its implications for practice, research, and education. New York: Ivy Books.

Henderson, V. A. (1980). Preserving the essence of nursing in a technological age. Journal of Advanced Nursing, 5, 245-260.

Herrick, C., Pearcey, L., \& Ross, C. (1997). Stigma and ageism: Compounding influences in making an accurate mental health assessment. Nursing Forum, 32 (3), 21-26.

Hill-Bailey, P. (1997). Finding your way around qualitative methods in nursing research. Journal of Advanced Nursing, 25, 18-22.

Hirst, S., \& Raffin, S. (2001). "I hated those darn chickens...” The power in stories for older adults and nurses. Journal of Gerontological Nursing, 27 (9), 2429.

Huber, M., Reno, B., \& McKenney, J. (1992). Long-term care personnel assess their attitudes and knowledge of the older adult. Journal of Advanced Nursing, 17, 1114-1121.

Hudson, K., \& Sexton, D. (1996). Perceptions about nursing care: Comparing elders' and nurses' priorities. Journal of Gerontological Nursing, 22, (12), 41-46.

Husserl, E. (translated by L. Hardy). (1999). The idea of phenomenology. The Netherlands: Kluwer Academic Publishers. 
Kingsolver, B. (1999). The Poisonwood Bible. London: Faber \& Faber.

Kitson, A. (1999a). The essence of nursing. Part One. Nursing Standard, 13 (23), 42-46.

Kitson, A. (1999b). The essence of nursing. Part Two. Nursing Standard, 13 (24), 34-36.

Koch, T. \& Webb, C. (1996). The biomedical construction of ageing: Implications for nursing care of older people. Journal of Advanced Nursing, 23, 954-959.

Lawler, J. (1997). The body in nursing. Melbourne: Churchill Livingstone.

Lawler, J. (1998). Phenomenologies as research methodologies for nursing: From philosophy to researching practice. Nursing Inquiry, 5, 104-111.

Lessing, D. (1984). The diaries of Jane Somers. London: Penguin Books.

Lookinland, S., \& Anson, K. (1995). Perpetuation of ageist attitudes among present and future health care personnel: Implications for elder care. Journal of Advanced Nursing, 21, 47-56.

McMinn, B. (1996). Ageism the challenge for nursing. Australian Nursing Journal, 3 (10), 18-21.

Merleau-Ponty, M. (translated by C. Smith). (1962). Phenomenology of perception. London: Routledge and Kegan Paul.

Ministry of Health. (1998). Consultation document on the introduction of nurse prescribing in aged care and child family health. Wellington: Author.

Minichiello, V., Aroni, R., Timewell, E., and Alexander L. (1990). In-depth interviewing: Researching people. Melbourne: Longman Cheshire.

Moch, S (1990). Personal knowing: Evolving research and practice. Scholarly Inquiry for Nursing practice, 4 (2), 155-165.

Mosby's Medical, Nursing, and Allied Health Dictionary. $3^{\text {rd }}$ Ed. 1990. St Louis: The C.V. Mosby Company .

Moss, C. (1991). Exploring storytelling as method. Nursing Research: Scholarship for Practice Conference (pp. 91-106). Geelong: Deakin University.

Munhall, P. (1994). Revisioning phenomenology: Nursing and health science research. New York: National League for Nursing.

Munhall, P. and Oiler, C. (Eds.), (1986). Nursing research: A qualitative perspective. Norwalk: Appleton-Century-Crofts. 
National Advisory Committee on Health and Disability. Report of the National Health Committee on health care for older people, 2000. Wellington: Author.

Nay, R., Garratt, S., Koch, S. (1999). Challenges for Australian nursing in the international year of older persons. Geriatric Nursing, 20 (1), 14-17.

New Zealand Workforce Statistics 1999 - Nurses and Midwives. Available: http://www.nzhis.govt.nz/stats/nursestats-p.html.

Nightingale, F. (1859). Notes on nursing - what it is and what it is not. London: Harrison. (Reprinted 1946 by J.B. Lippincott).

Nolan, M. (1994). Geriatric nursing: an idea whose time has gone? A polemic. Journal of Advanced Nursing, 20, 989-996.

Nolan, M. (1997). Gerontological nursing: wither now? Journal of Clinical Nursing, 6, 423-424.

Norton, D. (1990). The age of old age: The story of care provision for the elderly over the centuries. Harrow: Scutari Press.

Oberski, I.M., Carter, D.E., Gray, M., \& Ross, J. (1999). The community gerontological nurse: Themes from a needs analysis. Journal of Advanced Nursing, 29, 454-462.

O’Hare, N. (2000, July 29). Hanging in. The Listener, 61.

Oiler, C. (1982). The phenomenological approach in nursing research. Nursing Research, 31 (3), 171-181.

Omery, A. (1983). Phenomenology: A method for nursing research. Advances in Nursing Science, 5 (2), 49-63.

Oxford English Dictionary. $2^{\text {nd }}$ ed. 1989. (ed. J.A. Simpson and E.S.C. Weiner), Additions 1993-7 (ed. John Simpson and Edmund Weiner; Michael Proffitt), and $3^{\text {rd }}$ ed. (in progress) Mar. 2000- (ed. John Simpson). OED Online. Oxford University Press. <http://oed.com>

Palmer, R. (1969). Hermeneutics: Interpretation theory in Schleiermacher, Dilthey, Heidegger and Gadamer. Evanston: Northwestern University Press.

Parker, R. (1994). Appendix E: historical overview of phenomenology. In P. L. Munhall (Ed.), Revisioning phenomenology: Nursing and health science research (pp 286-295). New York: National League for Nursing.

Parse, R. (1992). Human becoming: Parse's theory of nursing. Nursing Science Quarterly, 5 (1), 35-42. 
Parse, R., Coyne, A., and Smith, M. (1985). Nursing research: Qualitative methods. Bowie: Brady.

Paterson, J. and Zderad, L. (1976). Humanistic Nursing. New York: Wiley.

Peplau, H. (1952). Interpersonal relations in nursing. New York: Putnam.

Pincombe, J., O’Brien, B., Cheek, J., \& Ballantyne, A. (1996). Critical aspects of nursing in aged and extended care. Journal of Advanced Nursing, 23, 672-678.

Polkinghorne, D. (1983). Methodology for human sciences. Albany: State University of New York Press.

Pursey, A., \& Luker, K. (1995). Attitudes and stereotypes: Nurses' work with older people. Journal of Advanced Nursing, 22, 547-555.

Ray, M. (1994). The richness of phenomenology: Philosophic, theoretic, and methodological concerns. In J.Morse, (Ed.), Critical issues in qualitative research methods (pp. 117-133). Thousand Oaks, Ca: Sage.

Reason, P. (1994). Three approaches to participative inquiry. In N. Denzin \& Y. Lincoln (Eds.), Handbook of qualitative research (pp.324-337). Thousand Oaks, Ca: Sage.

Retsas, A. \& Wilson, J. (1997). 'Effective' Australian gerontology nurses: A repertory grid analysis. Journal of Clinical Nursing, 6, 269-276.

Rieman, D. (1986). The essential structure of a caring interaction: Doing phenomenology. In P. Munhall, \& C. Oiler, (Eds.), Nursing research: A qualitative perspective. Norwalk: Appleton-Century-Crofts.

Roberts, K., \& Taylor, B. (1998). Nursing research processes: An Australian perspective. Melbourne: Nelson ITP.

Robertson, J.F., \& Cummings, C.C. (1996). Attracting nurses to long-term care. Journal of Gerontological Nursing, 22 (9), 24-32.

Rowe, M., Alfred, D. (1999). The effectiveness of slow stroke massage in diffusing agitated behaviours in individuals with Alzheimer's disease. Journal of Gerontological Nursing, 25 (6), 22-34.

Ryder, E. (1994). Gerontology within district nurse education. Journal of Advanced Nursing, 20, 430-436.

Sandelowski, M. (1991). Telling stories: Narrative approaches in qualitative research. IMAGE, 23 (3), 161-166.

Sandelowski, M. (1993). Rigor or rigormortis: The problem of rigor in qualitative research revisited. Advances in Nursing science, 16 (2), 1-8. 
Sandelowski, M., Davis, D., \& Harris, B. (1989). Artful design: Writing the proposal for research in the naturalist paradigm. Research in Nursing \& health, 12, 77-84.

Schumacher, A. (1999). Valuing gerontology nursing. Kai Tiaki: Nursing New Zealand, March, 20-21.

Schwandt, T. A. (1994). Constructivist, interpretivist approaches to human inquiry. In N. Denzin \& Y. Lincoln (Eds.), Handbook of qualitative research (pp.118-131). Thousand Oaks, Ca: Sage.

Scott, E., Leaper, D., Clark, M., Kelly, P. (2001). Effects of warming therapy on pressure ulcers - a randomised trial. AORN Journal, 73 (5), 921-933. 49-50.

Seymour, M. (1994). Putting an end to ageism. The Canadian Nurse, Nov.

Slevin, O. (1991). Ageist attitudes among young adults: Implications for a caring profession. Journal of Advanced Nursing, 16, 1197-1205.

Snape, J. (1986). Nurses' attitude to care of the elderly. Journal of Advanced Nursing, 11, 569-572.

Snyder, M., Brandt, C., \& Tseng, Y. (2000). Use of presence in the critical care unit. AACN Clinical Issues, 11 (1), 27-33.

Snyder, M., Tseng, Y., Brandt, C., Croghan, C., Hanson, S., Constantine, R., \& Kirby, L. (2001). A glider swing intervention for people with dementia. Geriatric Nursing, 22 (2), 86-90.

Spiegelberg, H., \& Schuhmann, K. (1994). The phenomenological movement: A historical introduction. Dordrcht: Kluwer Academic.

Spoelhof, G. (2001). Treatment of pressure ulcers. Home health care consultant, 8 (3), 10-18.

Statistics New Zealand. (2000). New Zealand population projections 1999 (base)-2051. Available:http://www.stats.govt.nz/

Stevens, J., \& Crouch, M. (1992). Working with the elderly: Do student nurses care for it? The Australian Journal of Advanced Nursing, 9 (3), 12-17.

Stevenson, D. (1996). The pitfalls of Project 2000. Nursing Times, 92 (1), 54-55.

Stewart, D., \& Mickunas, A. (1974). Exploring Phenomenology. Chicago: American Library Association.

Stewart, I. (1929). The science and art of nursing (editorial). Nursing Education Bulletin, 2 (1), 1. 
Taylor, B. (1994). Being Human: Ordinariness in nursing. Melbourne: Churchill Livingstone.

Thompson, J. L. (1990). Hermeneutic inquiry. In L. Moody, Advancing Nursing Science Through Research (pp.223-286). (Vol. 2). Newbury Park, Ca: Sage.

Treharne, G. (1990). Attitudes towards the care of elderly people: Are they getting better? Journal of Advanced Nursing, 15, 777-781.

Turkel, M., Tappen, R., \& Hall, H. (1999). Moments of excellence: Nurses’ response to role redesign in long-term care. Journal of Gerontological Nursing, 25 (1), 7-12.

Vaillot, M. (1966). Commitment to nursing: A philosophical investigation. Philadelphia: Lippincott.

Van Manen, M. (1990). Researching lived experience: Human science for an action sensitive pedagogy. London, Ontario: State University of New York Press.

Walters, A. J. (1994). Phenomenology as a way of understanding in nursing. Contemporary Nurse, 3 (3), 134-141.

Walters, A. J. (1996). Nursing research methodology: Transcending Cartesianism. Nursing Inquiry, 3, 91-100.

Watson, J. (1985). Nursing: Human science and human care, Norwalk, Conn: Appleton-Century-Crofts. 